\title{
LONG-TERM IN VITRO FLUORIDE RELEASE AND RE-RELEASE FROM ORTHODONTIC BONDING MATERIALS CONTAINING FLUORIDE
}

\author{
WARREN JASON COHEN
}

\section{D.D.S.}

A dissertation submitted in partial fulfillment of the

requirements for the degree of

Master of Science (M.Sc.)

in the

Section of Orthodontics,

Department of Preventive Dental Science

Faculty of Dentistry

of the

University of Manitoba

Winnipeg, Manitoba

(C) March, 2002 
National Library of Canada

Acquisitions and Bibliographic Services

395 Wellington Street Ottawa ON K1A ON4 canada
Bibliothèque nationale du Canada

Acquisitions et services bibliographiques

395, rue Wellington

Ottawa ON K1A ON4

Canada
Your file Votre réfierence

Our file Notre référence
The author has granted a nonexclusive licence allowing the National Library of Canada to reproduce, loan, distribute or sell copies of this thesis in microform, paper or electronic formats.
The author retains ownership of the copyright in this thesis. Neither the thesis nor substantial extracts from it may be printed or otherwise reproduced without the author's permission.
L'auteur a accordé une licence non exclusive permettant à la Bibliothèque nationale du Canada de reproduire, prêter, distribuer ou vendre des copies de cette thèse sous la forme de microfiche/film, de reproduction sur papier ou sur format électronique.

L'auteur conserve la propriété du droit d'auteur qui protège cette thèse. Ni la thèse ni des extraits substantiels de celle-ci ne doivent être imprimés ou autrement reproduits sans son autorisation. 


\section{THE UNIVERSITY OF MANITOBA \\ FACULTY OF GRADUATE STUDIES \\ $\star * * * *$ \\ COPYRIGHT PERMISSION PAGE}

Long-Term In Vitro Fluoride Release and Re-release from Orthodontic Bonding

Materials Containing Fluoride

BY

Warren Jason Cohen, D.D.S.

A Thesis/Practicum submitted to the Faculty of Graduate Studies

of the University of Manitoba

in partial fulfilment of the requirements for the degree

of

Master of Science

WARREN JASON COHEN @ 2002

Permission has been granted to the Library of the University of Manitoba to lend or sell copies of this thesis/practicum, to the National Library of Canada to microfilm this thesis and to lend or sell copies of the film, and to Dissertations Abstracts International to publish an abstract of this thesis/practicum.

The author reserves other publication rights, and neither this thesis/practicum nor extensive extracts from it may be printed or otherwise reproduced without the author's written permission. 


\section{$\underline{\text { Abstract }}$}

The objectives of this study were to compare in vitro long-term (30 month) fluoride release rates and re-release rates (following fluoride exposure) from three orthodontic bonding materials containing fluoride using a disc model, and to compare the fluoride release rates of two orthodontic bonding materials containing fluoride using an in vitro tooth-bracket model. For part I of the study, 10 samples of each material (Python ${ }^{\text {TM }}$, TP Orthodontics, Laporte, IN; Assure ${ }^{\mathrm{T} M}$, Reliance Orthodontic Products Inc., Itasca, IL; Fuji Ortho $^{{ }^{T M}}$ LC, GC America Inc., Central Islip, NY; and Transbond ${ }^{\mathrm{TM}}$ XT, 3M Unitek, Monrovia, CA) were fabricated and stored in de-ionized distilled water at $37^{\circ} \mathrm{C}$. Five samples had fluoride release rates measured at days 546, 637, 730, 821 and 913 from time of initial fabrication, while 5 samples were exposed to fluoride (Nupro $2 \% \mathrm{NaF}$ gel, Dentsply Canada, Woodbridge, ON) for 4 minutes at day 535 and had measurements taken on days $546,548,552,575,637,730,821$ and 913 . To prevent cumulative measurements, the storage solutions were changed 24 hours prior to measurement. For part II of the study, 10 samples of each material (Assure ${ }^{\top M}$ and Quick Cure ${ }^{\text {TM }}$, Reliance Orthodontic Products Inc., Itasca, IL; and Transbond ${ }^{\text {TM }}$ XT) were used to bond orthodontic brackets to extracted human premolars and stored as in part I. Measurements of fluoride release were taken on days $1,3,7,30,90$ and 180 . For part I, statistically significant differences were found in fluoride release rates ( $\mathrm{p}<0.0001)$, with Fuji Ortho LC releasing the most fluoride, followed by Python and Assure at all time points in the non-fluoride exposed group. In the group exposed to fluoride there were significant differences in fluoride release $(\mathrm{p}<0.0001)$, with Fuji Ortho LC releasing the most fluoride. A "bursteffect" pattern of fluoride release was seen following fluoride exposure for all materials. 
In part II, Assure released significantly greater levels of fluoride on day 1, and clinically significant levels of fluoride up to day 30. It was concluded that Fuji Ortho ${ }^{\mathrm{rM}} \mathrm{LC}$, Assure $^{\mathrm{TM}}$ and Python ${ }^{\mathrm{TM}}$ have sufficient long-term fluoride release rates to reduce white spot formation and all are recommended as suitable orthodontic bonding materials. 


\section{Dedication}

This thesis is dedicated to my

parents Leon and Sharon,

grandmother Annie Kustan,

brother Harvey,

and all my family and friends who supported

me throughout my academic experience. 


\section{Acknowledgements}

I would like to express my sincere appreciation and gratitude to the following people for making this project possible:

- My thesis committee - Drs. Billy Wiltshire, Colin Dawes and Chris Lavelle - for their invaluable guidance and time.

- Drs. Tom Hassard and Pat Martens for guidance with the statistical analysis.

- My classmates and friends, Drs. Pascal Carriere and Sean Corsini.

- The Alpha Omega Foundation of Canada and the American Association of Orthodontists Foundation for financial support.

- 3M/Unitek, American Orthodontics, GC America, Inc., Reliance Orthodontic

Products Inc. and TP Orthodontics for donating materials used in this study. 


\section{Contents}

Page Number

$\begin{array}{lc}\text { Abstract } & \text { i-ii } \\ \text { Dedication } & \text { iii } \\ \text { Acknowledgements } & \text { iv } \\ \text { Contents } & \text { v-x } \\ \text { List of Figures } & \text { xi-xiii } \\ \text { List of Tables } & \text { xvi-xv }\end{array}$

\section{Chapter 1 Introduction}

1.1 Foreword 1-2

1.2 Motivation for the study 2-3

1.3 Purpose of the study 3

1.4 Null Hypothesis 4

Chapter 2 Review of the Literature

2.1 Enamel Decalcification

2.1.1 The white spot lesion 5

2.1.2 Enamel decalcification in orthodontics 5-7

2.1.3 Etiology of enamel demineralization around 7-8 orthodontic appliances 


\section{$2.2 \quad$ Fluoride}

2.2.1 Effects of fluoride on enamel

2.2.2 Effects of fluoride on oral bacteria

2.2.3 Topical fluoride application and white spot prevention

2.2.4 Chlorhexidine treatments and prevention of white spot formation

2.2.5 Local sustained-release materials

\subsection{Bonding Materials Releasing Fluoride}

2.3.1 Biomaterials and nomenclature

2.3.2 Mechanisms of setting and fluoride release

2.3.2.1 General release mechanisms

2.3.2.2 Glass-ionomer cement

2.3.2.3 Resin-modified glass-ionomer cement

2.3.2.4 Polyacid-modified composite resin

2.3.3 Fluoride release studies

2.3.3.1 Restorative materials

2.3.3.2 Orthodontic bonding materials

$22-24$

2.3.4 Sample size and fluoride release

2.3.5 Fluoride re-release

2.3.6 Cariostatic effect of fluoride-releasing orthodontic bonding materials

2.3.6.1 In vitro studies 


\section{Chapter 3 Methods and Materials}

3.1 Materials used in this study

3.1.1 Fuji Ortho ${ }^{\text {TM }}$ LC

3.1.2 Python $^{\top \mathrm{M}}$

3.1.3 Assure $^{\mathrm{TM}}$

$33-34$

3.1.4 Quick Cure ${ }^{\mathrm{TM}}$

3.1.5 Transbond ${ }^{\top M} \mathrm{XT}$

3.1.6 Orthodontic brackets

$37-38$

3.1.7 Teeth

3.1.8 Varnish

38-39

3.2 Experimental Method - Part I 39

3.2.1 Preparation of specimens $39-40$

3.2.1.1 Transbond ${ }^{\top M}$ XT $\quad 40$

3.2.1.2 Python $^{\top M}$

3.2.1.3 Assure $^{\top \mathrm{MM}} \quad 40$

3.2.1.4 Fuji Ortho ${ }^{\mathrm{TM}} \mathrm{LC}$

3.2.1.5 Sample manufacturing technique $\quad 41-43$

3.2.2 Specimen storage $\quad 43-44$

3.2.3 Measurement of fluoride release

3.2.3.1 Fluoride electrode calibration and use

3.2.3.2 Fluoride measurement schedule $\quad 47-48$ 
3.2.4 Statistical analysis

3.3 Experimental Method - Part II

3.3.1 Preparation of specimens

3.3.1.1 Assure $^{\top \mathrm{M}}$

$51-52$

3.3.1.2 Quick Cure ${ }^{\mathrm{TM}}$

52

3.3.1.3 Transbond ${ }^{T M} \mathrm{XT}$

$52-53$

3.3.2 Specimen storage

3.3.3 Measurement of fluoride release

3.3.3.1 Fluoride electrode calibration and use

3.3.3.2 Fluoride measurement schedule

3.3.4 Statistical analysis

55

\section{Chapter 4 Results}

4.1 Long-term fluoride release

4.1.1 Overall pattern

4.1.2 Fuji Ortho ${ }^{\mathrm{TM}} \mathrm{LC}$ fluoride release rates

4.1.3 Python ${ }^{\mathrm{TM}}$ fluoride release rates

4.1.4 Assure $^{\mathrm{TM}}$ fluoride release rates

4.1.5 Transbond ${ }^{T M}$ XT fluoride release rates

61

4.1.6 Day 546 fluoride release rates 62

4.1.7 Day 637 fluoride release rates 63

4.1.8 Day 730 fluoride release rates 64

4.1.9 Day 821 fluoride release rates 65 
4.2 Fluoride release from samples re-exposed to fluoride

4.2.1 Overall pattern

4.2.2 Fuji Ortho ${ }^{\mathrm{TM}} \mathrm{LC}$ fluoride re-release rates

4.2.3 Python ${ }^{\top \mathrm{M}}$ fluoride re-release rates 70

4.2.4 Assure $^{\mathrm{TM}}$ fluoride re-release rates 71

4.2.5 Transbond ${ }^{\top \mathrm{M}} \mathrm{XT}$ fluoride release rates $72-73$

4.2.6 Day 546 fluoride release rates $73-74$

4.2.7 Day 548 fluoride release rates 74-75

4.2.8 Day 552 fluoride release rates $75-76$

4.2.9 Day 575 fluoride release rates $76-77$

4.2.10 Day 637 fluoride release rates $77-78$

4.2.11 Day 730 fluoride release rates $78-79$

4.2.12 Day 821 fluoride release rates 80

4.2.13 Day 913 fluoride release rates $81-82$

4.3 Fluoride release rates from tooth-bracket model

4.3.1 Overall Pattern

$82-83$

4.3.2 Assure $^{T M}$ fluoride release rates

4.3.3 Quick Cure ${ }^{T M}$ fluoride release rates

4.3.4 Transbond ${ }^{\mathrm{TM}} \mathrm{XT}$ fluoride release rates

4.3.5 Day 1 fluoride release rates

4.3.6 Day 3 fluoride release rates

88-89

4.3.7 Day 7 fluoride release rates

$89-90$ 


\section{Chapter 5 Discussion}

5.1 Long-term fluoride release

5.2 Fluoride re-release pattern

5.3 Tooth-bracket model

\section{Chapter 6 Conclusions and Recommendations}

6.1 Conclusions

108-109

6.2 Recommendations

6.3 Future Research

References 


\section{$\underline{\text { List of Figures }}$}

Page Number

Figure 1: Pre-orthodontic treatment 2

Figure 2: Post-orthodontic treatment showing enamel decalcification 2

Figure 3: Pre-orthodontic treatment 9

Figure 4: Post-orthodontic treatment showing enamel decalcification and $\quad 9$ frank cavitation

Figure 5: Fuji Ortho ${ }^{\text {TM }}$ LC

$\begin{array}{ll}\text { Figure 6: } \text { Python }^{\text {TM }} & 38\end{array}$

Figure 7: Assure $^{\mathrm{TM}}$ Paste $\quad 39$

Figure 8: Assure $^{\mathrm{TM}}$ Etching Agent and Primer $\quad 39$

Figure 9: Quick Cure ${ }^{\mathrm{T}}$ Paste $\quad 40$

Figure 10: Transbond $^{\mathrm{rM}} \mathrm{XT}($ Part I) $\quad 41$

Figure 11: Transbond XT (Part II) $\quad 42$

Figure 12: Dentsply 34\% Tooth Conditioner Gel 42

Figure 13: Upper left first premolar bracket 43

Figure 14: Color Fast! ${ }^{\text {TM }}$ Varnish 44

Figure 15: Split-mould 44

Figure 16: Filling the split-mould 46

$\begin{array}{ll}\text { Figure 17: Light curing material in the split-mould } & 47\end{array}$

Figure 18: Sample released from split-mould $\quad 47$ 
Figure 19: Samples in polyethylene test tubes

Figure 20: Samples stored in incubator

Figure 21: Fluoride electrode setup

Figure 22: Preppies $^{\text {Ts }}$ Pumice Paste

Figure 23: Buccal view of paraffin wax template on tooth

Figure 24: Lateral view of paraffin wax template on tooth

Figure 25: Bracket bonded with paraffin wax template in place

Figure 26: Ortholux $^{\mathrm{TM}}$ Light Curing Unit

Figure 27: Fluoride measurement apparatus

Figure 28: Fuji Ortho ${ }^{\mathrm{TM}}$ LC long-term fluoride release rates

Figure 29: Python $^{\mathrm{TM}}$ long-term fluoride release rates

Figure 30: Assure $^{\text {rM }}$ long-term fluoride release rates

Figure 31: Transbond $^{\mathrm{TM}} \mathrm{XT}$ long-term fluoride release rates

Figure 32: Day 546 fluoride release rates

Figure 33: Day 637 fluoride release rates

Figure 34: Day 730 fluoride release rates

Figure 35: Day 821 fluoride release rates

Figure 36: Day 913 fluoride release rates 73

Figure 37: Fuji Ortho ${ }^{\mathrm{TM}}$ LC fluoride re-release rates

Figure 38: Python ${ }^{\mathrm{TM}}$ fluoride re-release rates

Figure 39: Assure $^{\top M}$ fluoride re-release rates

Figure 40: Transbond ${ }^{\mathrm{TM}} \mathrm{XT}$ fluoride re-release rates

Figure 41: Day 546 fluoride re-release rates 
Figure 42: Day 548 fluoride re-release rates

Figure 43: Day 552 fluoride re-release rates

Figure 44: Day 575 fluoride re-release rates

Figure 45: Day 637 fluoride re-release rates

Figure 46: Day 730 fluoride re-release rates

Figure 47: Day 821 fluoride re-release rates

Figure 48: Day 913 fluoride re-release rates

Figure 49: Assure $^{T M}$ fluoride release rates

Figure 50: Quick Cure ${ }^{\text {TM }}$ fluoride release rates

Figure 51: Transbond ${ }^{\mathrm{TM}} \mathrm{XT}$ fluoride release rates

Figure 52: Day 1 fluoride release rates

Figure 53: Day 3 fluoride release rates

Figure 54: Day 7 fluoride release rates

Figure 55: Day 30 fluoride release rates 99

Figure 56: Day 90 fluoride release rates

Figure 57: Day 180 fluoride release rates 


\section{$\underline{\text { List of Tables }}$}

Page Number

Table 1: Long-term fluoride release rates $\quad 64$

Table 2: Fuji Ortho ${ }^{\text {TM }}$ LC long-term fluoride release rate descriptive statistics 65

Table 3: Python ${ }^{\mathrm{TM}}$ long-term fluoride release rate descriptive statistics 66

Table 4: Assure $^{\mathrm{TM}}$ long-term fluoride release rate descriptive statistics 67

Table 5: Transbond ${ }^{\mathrm{TM}}$ XT long-term fluoride release rate descriptive statistics $\quad 68$

Table 6: Day 546 fluoride release rate descriptive statistics 69

Table 7: Day 637 fluoride release rate descriptive statistics $\quad 70$

Table 8: Day 730 fluoride release rate descriptive statistics 71

Table 9: Day 821 fluoride release rate descriptive statistics 72

Table 10: Day 913 fluoride release rate descriptive statistics 73

Table 11: Fluoride re-release rates following fluoride exposure 75

Table 12: Fuji Ortho ${ }^{\mathrm{TM}}$ LC fluoride re-release rate descriptive statistics 76

Table 13: Python ${ }^{\text {TM }}$ fluoride re-release rate descriptive statistics $\quad 78$

Table 14: Assure ${ }^{\mathrm{TM}}$ fluoride re-release rate descriptive statistics $\quad 79$

Table 15: Transbond ${ }^{\text {TM }} \mathrm{XT}$ fluoride re-release rate descriptive statistics $\quad 80$

Table 16: Day 546 fluoride re-release rate descriptive statistics 82

Table 17: Day 548 fluoride re-release rate descriptive statistics 83

Table 18: Day 552 fluoride re-release rate descriptive statistics 84

Table 19: Day 575 fluoride re-release rate descriptive statistics 85 
Table 20: Day 637 fluoride re-release rate descriptive statistics

Table 21: Day 730 fluoride re-release rate descriptive statistics

Table 22: Day 821 fluoride re-release rate descriptive statistics

Table 23: Day 913 fluoride re-release rate descriptive statistics

Table 24: Fluoride release rates for tooth-bracket model

Table 25: Assure $^{\text {TM }}$ fluoride release rate descriptive statistics

Table 26: Quick Cure ${ }^{\mathrm{TM}}$ fluoride release rate descriptive statistics

Table 27: Transbond ${ }^{\text {TM }}$ XT fluoride release rate descriptive statistics

Table 28: Day 1 fluoride release rate descriptive statistics

Table 29: Day 3 fluoride release rate descriptive statistics

Table 30: Day 7 fluoride release rate descriptive statistics

Table 31: Day 30 fluoride release rate descriptive statistics 99

Table 32: Day 90 fluoride release rate descriptive statistics 100

Table 33: Day 180 fluoride release rate descriptive statistics 


\section{Chapter 1}

\section{Introduction}

\subsection{Foreword}

As orthodontic treatment is a very common procedure, it is critical to minimize any associated complications. This is a particular concern for orthodontics as the occurrence of enamel demineralization is a significant problem related to the placement of fixed orthodontic appliances (Gorelick et al., 1982; Øgaard, 1989; Thilander, 1992).

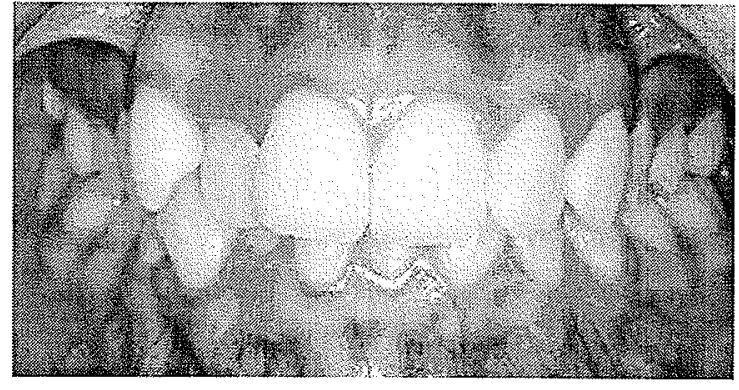

Figure 1: Pre-orthodontic treatment

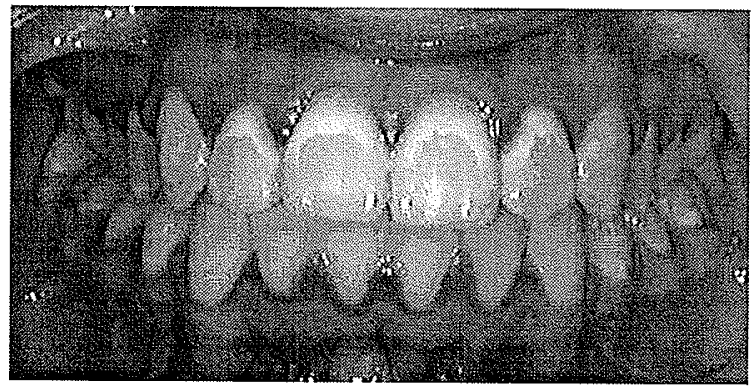

Figure 2: Post-orthodontic treatment showing enamel decalcification

Finding methods of reducing such iatrogenic decalcification following orthodontic treatment is imperative and centers on attempts to develop bonding adhesives that release fluoride. Valk and Davidson (1987) reported that bonding with glass-ionomer cement provided protection for a $1 \mathrm{~mm}$ area around brackets. As glass-ionomer cements have 
low bond strengths (Fricker, 1994), modifications to both glass-ionomer cements and composite resins have produced "hybrid" bonding materials with fluoride release and improved bond strengths $(5 \%$ bond failure of resin-modified glass ionomer cement vs. 8.3\% for composite resin). Chadwick and Gordon (1995) found higher fluoride concentrations in biopsies of enamel bonded with Vitrebond ${ }^{\circledR}$, a resin-modified glassionomer material, as compared with initial biopsy measurements.

Polyacid-modified composite resins have been modified through the addition of polyacids and/or fluoride-containing ground glass, which Ashcraft et al. (1997) found to release less fluoride than resin-modified glass-ionomer materials. Such modifications have created a continuum of materials purported to release fluoride where "hybrid" bonding materials take up and release fluoride from the oral environment (Ashcraft et al., 1997).

\subsection{Motivation for the Study}

It is important to determine which materials release the amount of fluoride required to provide clinically significant caries inhibition (Rawls, 1987) using different in vitro models since the amount of fluoride released varies with the in vitro model (Monteith et al., 1999). This study investigated three materials - Python ${ }^{\mathrm{TM}}$ (TP Orthodontics); Assure ${ }^{\mathrm{TM}}$ (Reliance Orthodontic Products Inc.); and Fuji Ortho ${ }^{\text {TM }}$ LC (GC America Inc.), and two in vitro models - disc and tooth-bracket samples. This investigation partly served as a 
continuation of a previous study (McNeill, 2000), to provide information on the fluoride release patterns of these materials.

\subsection{Purpose of the Study}

The aims of this study were threefold:

1) To compare the long-term (30 month) fluoride release rates in vitro from discs of two recently marketed polyacid-modified composite resins - Python ${ }^{\mathrm{TM}}$ (TP Orthodontics) and Assure ${ }^{\top M}$ (Reliance Orthodontic Products Inc.) with that from a resin-modified glass-ionomer (Fuji Ortho ${ }^{\top M}$ LC - GC America Inc.) and with a non-fluoride-containing composite resin (Transbond ${ }^{\mathrm{TM}} \mathrm{XT}-3 \mathrm{M}$ Unitek) serving as a control. The interest was to provide a long-term continuation of a previous short-term study (McNeill, 2000), which ended at the 6-month evaluation point.

2) To assess the capability of Python ${ }^{\mathrm{TM}}$, Assure ${ }^{\mathrm{TM}}$ and Fuji Ortho ${ }^{\mathrm{TM}}$ LC to imbibe and re-release fluoride compared with a non-fluoride-containing composite resin (Transbond $^{\mathrm{TM}} \mathrm{XT}$ ) as a control.

3) To compare the fluoride release rates from Assure ${ }^{\mathrm{TM}}$ and Quick Cure ${ }^{\mathrm{TM}}$ (Reliance Orthodontic Products, Inc.) with that from a non-fluoride-containing composite resin (Transbond ${ }^{\mathrm{TM}} \mathrm{XT}-3 \mathrm{M}$ Unitek) as a control using an in vitro tooth-bracket model. 


\subsection{Null Hypothesis}

The null hypothesis states:

1) Samples of resin-modified glass-ionomer (Fuji Ortho ${ }^{T M}$ LC) will not release more fluoride than either polyacid-modified composite resin (Assure ${ }^{\text {TM }}$ and Python $^{\mathrm{TM}}$ ) or a non-fluoride-containing composite resin (Transbond ${ }^{\mathrm{TM}} \mathrm{XT}$ ).

2) Samples of resin-modified glass-ionomer (Fuji Ortho ${ }^{T M}$ LC) will not imbibe and re-release more fluoride than either polyacid-modified composite resin (Assure $^{\text {TM }}$ and Python ${ }^{\top M}$ ) or a non-fluoride-containing composite resin (Transbond ${ }^{\mathrm{TM}} \mathrm{XT}$ ).

3) A tooth-bracket model of either polyacid-modified composite resin (Assure ${ }^{\mathrm{TM}}$ and Quick Cure $^{\mathrm{TM}}$ ) will not release more fluoride than a non-fluoridecontaining composite resin (Transbond ${ }^{\mathrm{TM}} \mathrm{XT}$ ). 


\section{Chapter 2}

\section{Review of the Literature}

\subsection{Enamel Decalcification}

\subsubsection{The White Spot Lesion}

Enamel demineralization involves the loss of phosphate and calcium ions from enamel, leading to increased opacity. Such white spot lesions cover changes that range from very early whitish opaque enamel surface spots to extensive chalky enamel surfaces where small parts may fracture (Fejerskov and Clarkson, 1996).

\subsubsection{Enamel Decalcification in Orthodontics}

Direct bonding of brackets to enamel is useful because it eliminates the need for orthodontic bands (Proffit 2000), although the downside includes an increased prevalence of enamel demineralization and white spot formation (Gorelick et al., 1982). In their study of 121 patients with bonded orthodontic appliances, $49.6 \%$ showed visually determined enamel demineralization of at least one tooth, compared with only $24 \%$ of control patients. Of the total teeth examined, only $10.8 \%$ showed such lesions, indicating significant variation among patients. As $50 \%$ of bonded patients showed no increase in 
white spot lesion formation, Gorelick et al. (1982) suggested that variations in enamel structure, salivary composition, or tooth brushing influenced this process.

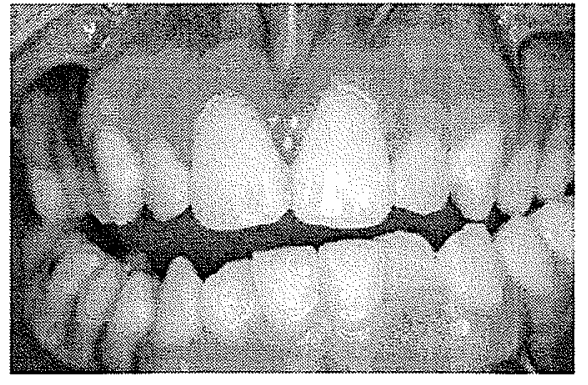

Figure 3: Pre-orthodontic treatment

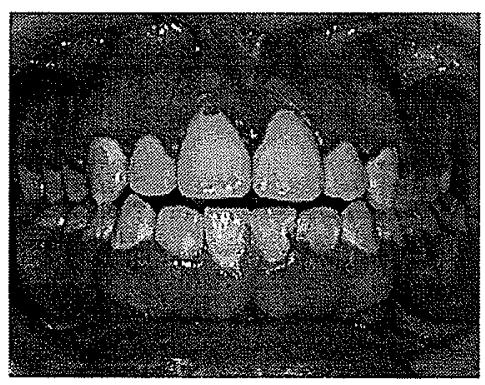

Figure 4: Post-orthodontic treatment showing enamel decalcification and frank cavitation

Øgaard et al. (1988) utilized an in vivo orthodontic band model to induce caries lesions in premolars planned for extraction, and cemented ill-fitting orthodontic bands to facilitate plaque accumulation on the buccal surfaces. The teeth were extracted after 4 weeks and showed visible white spot lesions in the absence of a fluoride regimen, with mineral loss up to a depth of $100 \mu \mathrm{m}$ and an intact surface layer.

Øgaard (1989) investigated the prevalence of white spot lesions in 51 patients five years after conclusion of orthodontic treatment. The presence of bonded orthodontic appliances led to significantly more patients with white spot lesions as compared with untreated control subjects ( $96 \%$ of orthodontic patients had white spot lesions, compared with only $85 \%$ of control patients). The greatest prevalence of white spot lesions was found on first molars, canines and premolars in the treated group, possibly related to the 
presence of molar bands or the anatomic shape of teeth necessitating more gingival bracket placement. The authors suggested that the use of fluoride toothpaste and mouth rinses probably lead to a layer of fluorapatite (FAP) sealing the lesion, preventing remineralization and disappearance of the white spots even five years after treatment.

O'Reilly and Featherstone (1987) also demonstrated in vivo enamel demineralization around orthodontic brackets after only one month. They performed enamel microhardness testing around orthodontic brackets on 58 teeth extracted one month after bonding. Teeth that were brushed at least once daily with a fluoride-containing dentifrice $(1,100 \mathrm{ppm}$ fluoride) showed a significant amount of demineralization immediately adjacent to bonded orthodontic brackets. Microhardness testing revealed that the mineral loss was limited to an area 50 to $75 \mu \mathrm{m}$ beyond the periphery of the bracket, and was not visible clinically. This is consistent with very early stages of caries lesion formation (surface softening), which normally precedes the formation of a well-mineralized surface layer (O'Reilly and Featherstone, 1987).

\subsubsection{Etiology of Enamel Demineralization Around Orthodontic Appliances}

Fixed orthodontic appliances alter the ecology of the oral environment by creating areas of stagnation. Normal physical cleansing forces such as movement of food and the oral musculature, as well as the flow of saliva are reduced or prevented, allowing acceleration of plaque accumulation (Chang et al., 1997). This results in a favourable environment 
that leads to increased levels of Streptococcus mutans and lactobacilli (Arneberg et al., 1984; Lundström and Krasse, 1987b; Rosenbloom and Tinanoff, 1991). Plaque from such retentive sites in orthodontic patients varies in $\mathrm{pH}$ values and fluoride concentrations, with lower values on maxillary teeth than on mandibular anterior teeth (Arneberg et al., 1997). Thilander (1992) suggested that acid etching of enamel might be a causative factor in enamel white spot formation. However, Gorelick et al. (1982) found that the presence of lower lingual bonded retainers resulted in no white spot formation over an average wear time of 24 months in 60 patients, and suggested that the acid application did not, by itself, cause white spot lesions probably because of the protection afforded from free flowing saliva in the lingual area. Since an increased surface for plaque adhesion coupled with poor oral hygiene provides the environment for increased demineralization of tooth surface around the orthodontic bracket base, it is the goal of the orthodontic profession to prevent the occurrence of such iatrogenic damage.

\subsection{Fluoride}

\subsubsection{Effects of Fluoride on Enamel}

The cariostatic effect of fluoride is thought to relate to a series of unrelated, yet synergistic effects, arising through application of various concentrations of fluoride at different times (White and Nancollas, 1990; Levine, 1991). Unfortunately, space is limited in this context to expand on the cariostatic mechanisms of fluoride; however many schools of thought prevail regarding the method by which fluoride reduces dental 
caries (ten Cate and Featherstone, 1996). Levine (1991) believes that pre-eruptive systemic fluoride treatment and fluoride content in enamel is important for providing protection from caries. In summarizing the literature White and Nancollas (1990) found that many authors view the lower solubility and presumed increased fluoride retention of "firmly bound" fluorapatite (FAP) as important in imparting caries resistance. However, Fejerskov et al. (1981) feel that use of systemic fluoride treatment during enamel formation is of "limited value". Øgaard et al. (1988) used shark enamel to show limited resistance of FAP against caries attacks in an intra-oral human caries model.

The current view is that firmly incorporated fluoride is of less importance than fluoride ion present in oral fluid during de- and remineralization cycles (Fejerskov, 1981; ten Cate and Featherstone, 1996). This view depends on the following observation stated by Fejerskov et al. (1981): "Based on our present knowledge obtained from epidemiological studies, clinical trials, microbiological and clinical studies, laboratory experiments and theoretical physico-chemical considerations, considerable evidence is available to substantiate the assertion that fluoride, even in low concentrations, is necessary in the oral fluids to obtain maximum caries inhibition. The relative significance of fluoride bound in the enamel remains uncertain. Therefore continuous or frequent supplementation to oral fluids is mandatory, particularly in cases of increased cariogenic challenge at any age." ten Cate and Featherstone (1996) state that "fluoride acts by inhibiting mineral loss at the crystal surfaces and by enhancing this rebuilding or remineralization of calcium and phosphate in a form more resistant to subsequent attack." Fluoride in solution has greater influence on demineralization and remineralization than 
do the bulk precipitate forms $\left(\mathrm{CaF}_{2}\right.$ and $\left.\mathrm{FAP}\right)$ (Featherstone et al., 1990; White and Nancollas, 1990). However, renewed interest has focused on "loosely bound" $\mathrm{CaF}_{2}$ as a potential "reservoir" for solution ionic fluoride (White and Nancollas, 1990). $\mathrm{CaF}_{2}$ provides free fluoride ions as it dissolves and may act as a long-term store for fluoride during periods of de- and remineralization (ten Cate and Featherstone, 1996). In summarizing the literature, White and Nancollas (1990) reported that carious enamel is much more reactive with fluoride than sound enamel, as shown by rapid acquisition of greater amounts of total fluoride. Additionally, acquired fluoride strongly enhances both remineralization and demineralization resistance (White and Nancollas, 1990). Clarkson et al. (1988) showed that the progress of carious lesions within enamel is inversely proportional to the fluoride concentration within the lesion, which is in turn dependent on the presence of acquired loosely bound fluoride $\left(\mathrm{CaF}_{2}\right)$ in the sound enamel following topical fluoride application.

Much debate has focused on finding the most beneficial method and concentration for supplemental fluoride delivery. Featherstone et al. (1990) found an inverse dependence of relative mineral loss on the logarithm of fluoride concentration, or stated in another way, that an increase in fluoride in the treatment solution does not translate directly into a proportionately larger effect. According to their mathematical model, a fluoride concentration of $62 \mathrm{mg} / \mathrm{L}$ (or ppm) would provide $80 \%$ protection while $178 \mathrm{mg} / \mathrm{L}$ would give $90 \%$ protection. Rather than simply empirically increasing fluoride dosages, delivery mechanisms are needed that provide relatively low fluoride concentrations for longer time periods. This would allow fluoride to accumulate in plaque fluid and 
subsequently diffuse between the enamel crystals, enhancing the remineralization process (Featherstone et al., 1990; Margolis and Moreno, 1990; ten Cate and Featherstone, 1996). This provides strong theoretical support for bonding materials that provide continual local fluoride release at the site of demineralization around orthodontic brackets.

\subsubsection{Effects of Fluoride on Oral Bacteria}

Fluoride has several direct and indirect effects on the bacterial cell, some of which may influence acidogenic bacteria in dental plaque (Hamilton and Bowden, 1996). The uptake of fluoride into bacterial cells during periods of carbohydrate metabolism is facilitated with the permeable form, HF. Once inside the bacterial cell, HF dissociates into $\mathrm{H}^{+}$and $\mathrm{F}^{-}$, each with significant effects (Hamilton and Bowden, 1996). $\mathrm{H}^{+}$causes decreased intracellular $\mathrm{pH}$, leading to a less favourable cytoplasmic environment for the function of many enzymes. $\mathrm{F}^{-}$interacts with various $\mathrm{F}$-sensitive enzymes, causing inhibition of enzymatic activity. This affects many metabolic activities including the glycolytic pathway, sugar transport, proton-extruding ATPases, the proton motive force, macromolecule synthesis and others (Hamilton and Bowden, 1996). Fluoride levels as low as $0.45 \mu \mathrm{g} / \mathrm{mL}$ at $\mathrm{pH} 5.0$ can inhibit lactic acid production of certain strains of $S$. mutans (Harper and Loesche, 1986). However, the minimum inhibitory concentration of fluoride ion in solution required to inhibit demineralization in a solution containing $\mathrm{Ca}$ and $\mathrm{P}$ at levels found in dental plaque (Moreno and Margolis, 1988) is estimated at 1 to 2 ppm (or possibly higher in vivo). If the fluoride concentration in plaque rises above the 
minimum inhibitory concentration, the enamel becomes insoluble and the antimicrobial effects of fluoride become less significant (Van Loveren, 1990).

\subsubsection{Topical Fluoride Application and White Spot Prevention}

Fluoride rinsing programs can help to reduce white spot formation (Geiger et al., 1992). Their protocol involved rinsing with $10 \mathrm{ml}$ of $0.05 \%$ sodium fluoride daily before bedtime after brushing with fluoride-containing toothpaste (for 9 to 49 months depending on treatment time). They showed significant reduction in white spot formation in patients compliant with a fluoride rinsing protocol ( $21 \%$ of patients with white spots) compared with non-compliant patients ( $49 \%$ showed white spots). Interestingly, they also found that patients who had poor oral hygiene but complied with the daily rinsing program had a significant reduction (from $91 \%$ to $50 \%$ ) in white spot formation as well. The use of 1100-ppm fluoride toothpaste together with either a once-daily $0.05 \% \mathrm{NaF}$ rinse (O'Reilly and Featherstone, 1987; Boyd, 1993) or twice-daily 0.4\% $\mathrm{SnF}_{2}$ gel (Boyd, 1993) is significantly more effective than the use of fluoridated toothpaste alone in preventing decalcification in adolescents undergoing treatment with fixed orthodontic appliances. This emphasizes the difficulty in attaining adequate plaque removal with fixed appliances, even with comprehensive initial toothbrushing instructions, the use of fluoridated toothpaste and monthly follow-up instructions and reinforcement. Daily $0.4 \%$ $\mathrm{SnF}_{2}$ applications for 18 to 24 months also reduce white spot formation (Stratemann and Shannon, 1974). 
However, compliance with rinsing protocols is an important issue. Geiger et al. (1992) reported poor compliance with fluoride rinsing regimens, assessed by using bottles with $10 \mathrm{~mL}$ dosimeters and recording the number of bottles used by each patient. The compliance results ranged from only $13 \%$ of children rinsing daily, to $42 \%$ rinsing every other day, and $45 \%$ of patients rinsing less frequently (Geiger et al., 1992). Stratemann and Shannon (1974) also found poor compliance - only $52 \%$ of patients complied fully with daily $\mathrm{SnF}_{2}$ gel application and $29 \%$ applied the gel once weekly or less. While higher compliance has been obtained with continued monthly reinforcement (Boyd, 1993), other authors found that poor compliance occurred even with special educational efforts and providing free fluoride rinse (Geiger et al., 1992). Geiger et al. (1992) found that in compliant patients (those whose rinsed at least every other day) the occurrence of teeth with white spot lesion was $21 \%$ compared with $49 \%$ for less compliant children. The authors concluded that use of a $10 \mathrm{ml}$ neutral sodium fluoride rinse at least every second day resulted in a significant reduction in white spot lesions, but methods to improve motivation and compliance must be found.

\subsubsection{Chlorhexidine Treatments and Prevention of White Spot}

\section{Formation}

Lundström and Krasse (1987a,b) investigated the effectiveness of chlorhexidine treatments on the caries incidence in orthodontic patients with high levels of Streptococcus mutans. The experimental patients were treated with $1 \%$ chlorhexidine gel 
in custom trays at the beginning of treatment and whenever $S$. mutans levels exceeded $5 \times 10^{5} \mathrm{CFU}$ per $\mathrm{ml}$ of saliva (in addition to use of fluoridated toothpaste, and biweekly fluoride mouth rinses and/or annual topical fluoride application). They found no significant difference in caries incidence between the experimental patients and the control patients who received no chlorhexidine treatments, suggesting that other methods of preventing dental caries in orthodontic patients must be investigated.

\subsubsection{Local Sustained-Release Materials}

Given the important effects of fluoride on enamel and oral bacteria, along with the poor results achieved with mouthrinsing programs, it is obvious that a better solution needs to be found. Rawls (1991) summarized the potential advantages of sustained-release materials that can be placed in the mouth:

- The agent can be delivered directly to or near the disease site

- The systemic dosage can be minimized while the local therapeutic level is optimized

- The agent can be present continuously over an extended period

- The dosage can be maintained at a uniform level within the therapeutic range

- Direct involvement of health professionals is minimized

- The need for patient compliance is eliminated or reduced

It is important to determine whether any of the current orthodontic bonding materials fulfill some or all of these goals, and how they can be made more effective. 


\subsection{Bonding Materials Releasing Fluoride}

\subsubsection{Biomaterials and Nomenclature}

With the advent of hybrid bonding materials ranging from composite resin to glassionomer, there has been much confusion over nomenclature (McLean et al., 1994). As a result, McLean et al. (1994) recommended the following definitions:

- Glass-ionomer cement: cement that consists of a basic glass and an acidic polymer that sets by an acid-base reaction between these components.

- Resin-modified glass-ionomer: a material that sets partly by an acid-base reaction and partly by a photochemical polymerization. These materials retain a significant acid-base reaction as part of their overall curing process.

- Polyacid-modified composite resin (a.k.a. compomers): materials that contain either or both of the essential components of a glass-ionomer cement but at levels insufficient to result in the acid-base cure reaction in the dark.

\subsubsection{Mechanisms of Setting and Fluoride Release}

\subsubsection{General Release Mechanisms}

Rawls (1991) summarized the two general methods of releasing therapeutic agents from dental biomaterials:

- Materials with a release rate that gradually decreases with time: 
- Non-degradable - water from the oral environment diffuses into the matrix, dissolves the entrapped agent, which diffuses out in the direction of decreasing concentration. As time progresses, the agent must be leached from deeper within the matrix, causing the rate of release to fall

- Degradable - occurs by dissolution or some other method of matrix erosion. Water diffuses in, degrades the matrix and releases the agent, causing the outer layers to be removed, reducing the surface area of the material (unless the eroding surface is flat, then the surface area remains the same and the rate of release does not change with time).

- Materials with a steady, linear release rate independent of time:

- High loading/Matrix with low rate of diffusion - the required life of the delivery system must be less than the time needed to deplete enough agent to slow the rate of release.

- Reservoir/Rate-controlling membrane barrier - a membrane slows the rate of diffusion from a solid solution or matrix in which the agent concentration is above the saturation limit.

\subsubsection{Glass-Ionomer Cement}

Extensive testing has shown that the fluoride release ability of conventional glassionomer is directly affected by the polycarboxylic acid-fluoroaluminosilicate glass setting reaction (Erickson and Glasspoole, 1995). Setting of this cement involves neutralization of the polyacid by the basic glass, with the formation of metal polyacrylate units 
(Nicholson, 1998). The surface layer of the glass particle reacts with acid, while the glass core remains intact and acts as filler in the cement matrix. The surface layer of the glass powder becomes silicon-rich, and a silica gel layer is formed at the interface between the cement matrix and the glass particles (Saito et al., 1999). During this acid-base reaction, fluoride along with many other ionic constituents is released. It has been hypothesized that the kinetics of fluoride elution from GIC involves two reactions (Tay and Braden, 1988). After reviewing the literature, Verbeeck et al. (1993) theorized that the first reaction involves a short-term surface process that reaches equilibrium, while the second process is a prolonged bulk diffusion that is responsible for long-term release of fluoride. Verbeeck et al. (1998) determined that it takes two weeks for this process to release $90 \%$ of the total amount of fluoride (measured in $\mathrm{mg} / \mathrm{cm}^{2}$, thus depending on the size of the specimen).

After reviewing the literature and analyzing their results, Verbeeck et al. (1998) suggest that once the glass-ionomer has set, the fluoride released by the set cement may originate from:

1. The remaining and not yet attacked leachable fluoride glass

2. The silica gel phase resulting from the acid-base reaction and covering the glass particles

3. The polysalt matrix where fluoride ions can be bound in strong complexes with the metal ions, especially aluminum

4. The pore liquid in which the fluoride ions are only loosely bound and free to move 
The contribution of the first two sources was determined by leaching unreacted glass particles in water followed by acetic acid, and vice versa. It was shown that significant fluoride is released into the matrix when the acid attacks the glass during the setting reaction. However, when the glass particles come into contact with water, the fluoride release rate decreases rapidly and substantially to low levels (Verbeeck et al., 1998). The authors stated that this might indicate that the silica gel layer is not a reservoir for the fluoride, but a barrier to further fluoride release from the remaining glass. The third and fourth sources relate to the organic matrix of the material and may also contribute to fluoride release. Glass-ionomer cement is cation permselective and fluoride transport across glass-ionomer cements is not based on simple diffusion. More specifically, the fluoride release depends on the time from start of the acid-base reaction to first contact of the set cement with an aqueous solution, with greater fluoride release when set cement is submerged in water 15 minutes after the start of mixing as compared with 1 day or 1 week (Verbeeck et al., 1998). This effect of maturation is most probably the result of a change in the constitution of the matrix due to a loss of relatively soluble forms of fluoride during the cement's hardening and maturation.

\subsubsection{Resin-Modified Glass-Ionomer Cement}

As previously mentioned, resin-modified glass-ionomer cements set partly via an acidbase reaction and partly via a photochemical polymerization. These materials retain a significant acid-base reaction as part of their overall curing process (McLean et al., 1994). However, Kakaboura et al. (1996) used MIR-FTIR (multiple internal reflection 
Fourier transform infrared) spectroscopy to show that the acid-base reaction of resinmodified glass-ionomers is significantly slowed after light exposure. Momoi and McCabe (1993) postulated that for light-activated glass ionomer cements, the type and amount of resin used for the photochemical polymerization reaction might affect the rate

of fluoride release. Once set, these hybrid materials have various mechanisms of releasing fluoride. The fluoride release can be due primarily to ion exchange, leaving the material intact (McCabe, 1998). Other materials show 'wash-out' or dissolution, which is characterized by leaching of ions other than fluoride, particularly calcium, leading to gradual disintegration of the material (Tam et al., 1991; McCabe, 1998). In comparison with traditional glass-ionomer cements, fluoride release from Vitremer is significantly higher immediately after light cure than after 1 day, indicating that resin-modified glassionomers are moisture sensitive like their glass ionomer cement counterparts, but to a lesser extent (Verbeeck et al., 1998).

\subsubsection{Polyacid-Modified Composite Resin}

Materials in this category are water-free, single-component, light-cured composites consisting of polyacid-modified dimethacrylate monomers reinforced with strontium or barium aluminosilicate glass particles (Eliades et al., 1998). The setting reaction of a polyacid-modified composite resin is initiated by photo-polymerization, with the acidic monomer components polymerized to the acidic polymer, or the polymer with the acidic group (Saito et al., 1999). The acid-base reaction is inhibited until the material hardens and absorbs water from saliva, when the acid group in the polymer reacts with the basic 
glass filler to produce a glass-ionomer core analog (Eliades et al., 1998). Using FTIR spectroscopy, Eliades et al. (1998) stated that polyacid-modified composite surfaces stored in distilled water undergo a slow, solid-state transformation causing an acid-base reaction to produce carboxylate salts, reaching a saturation point after approximately 4 weeks. The glass particles in Dyract $^{\circledR}$ were shown to degrade easily in pure water resulting in a significant release of fluoride, but the release rate decreased with time due to the development of a silica gel layer covering the glass particles (Verbeeck et al., 1998). Polyacid-modified composite resins release considerably less fluoride than acidbase setting materials, but do not show moisture sensitivity since there is no difference in fluoride release immediately after curing or 24 hours later (Verbeeck et al., 1998).

\subsubsection{Fluoride Release Studies}

Any potential benefit of fluoride-containing orthodontic bonding materials is dependent on the actualization of fluoride release from these materials. Studies have been conducted both in vitro and in vivo to determine fluoride release levels and duration from a variety of materials. Since the dental materials literature also contains substantial information on the fluoride release characteristics of restorative materials, these will be included along with orthodontic materials studied in vitro and in vivo.

\subsubsection{Restorative Materials}

It is well known that glass-ionomer cements release fluoride in vitro (Forsten, 1977). Creanor et al. (1994) found that discs (6 $\mathrm{mm}$ in diameter and $1.5 \mathrm{~mm}$ thick) of Vitrebond 
(GIC) released a concentration of $155.2 \mathrm{ppm}$ fluoride in $2 \mathrm{~mL}$ of deionized water at 24 hours, decreasing to only $3.99 \mathrm{ppm}$ through to day 60. Forsten (1977) also found high release during the first 2 weeks, decreasing to low, but consistent levels by 2 months from samples with dimensions $2 \mathrm{~mm} \times 2 \mathrm{~mm} \times 12 \mathrm{~mm}$ (Forsten, 1977). This pattern has been termed a "burst effect", where the largest release of fluoride occurs in the first few days, and then tapers off to a lower, constant level (Ashcraft et al., 1997). It has been shown that this low-level fluoride release is maintained long term. Wilson et al. (1985) reported that fluoride was still being released from samples of Chembond (GIC) after 598 days, Forsten (1990) found a fluoride concentration of at least $0.5 \mathrm{ppm}$ in $5 \mathrm{~mL}$ of deionized water after 1 year in running non-fluoridated tap water $(0.5 \mathrm{~L} / \mathrm{min})$ from samples $2.8 \mathrm{~mm}$ thick and $10.7 \mathrm{~mm}$ in diameter; and Forsten (1998) reported long-term fluoride release from GICs at such a constant level for a period exceeding 8 years.

Regarding the more recent resin-modified glass-ionomer materials, Momoi and McCabe (1993) found no significant difference in fluoride release between light-activated and conventional glass ionomer cements. Forsten (1998) also reported that 'true' resinmodified glass-ionomers released fluoride to the same extent and in a similar way to conventional GICs. This contrasted with the results of Creanor et al. (1994) who found that light-cured Fuji II LC released significantly less fluoride than Vitrebond GIC (at day 20 the concentration of fluoride released by Vitrebond was $1.47 \mathrm{ppm} \mathrm{F}^{-}$while Fuji II LC had a concentration of $0.77 \mathrm{ppm} \mathrm{F}^{-}$in $2 \mathrm{~mL}$ of deionized water). 
Creanor et al. (1994) also found that the fluoride release pattern of the polyacid-modified composites Compoglass and Dyract was similar to those of glass-ionomer and resinmodified glass-ionomer materials in that there was high release initially followed by a low release period. However, the values were lower than those reported by Momoi and McCabe (1993) for resin-modified or traditional glass-ionomers (Eliades et al., 1998). Forsten (1998) found evidence to the contrary, reporting that polyacid-modified composites (Variglass ${ }^{\circledR}$ and Dyract ${ }^{\circledR}$ ) did not show a burst effect.

\subsubsection{Orthodontic Bonding Materials}

Cooley et al. (1989) determined fluoride release from Precise Paste and Paste Orthodontics Bonding System (resin) and Precise Glass Ionomer Band Cement (glass ionomer), as well as from Ketac-Fil (restorative glass ionomer). Precise Glass Ionomer released fluoride at a high rate on day $1\left(112 \mu \mathrm{g} / \mathrm{cm}^{2}\right)$ but this diminished to $22 \mu \mathrm{g} / \mathrm{cm}^{2}$ by day 7 and continued at $20 \mu \mathrm{g} / \mathrm{cm}^{2}$ at three months. Ketac-Fil ${ }^{\circledR}$, for comparison, released $200 \mu \mathrm{g} / \mathrm{cm}^{2}$ on day 1 , decreasing to $15 \mu \mathrm{g} / \mathrm{cm}^{2}$ by day 7 and continuing at 17 $\mu \mathrm{g} / \mathrm{cm}^{2}$ at 3 months. Meanwhile, Precise Orthodontic Bonding Resin released $1 \mu \mathrm{g} / \mathrm{cm}^{2}$ on day 1 , dropping to $0.2 \mu \mathrm{g} / \mathrm{cm}^{2}$ by day 3 , and to undetectable levels from day 4 onward, indicating that it is ineffective for prolonged fluoride release.

Fox (1990) compared the release rate (in $\mu \mathrm{g} / \mathrm{day}$ ) of fluoride from a conventional GIC $\left(\mathrm{Ketac}^{-\mathrm{Cem}^{\circledR}}{ }^{\circledR}\right.$ with those from two no-mix composite orthodontic bonding materials $\left(\right.$ Direct $^{\circledR}$ and Right-On ${ }^{\circledR}$ ). Ketac-Cem ${ }^{\circledR}$ released the most fluoride, averaging $88 \pm 6.3$ 
over the first 2 days, falling to $<0.1$ by 10 weeks. Direct ${ }^{\circledR}$ (which claimed fluoride release) averaged $9.9 \pm 1.1$ for the first 2 days, falling to $0.24 \pm 0.01$ at 20 weeks. Right$\mathrm{On}^{\circledR}$ (which did not claim fluoride release) released $2.9 \pm 0.32$ for the first 2 days, but by the second week it was down to $0.1 \pm 0.01$. The cumulative release patterns were also different; Ketac-Cem ${ }^{\circledR}$ had exponentially decreasing fluoride release rates over time, while Direct ${ }^{\circledR}$ and Right-On ${ }^{\circledR}$ had linearly decreasing release curves.

Wiltshire and Janse van Rensburg (1995) evaluated fluoride release from FluorEver OBA and Light-Bond. FluorEver OBA released approximately $35 \mu \mathrm{g} \mathrm{F} / \mathrm{cm}^{2}$ on the first day, dropping to $0.86 \mu \mathrm{g} \mathrm{F} / \mathrm{cm}^{2}$ by the third week. Fluoride release continued from week 17 through week 85 at levels ranging from 0.35 to $0.5 \mu \mathrm{g} \mathrm{F}^{-} / \mathrm{cm}^{2}$. Meanwhile, Light-Bond released approximately $5 \mu \mathrm{g} \mathrm{F}^{-} / \mathrm{cm}^{2}$ on the first day, falling to $0.11 \mu \mathrm{g} \mathrm{F}^{-} / \mathrm{cm}^{2}$ by the third week. Light-Bond failed to demonstrate long-term fluoride release, falling below the detection limit of the fluoride electrode by day 29 .

In order to simulate more closely the clinical situation, Chan et al. (1990) used a toothbracket model to study fluoride release from a fluoride-releasing resin composite orthodontic adhesive (FluorEver OBA). They found that fluoride release was evident, and ranged from $52.6 \pm 13.2 \mu \mathrm{g} / \mathrm{cm}^{2}$ on day 3 to $10.5 \pm 2.6 \mu \mathrm{g} / \mathrm{cm}^{2}$ on day 43 . They compared these results with fluoride release from larger discs of the same material, and reported that, as expected, fluoride release was much greater, but the pattern was similar to that with the tooth-bracket model. 
Wiltshire (1999) studied release of fluoride from orthodontic elastomeric ligature ties. The 24-hour residual leachable fluoride in ligatures tested after one month of intraoral use was significantly greater than for those stored in distilled water. Fluorideimpregnated ligatures stored in vitro had mean 24-hour release of $0.02 \mu \mathrm{g} \mathrm{F}$ $/ \mathrm{mL} /$ elastomeric ligature while those used in the mouth had $1.43 \pm 0.37 \mu \mathrm{g} \mathrm{F}$ $/ \mathrm{mL} /$ lastomeric ligature. Non-fluoridated ligatures also had higher fluoride content after 1 month of intraoral use when compared with in vitro storage. The non-fluoridated elastomerics released $0.44 \pm 0.05 \mu \mathrm{g} \mathrm{F} / \mathrm{mL} /$ elastomeric ligature after 1 month of intraoral use, while the controls samples released $0.003 \mu \mathrm{g} \mathrm{F} / \mathrm{mL} /$ elastomeric ligature. The author concluded that residual, leachable fluoride is present in used elastomeric ligatures and that elastomeric ligatures imbibe fluoride in vivo.

\subsubsection{Sample Size and Fluoride Release}

As in vitro research attempts to investigate the properties of fluoride-releasing materials, the most appropriate sample shape for such tests is controversial. As mentioned previously, Cranfield et al. (1982) were interested in learning whether fluoride ions were derived from near-surface regions of the cement or from throughout the sample. They fabricated the cements into tubes of various lengths $(1,3,5$ and $10 \mathrm{~mm})$ with only the end faces exposed to solution. Their data showed that fluoride release was greater with larger samples, regardless of similar surface area exposure. Williams et al. (1999) found evidence to the contrary using samples of conventional glass-ionomer in various shapes (cylinder, bar, disc) and sizes. Fluoride release from GIC (for up to 3 years) was 
dependent on sample surface area rather than volume. They also mentioned that had fewer cylinder sizes been used, a correlation between sample volume and fluoride release would have been found.

Wilson et al. (1985) found that discs that had a greater surface area $(20 \mathrm{~mm}$ diameter $\mathrm{x}$ $1.5 \mathrm{~mm}$ thick) released proportionately greater amounts of fluoride than did cylinders (12 $\mathrm{mm}$ high x $6 \mathrm{~mm}$ diameter). Monteith et al. (1999) did not find such proportionality of fluoride release using three different models. They fabricated two sets of discs $3.0 \mathrm{~mm}$ in diameter x $1.5 \mathrm{~mm}$ thick of Vitremer (RMGIC), Dyract Ortho (polyacid-modified composite) and a composite resin control. They also bonded teeth in a tooth-bracket model using the same materials. One set of discs was coated with varnish on the upper and lower surfaces, halving the surface area. Their results showed that unvarnished discs with twice the surface area only released 1.2 to 1.5 times more fluoride than the varnished discs. Also, unvarnished discs released 3.0 to 4.5 times more fluoride than the tooth-bracket model, while varnished discs only released 2.2 to 3.7 times more fluoride (Monteith et al., 1999). Thus it appears that the in vitro model used is important when considering the fluoride release levels, and choosing a tooth-bracket model would most closely simulate the in vivo situation.

\subsubsection{Fluoride Re-release}

It is important to have constant release of fluoride from fluoride-releasing materials, and it is therefore desirable to use a material that can be "recharged" with fluoride (Forsten, 1990). Since teeth are exposed to fluoride on a daily basis in the form of fluoridated 
toothpaste, mouthrinses, etc., as well as on a periodic basis to more concentrated fluoride (such as topical gels), it is essential to determine whether fluoride-containing orthodontic bonding materials are capable of imbibing fluoride from the environment.

Hatibovic-Kofman and Koch (1991) studied fluoride uptake and re-release from three glass-ionomer cements (Vitrebond ${ }^{\circledast}$, Ketac-Fil ${ }^{\circledR}$ and ChemFil II ${ }^{\circledR}$ ). After 11 weeks in distilled water the samples were exposed to toothpaste ( $250 \mathrm{ppm} \mathrm{F}$ ) for 15 minutes. From the $11^{\text {th }}$ to $12^{\text {th }}$ weeks, the fluoride release of all materials increased. The concentration of fluoride released from Vitrebond ${ }^{\circledR}$ increased from $1.1 \pm 0.9 \mathrm{ppm} \mathrm{F}^{-}$to $31.3 \pm 3.3 \mathrm{ppm} \mathrm{F}^{-}$, Ketac-Fil ${ }^{\circledR}$ increased from $0.8 \pm 0.8$ to $15.3 \pm 1.0 \mathrm{ppm} \mathrm{F}^{-}$and ChemFil $\mathrm{II}^{\circledR}$ increased from $0.2 \pm 0.9$ to $11.2 \pm 1.1 \mathrm{ppm} \mathrm{F}^{-}$. Fluoride release subsequently decreased for each material up to the $16^{\text {th }}$ week. The authors concluded that regular use of fluoridated toothpaste could result in the absorption of fluoride into glass-ionomer cements, and the subsequent fluoride release would increase fluoride levels in the oral environment (Hatibovic-Kofman and Koch, 1991).

Takahashi et al. (1993) investigated the use of different concentrations of fluoride for reexposure. They exposed samples of various glass-ionomer cements and a fluoridecontaining composite to $0.02 \%, 0.2 \%$ and $2 \% \mathrm{NaF}$ solutions. They found that the amount of fluoride released after exposure was dependent on the concentration of the fluoride solution, and that the net amount of fluoride release was significantly higher after exposure to $2 \% \mathrm{NaF}$ solution than to $0.02 \%$ or $0.2 \% \mathrm{NaF}$. Most glass-ionomers eluted fluoride at levels above control samples for a longer period following exposure to $0.2 \%$ 
and $2 \% \mathrm{NaF}$, leading the authors to conclude that some fluoride must have diffused into the matrix of the material, thus acting as a reservoir for subsequent release. Interestingly, the fluoride-containing composite tested (Heliomolar Ro) released minimal fluoride and did not seem to bind fluoride after exposure (Takahashi et al., 1993).

Creanor et al. (1994) reported fluoride re-release from various glass-ionomer cements. The samples were stored in $1 \mathrm{~L}$ of water each for 60 days to leach most of the fluoride. They were then exposed to $1000 \mathrm{ppm} \mathrm{F}^{-}$daily for 20 days and compared with unexposed control samples. While the control samples released small concentrations, the test samples consistently released more fluoride (Creanor et al., 1994).

Ashcraft et al. (1997) tested three light-cured glass-ionomers (Band-Lok, Zionomer and Geristore) using a tooth-bracket model. On day 48 (after bonding) the samples were exposed to $0.4 \% \mathrm{SnF}_{2}$ gel for 30 seconds. The concentration of fluoride released from Band-Lok cement increased to $78 \%(1.50 \mathrm{ppm}$ on day $1 ; 1.17 \mathrm{ppm}$ on day 49$)$ of initial levels after exposure to fluoride, while Zionomer increased to $70 \%$ (0.36 ppm on day 1 ; $0.25 \mathrm{ppm}$ on day 49) and Geristore to $63 \%(0.50 \mathrm{ppm}$ on day $1 ; 0.32 \mathrm{ppm}$ on day 49$)$. The concentration of fluoride released by the composite resin control (Concise) increased $300 \%$ the day after fluoride gel exposure than on the first day after bonding $(0.04 \mathrm{ppm}$ on day $1 ; 0.12 \mathrm{ppm}$ on day 49). The fluoride released from teeth bonded with composite resin showed that the exposed enamel, bracket surface and composite resin could adsorb and release small amounts of fluoride (Ashcraft et al., 1997). 


\subsubsection{Cariostatic Effect of Fluoride-Releasing Orthodontic Bonding Materials}

It is essential to realize that fluoride release from orthodontic bonding materials is of importance only if cariostatic effects are imparted to the bonded teeth. The ultimate goal of using fluoride-releasing materials, as a supplement to good oral hygiene, is to decrease or prevent the incidence of white-spot decalcification. Only if such benefits can be demonstrated will the use of such materials be of value.

\subsubsection{In vitro studies}

The caries inhibitory effect of fluoride-releasing adhesives used for orthodontic bonding has been demonstrated in several studies (Valk and Davidson, 1987; Kindelin, 1996; Basdra et al., 1996; Vorhies et al., 1998). Valk and Davidson (1987) bonded brackets to bovine enamel and showed that, after demineralization treatment, glass-ionomer protected a substantial area of uncovered enamel adjacent to the cemented bracket. This was in contrast to traditional composite resin, which showed caries even underneath the bonded bracket. Kindelan (1996) showed that the fluoride-releasing bonding agents Ketac-Cem $^{\circledR}$ (GIC) and Pulpdent $\mathrm{OBA}^{\circledR}$ (polyacid-modified composite) protected extracted human premolars from demineralization, while Rely-a-Bond ${ }^{\circledR}$ (polyacidmodified composite) did not afford such protection. Basdra et al. (1996) contradicted this result by reporting that Rely-a-Bond and Fluorobond/Concise (fluoride-releasing 
sealant and traditional composite resin) showed significantly less enamel demineralization in an acidic medium. This correlated with fluoride-release data, showing that Fluorobond/Concise released the most fluoride and offered the best protection from demineralization. Vorhies et al. (1998) used polarized light microscopy to show that teeth bonded with hybrid glass ionomer cements (Advance ${ }^{\circledR}$ and Fuji Ortho ${ }^{\text {rM }}$ LC) provided significant protection from demineralization compared with a composite resin control (Transbond $\mathrm{XT}^{\circledR}$ ). Interestingly, brushing twice daily with fluoridated toothpaste (1500 ppm F-) reduced enamel lesion depths for the Transbond XT group, but not for the fluoride-releasing groups. This led the authors to attribute most of the inhibition of enamel demineralization to fluoride release from the materials, with a small contribution from topical fluoride in the toothpaste.

\subsubsection{In vivo studies}

Successful inhibition of enamel demineralization in vitro by fluoride-releasing orthodontic bonding materials has also been demonstrated in vivo (Sonis and Snell, 1989; Øgaard et al., 1992; Underwood et al., 1989; Chung et al., 1998). In following orthodontic patients through the full course of treatment, Sonis and Snell (1989) bonded opposite quadrants with either Fluorever (fluoride-releasing composite) or Aurafill (traditional composite). They found that teeth bonded with FluorEver showed no decalcification, as compared with control teeth that had a $12.6 \%$ overall decalcification rate. Øgaard et al. (1992) used microradiography to demonstrate that a fluoridecontaining adhesive (Orthodontic Cement VP 862) reduced lesion depths by $48 \%$ during 
a 4-week in vivo period when compared with samples bonded with Heliosit Orthodontic (fluoride-free composite resin). Underwood et al. (1989) bonded teeth in vivo with either Concise (control) or an experimental fluoride-exchanging resin and extracted those teeth after 60 days. To determine enamel lesion depth they used a polarized light microscopy method with either water or quinoline (to show dark zone formation). With water imbibition, 5 to $25 \%$ pore volume (showing the body of the lesion) was found in $2.78 \%$ of teeth bonded with fluoride-exchanging resin and $1.73 \%$ with Concise. However, with quinoline as the imbibition medium, dark zone formation (which is a more reliable indicator of early demineralization) indicated by 2 to $4 \%$ pore volume, was found in $2.3 \%$ of teeth bonded with fluoride-exchanging resin and 33.5\% for Concise, a $93 \%$ reduction in the early enamel demineralization stages (Underwood et al., 1989). Chung et al. (1998) compared extracted teeth one month after bonding with Vitremer ${ }^{\circledR}$ (resin-modified glass-ionomer), Dyract ${ }^{\circledR}$ Ortho (polyacid-modified composite) and Right-On (control composite). They found that the Vitremer ${ }^{\circledR}$ and Dyract ${ }^{\circledR}$ Ortho group combined had significant reduction in enamel demineralization, but each group individually showed no significant differences from the control group.

Some studies have not shown the enamel protection benefits of fluoride-releasing materials (Mitchell, 1992; Banks et al., 1997; Millett et al., 1999). Mitchell (1992), using a photographic technique, found that Direct $^{\circledR}$ did not result in significant protection against enamel decalcification during orthodontic treatment. Banks et al. (1997) supported in vitro data (Kindelan, 1996) by reporting that Rely-a-Bond did not significantly reduce enamel decalcification in vivo. Millett et al. (1999) compared Ketac- 
Cem (GIC) and Right-On (composite resin control) using a split-mouth design for an extended treatment time (averaging 15.3 months), and found no significant difference in the incidence of enamel decalcification between the groups.

Fluoride release studies of orthodontic bonding materials are only relevant if the level of fluoride release required to provide protection from enamel demineralization can be determined. For this to occur, it is necessary to correlate in vitro and in vivo data. Rawls (1995) reviewed the literature on fluoride-releasing resin-based dental materials in an attempt to determine the lowest effective level of fluoride required for caries protection. He states "to inhibit caries initiation in sound enamel in the vicinity of a resin-based dental material...exposed to the oral environment: 0.65 to $1.3 \mu \mathrm{g} \mathrm{F}^{*} / \mathrm{cm}^{2} / \mathrm{d}$ for specimens exposed on one side and having thickness of up to about $2 \mathrm{~mm}$ " is necessary. In summary, there is a potential benefit for fluoride-releasing bonding materials in orthodontics, provided adequate fluoride release rates are achieved. 


\section{Chapter 3}

\section{Methods and Materials}

\subsection{Materials used in this study}

\subsubsection{Fuji Ortho ${ }^{T M}$ LC}

Fuji Ortho ${ }^{\mathrm{TM}} \mathrm{LC}$ is a light-cured resin-modified glass ionomer in powder-liquid form and requires mixing (Lai et al., 1999). The powder is composed of fluoroaluminosilicate glass and the liquid contains hydroxyethyl methacrylate (HEMA), water copolymer of acrylic and maleic acids, and activator. The liquid also contains camphorquinone as a photoinitiator (Lai et al., 1999).

\begin{tabular}{|l|l|l|}
\hline \multicolumn{1}{|c|}{ Material } & \multicolumn{1}{|c|}{ Manufacturer } & \multicolumn{1}{|c|}{ Lot Number } \\
\hline Fuji Ortho ${ }^{\text {TM }}$ LC & $\begin{array}{l}\text { (GC America Inc., Alsip, } \\
\text { IL) }\end{array}$ & 071267 \\
\hline
\end{tabular}

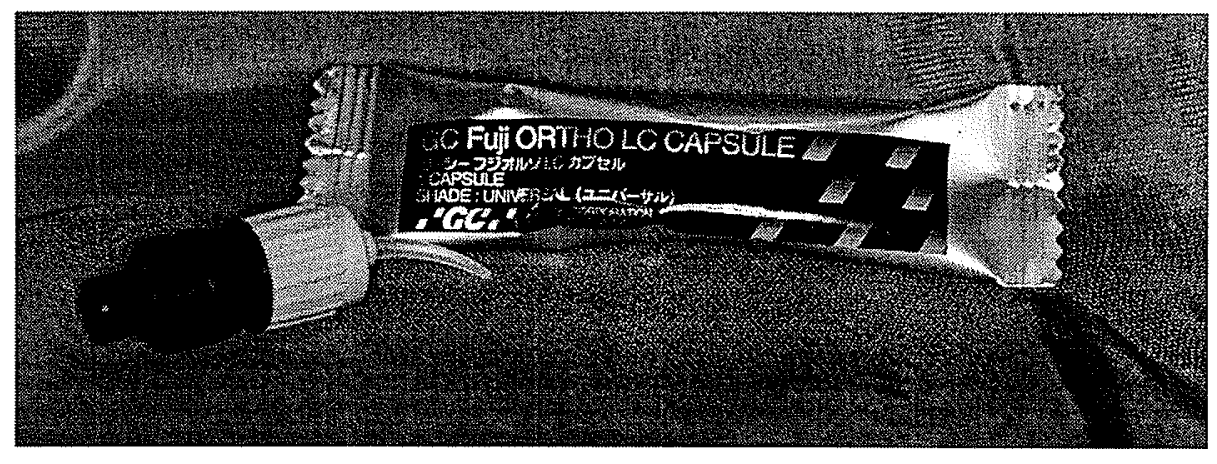

Figure 5: Fuji Ortho ${ }^{T M}$ LC 


\subsubsection{Python $^{T M}$}

Python $^{\mathrm{TM}}$ is a light-cure, no-mix bonding system. It is a bisphenol A diglycidylmethacrylate (Bis-GMA) system containing a pre-polymerized acrylic modified resin with an acrylic monomer and containing glass particles as an active filler (McNeill, 2000). Python ${ }^{\mathrm{TM}}$ contains $>20 \%$ Bis-GMA, $>1 \%$ polyethyleneglycol dimethacrylate, $>0.5 \%$ benzoyl peroxide, $5-10 \%$ aluminum oxide, and $10-35 \%$ fumed silica (M.S.D.S. 151-100, 151-105).

\begin{tabular}{|l|l|l|}
\hline \multicolumn{1}{|c|}{ Material } & \multicolumn{1}{|c|}{ Manufacturer } & Lot Number \\
\hline Python $^{\mathrm{TM}}$ & $\begin{array}{l}\text { TP Orthodontics, LaPorte, } \\
\text { IN, USA }\end{array}$ & CE 0646 (no fault) \\
\hline
\end{tabular}

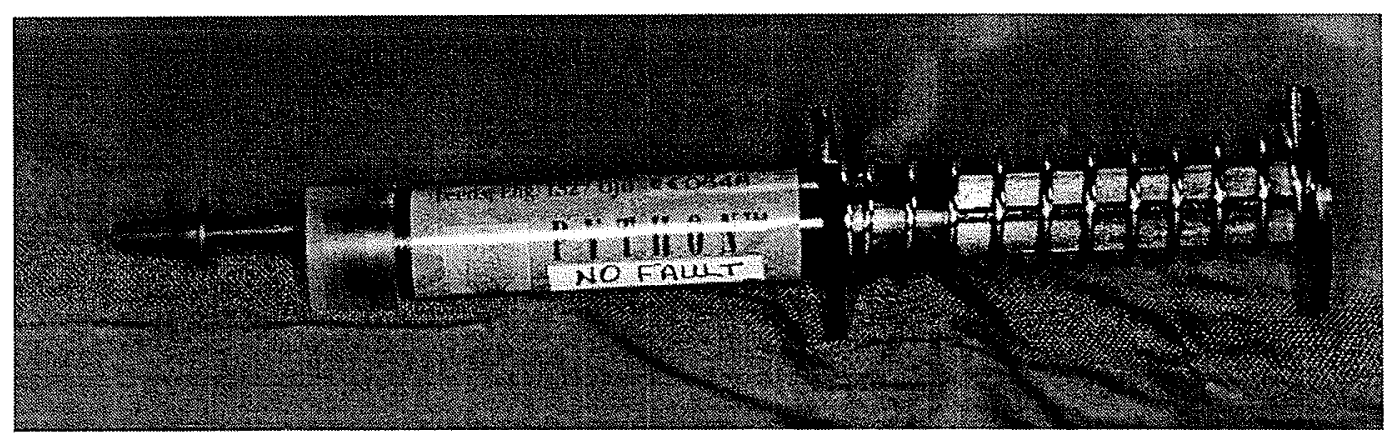

Figure 6: Python ${ }^{\mathrm{TM}}$

\subsubsection{Assure $^{T M}$}

Assure $^{\mathrm{TM}}$ (Reliance Orthodontic Products Inc., Itasca, IL) is described by the manufacturer as a "fluoride-releasing light cure sealant paste system for wet or dry environment" (Assure ${ }^{\mathrm{TM}}$ product literature, 2001). Assure ${ }^{\mathrm{TM}}$ paste contains $8-30 \%$ hydroxyethyl methacrylate, $60-99 \%$ glass frit and $1-5 \%$ sodium fluoride (Assure ${ }^{\mathrm{TM}}$ M.S.D.S, 1998). The US-EPA description of frit "is a mixture of inorganic substances 
produced by rapidly quenching a molten, complex combination of materials confining the chemical substances thus manufactured as non-migratory components of glassy solid flakes or granules" (Assure ${ }^{\mathrm{TM}}$ M.S.D.S., 1998). Assure ${ }^{\mathrm{TM}}$ primer contains $15-40 \%$ biphenyl dimethacrylate and 40-70\% acetone (Assure ${ }^{\mathrm{TM}}$ Primer M.S.D.S, 1998).

\begin{tabular}{|c|c|c|}
\hline Material & Manufacturer & Lot Number \\
\hline Assure ${ }^{\mathrm{TM}}$ Paste & $\begin{array}{l}\text { Reliance Orthodontic } \\
\text { Products Inc., Itasca, IL, } \\
\text { USA }\end{array}$ & $\begin{array}{l}039188 \text { (Part 1) } \\
002240 \text { (Part 2) }\end{array}$ \\
\hline $\begin{array}{l}\text { Assure }^{\mathrm{TM}} \text { Light Cure } \\
\text { Sealant Resin/Primer }\end{array}$ & $\begin{array}{l}\text { Reliance Orthodontic } \\
\text { Products Inc., Itasca, IL, } \\
\text { USA }\end{array}$ & 002180 \\
\hline
\end{tabular}

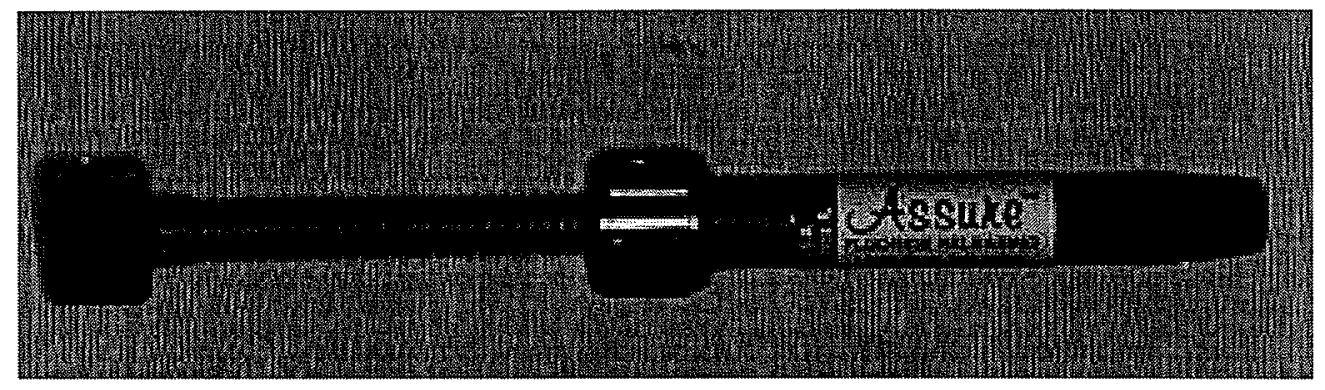

Figure 7: Assure ${ }^{\mathrm{TM}}$ Paste

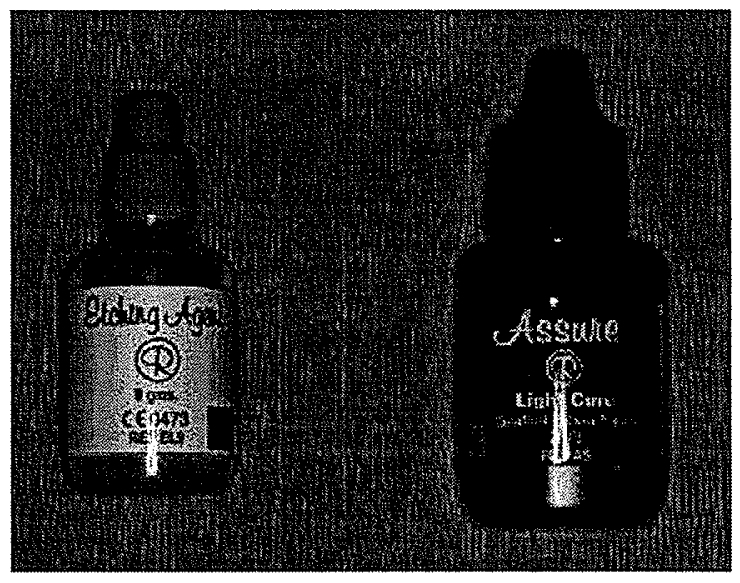

Figure 8: Assure ${ }^{\mathrm{TM}}$ Primer and Etching Agent 


\subsubsection{Quick Cure ${ }^{T M}$}

Quick Cure ${ }^{\mathrm{TM}}$ (Reliance Orthodontic Products Inc., Itasca, IL) is described by the manufacturer as a "fluoride-releasing light cure bracket bonding system", and is a "new generation of light cure paste that provides a much broader area of sensitivity to blue light for a faster and more complete cure" (Quick Cure ${ }^{T M}$ Product literature, 2001). Quick Cure $^{\mathrm{TM}}$ contains unspecified percentages of fused silica, bisphenol A diglycidylmethacrylate (Bis-GMA) and triethyleneglycol dimethacrylate (TEGDMA) (Quick Cure ${ }^{T M}$ M.S.D.S., 2000).

\begin{tabular}{|l|l|l|}
\hline \multicolumn{1}{|c|}{ Material } & \multicolumn{1}{|c|}{ Manufacturer } & \multicolumn{1}{|c|}{ Lot Number } \\
\hline Quick Cure $^{\mathrm{TM}}$ Paste & $\begin{array}{l}\text { Reliance Orthodontic } \\
\text { Products Inc., Itasca, IL, } \\
\text { USA }\end{array}$ & 004100 \\
\hline Assure $^{\mathrm{TM}}$ Sealant & $\begin{array}{l}\text { Reliance Orthodontic } \\
\text { Products Inc., Itasca, IL, } \\
\text { USA }\end{array}$ & 002180 \\
\hline
\end{tabular}

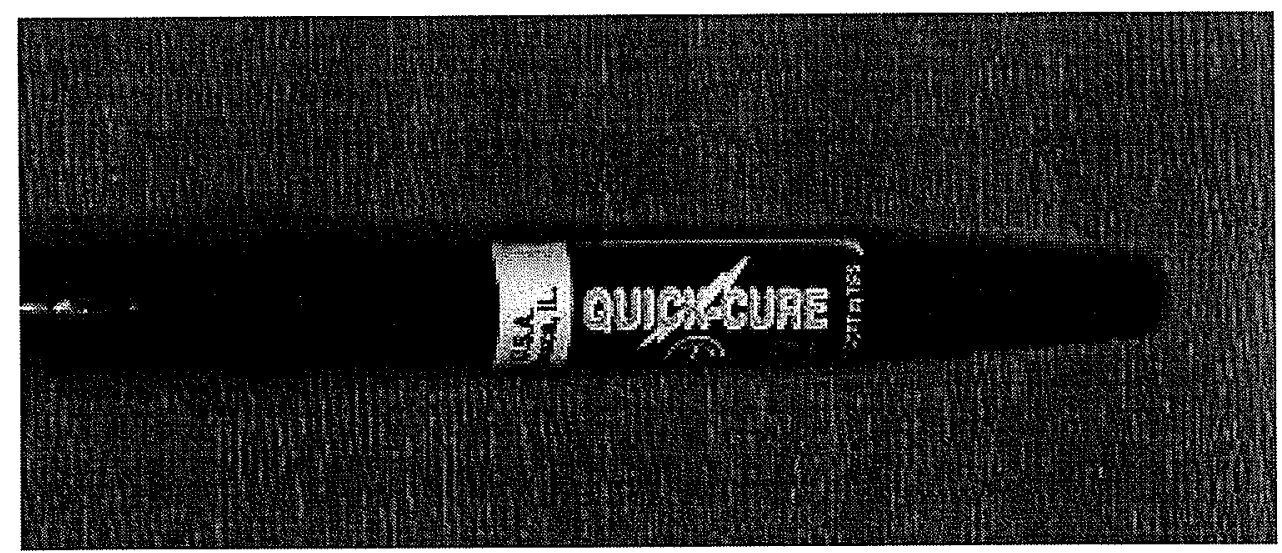

Figure 9: Quick Cure ${ }^{\mathrm{TM}}$ Paste 


\subsubsection{Transbond ${ }^{\mathrm{TM}} \mathrm{XT}$}

Transbond ${ }^{\mathrm{TM}} \mathrm{XT}$ is a no-mix paste-liquid light-cured composite adhesive (Lai et al., 1999). The paste is composed of approximately $18 \%$ Bis-GMA/TEGDMA monomers and approximately $82 \%$ hybrid filler ( $3 \mu \mathrm{m}$ silica particles) with adiketone and organic amine as photoinitiators. The liquid primer is composed of Bis-GMA in combination with a urethane oligomer (Lai et al., 1999).

\begin{tabular}{|l|l|l|}
\hline \multicolumn{1}{|c|}{ Material } & \multicolumn{1}{|c|}{ Manufacturer } & \multicolumn{1}{c|}{ Lot Number } \\
\hline $\begin{array}{l}\text { Transbond XT } \\
\text { adhesive paste }\end{array}$ & $\begin{array}{l}\text { 3M Unitek } \\
\text { CA, USA }\end{array}$ & $\begin{array}{l}\text { 062697 (Part 1) } \\
\text { 0AK (Part 2) }\end{array}$ \\
\hline Transbond XT' ${ }^{\mathrm{TM}}$ primer & $\begin{array}{l}\text { 3M Unitek } \\
\text { CA, USA }\end{array}$ & 0AC Monrovia, \\
\hline $\begin{array}{l}\text { Dentsply 34\% tooth } \\
\text { conditioner gel }\end{array}$ & $\begin{array}{l}\text { Dentsply Canada, } \\
\text { Woodbridge, ON, Canada }\end{array}$ & 9912021 \\
\hline
\end{tabular}

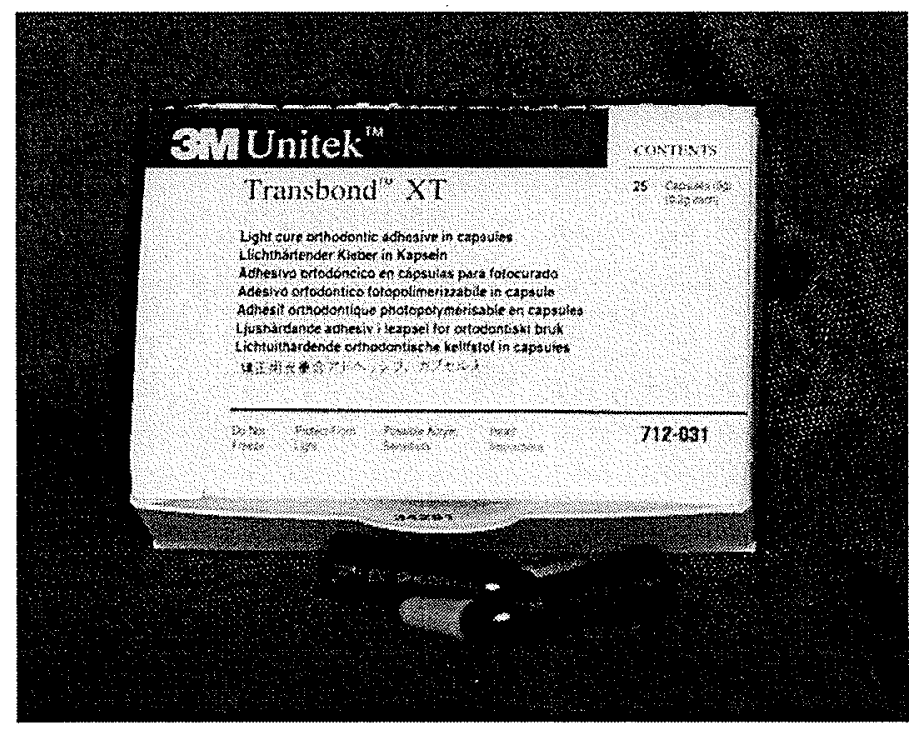

Figure 10: Transbond ${ }^{\mathrm{TM}}$ XT (Part I) 


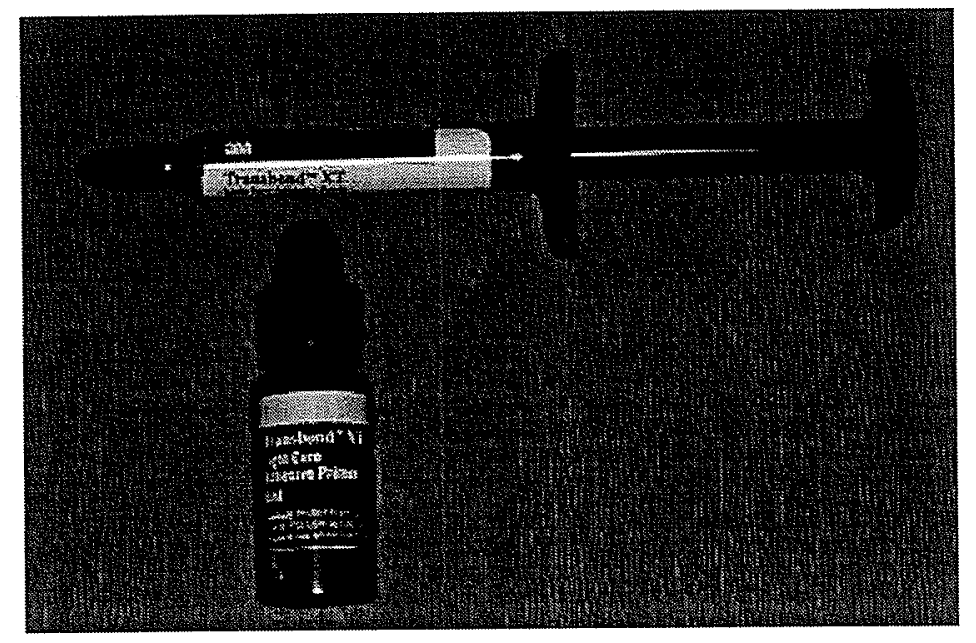

Figure 11: Transbond ${ }^{\mathrm{TM}}$ XT (Part II)

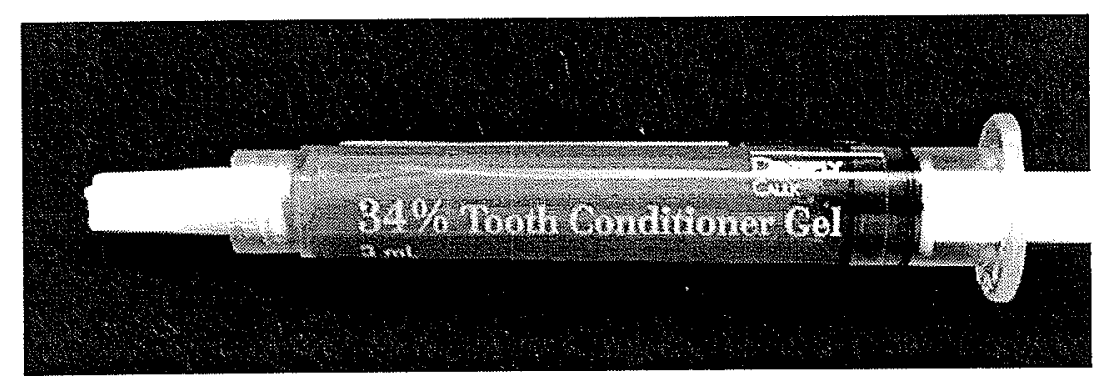

Figure 12: Dentsply 34\% Tooth Conditioner Gel

\subsubsection{Orthodontic brackets}

Thirty pre-adjusted upper left first premolar edgewise orthodontic brackets (American Orthodontics, Sheboygan, WI) were used for bonding to teeth in part II of the study. Using a scientific digital image analysis software program (SigmaScan Pro ${ }^{\circledR}$, SPSS Inc., Chicago, IL) the bracket base perimeter was calculated to be $1.185 \mathrm{~cm}$.

\begin{tabular}{|l|l|l|}
\hline \multicolumn{1}{|c|}{ Bracket } & \multicolumn{1}{|c|}{ Manufacturer } & Lot Number \\
\hline $\begin{array}{l}\text { Upper left first premolar } \\
\text { brackets }\end{array}$ & $\begin{array}{l}\text { American Orthodontics, } \\
\text { Sheboygan, WI, USA }\end{array}$ & Unknown \\
\hline
\end{tabular}




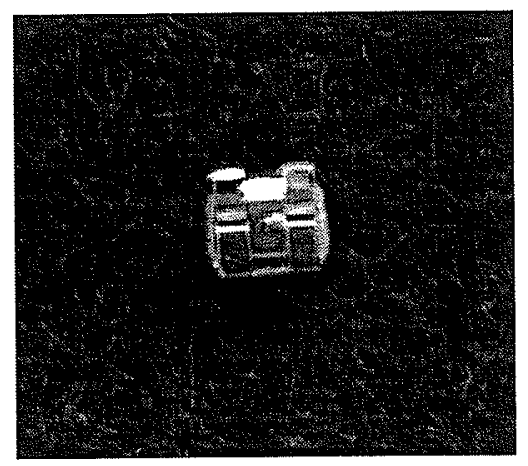

Figure 13: Upper left first premolar bracket

\subsubsection{Teeth}

Thirty-one intact, caries-free human premolar teeth extracted for orthodontic purposes were collected. These teeth were stored for at least two weeks in de-ionized, distilled water to allow free fluoride ions within the tooth to diffuse out (Monteith et al., 1999). One tooth was used in a pilot study to determine whether the varnish used would prevent fluoride release from the tooth. The thirty remaining teeth were used in part II of the study.

\subsubsection{Varnish}

The varnish used to prevent fluoride release from the teeth was Color Fast! ${ }^{\mathrm{TM}}$, a clear, one coat, fast dry varnish (Sally Hansen, Del Laboratories (Canada) Inc., Barrie, ON). A pilot study was done to confirm that the varnish would not release fluoride. One tooth was completely coated with the varnish and placed in $5 \mathrm{~mL}$ of de-ionized distilled water for 7 days. The water was subsequently tested for fluoride and none was detected. 


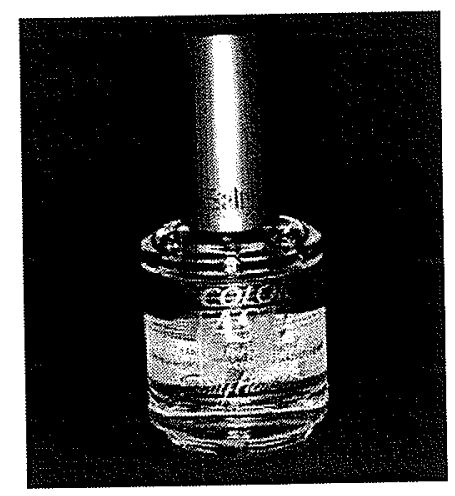

Figure 14: Color Fast! ${ }^{\mathrm{TM}}$ Varnish

\subsection{Experimental Method - Part I}

Part I of this study is the continuation of a previous research project (McNeill, 2000).

The following sections reiterate the experimental methods used in that study:

\subsubsection{Preparation of Specimens}

In the previous study, specimens were fabricated using a steel and Teflon split-mould machined at the University of Pretoria, South Africa.

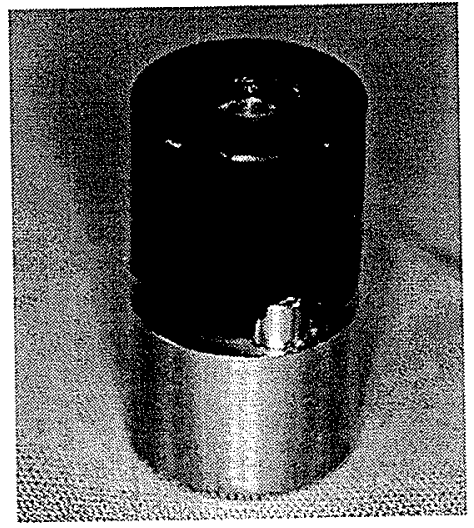

Figure 15: Split-mould 
Twenty standard-sized specimens ( $6 \mathrm{~mm}$ in diameter and $2 \mathrm{~mm}$ in thickness) of each of the following materials were manufactured:

1. Transbond ${ }^{T M} \mathrm{XT}$ (3M Unitek ${ }^{T M}$, Monrovia, CA)

2. Python ${ }^{T M}$ (TP Orthodontics, LaPorte, IN)

3. Assure $^{T M}$ (Reliance Orthodontic Products Inc., Itasca, IL)

4. Fuji Ortho ${ }^{\mathrm{TM}}$ LC (GC America Inc., Alsip, IL)

\subsubsection{Transbond ${ }^{\mathrm{TM}} \mathrm{XT}$}

A capsule of Transbond ${ }^{\top M}$ XT adhesive paste was placed in the application gun supplied by the manufacturer and the paste was expressed into the mould, avoiding inclusion of voids. The Transbond primer was not used. The mould was filled flush to the top with adhesive paste. (from McNeill, 2000)

\subsubsection{Python ${ }^{T M}$}

The syringe tip of Python ${ }^{\mathrm{TM}}$ adhesive paste was held just over the mould as the paste was expressed into the split-mould. The mould was filled completely. Neither Python ${ }^{\mathrm{TM}}$ conditioning liquid nor sealant was used. (from McNeill, 2000)

\subsubsection{Assure $^{T M}$}

Adhesive paste from the syringe was expressed into the split-mould in the same manner as described for Python ${ }^{\top M}$. The light-cure sealant was not used. (from McNeill, 2000) 


\subsubsection{Fuji Ortho ${ }^{T M}$ LC}

The adhesive-filled capsule was squeezed together by hand to break the membrane separating powder and liquid. The capsule was then triturated for 10 seconds in a VariMix III triturator (Caulk/Dentsply, Milford, DE) at approximately 4000

oscillations/minute. The capsule was then loaded into the application gun supplied by the manufacturer and the adhesive paste was squeezed into the mould. (from McNeill, 2000)

\subsubsection{Sample Manufacturing Technique}

When the split-mould was filled flush to the top with a sample of each type of the uncured bonding material, a clear Mylar strip (Palmero Health Care, Stratford, CT), was held with light finger pressure over the unset material, in contact with the superior surface of the mould.

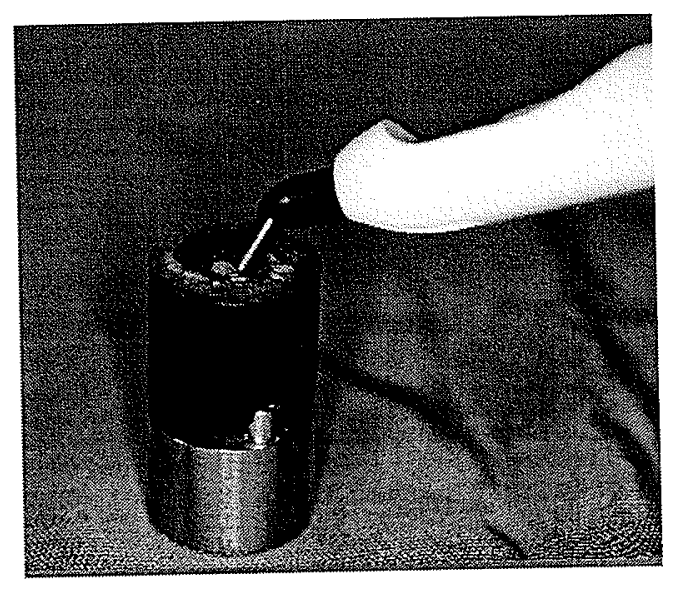

Figure 16: Filling the split-mould 
An Ortholux ${ }^{\mathrm{TM}}$ XT Visible Light Curing Unit (3M Unitek ${ }^{\mathrm{TM}}$, Monrovia, CA) was used to light-cure all materials. The light tip was held directly over, but not in contact with, the sample. Curing time was 40 seconds per specimen for all material types.

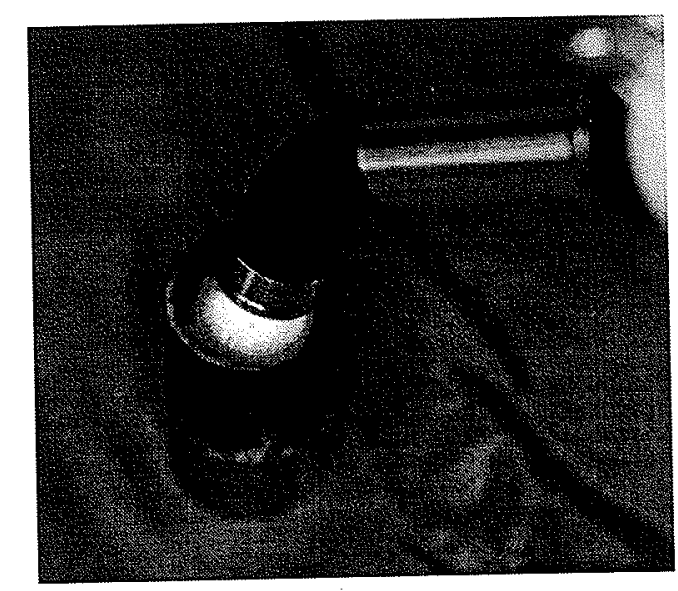

\section{Figure 17: Light curing material in the split-mould}

Once curing was completed, each specimen was released from the mould.

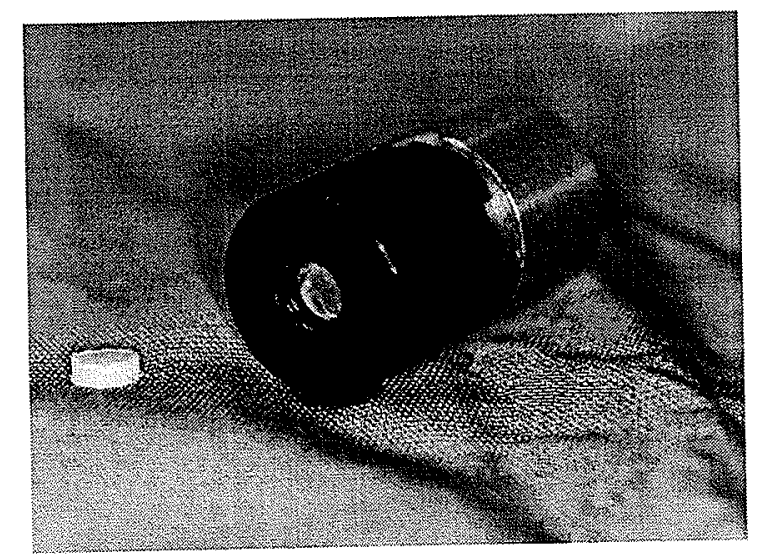

Figure 18: Sample released from split-mould 
All discs were then weighed on a model 2001 MP2 electronic analytical balance (Sartorius, Gottingen, Germany) to the nearest $0.0001 \mathrm{~g}$. Each disc was then placed into an individual $10 \mathrm{~mL}$ polyethylene test tube (\#14-956-3D, 12x75 mm with snap caps, Fisher Scientific, Pittsburgh, PA), and labelled with the material type and specimen number.

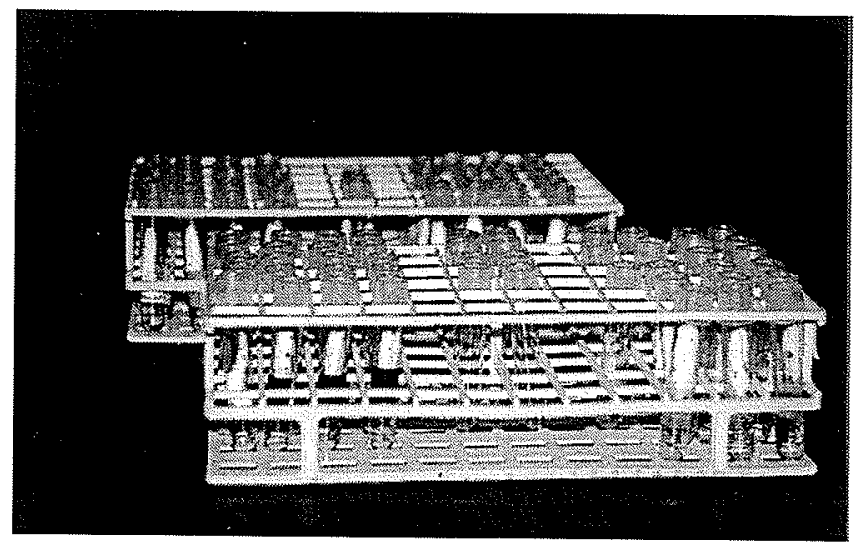

Figure 19: Samples in polyethylene test tubes

A time period of 24 hours elapsed between fabrication of the specimens and immersion in sample solutions, during which time the samples were maintained in their test tubes in an incubator (Thelco Precision Scientific, model \#18, Chicago, IL) at $37^{\circ} \mathrm{C}$ and $100 \%$ relative humidity. The surface area of the discs was calculated using the formula $[\pi \mathrm{dh}]+\left[2 \pi\left(\mathrm{r}^{2}\right)\right]$, as stated by Monteith et al. (1999). The calculated surface area of each specimen was $0.9425 \mathrm{~cm}^{2}$. (from McNeill, 2000)

\subsubsection{Specimen storage}

De-ionized distilled water was used as the immersion solution for 10 samples of each material. Using an automatic pipette (Brinkman Dispensette $2 \mathrm{~mL}$, Westbury, NY), $1 \mathrm{~mL}$ 
of water was added to 10 test tubes for each material, for a total of 40 specimens. The remaining 40 specimens were immersed in $1 \mathrm{~mL}$ of artificial saliva. However, McNeill (2000) found that at later time periods no differences in fluoride release were noted for the materials in distilled water vs. artificial saliva. As a result, it was decided only to follow the discs immersed in de-ionized distilled water for long-term study. All test tubes were capped with their polyethylene covers, placed in racks and stored in an incubator at $37^{\circ} \mathrm{C}$ and $100 \%$ relative humidity. This temperature was chosen since some glass-ionomers release more fluoride at $37^{\circ} \mathrm{C}$ than at $21^{\circ} \mathrm{C}$ (Jones et al., 1987). To prevent measurements from being cumulative, solutions were changed 24 hours before the samples were analyzed (Cooley et al., 1989). (from McNeill, 2000)

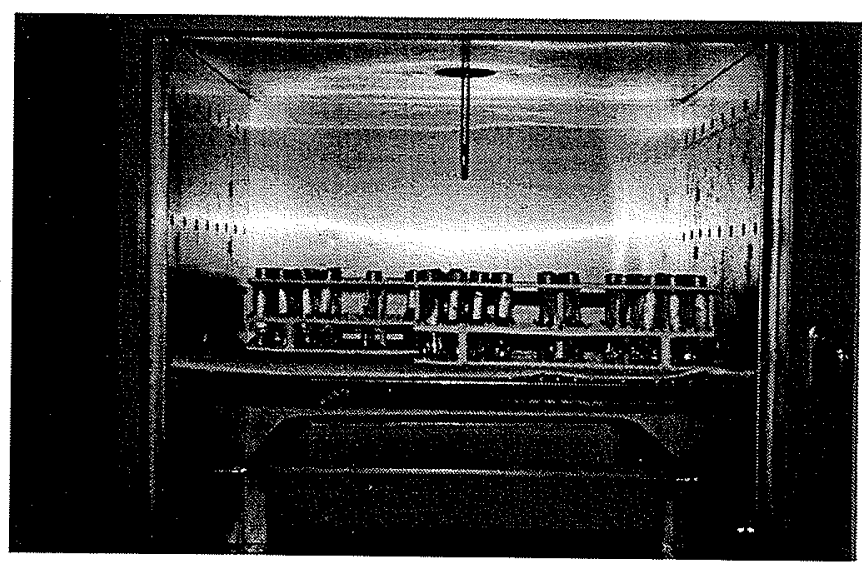

Figure 20: Samples stored in incubator 


\subsubsection{Measurement of Fluoride Release}

\subsubsection{Fluoride Electrode Calibration and Use}

A fluoride ion-specific combination electrode (model 13-620-528, Orion Research Inc., Beverly, MA) connected to a $\mathrm{pH}$ meter (Radiometer pHM 82 standard $\mathrm{pH}$ meter, Copenhagen, Denmark) was used to measure fluoride in solution (Fox, 1990). When not in use, the electrode was immersed in a standard fluoride solution as per manufacturer instructions.

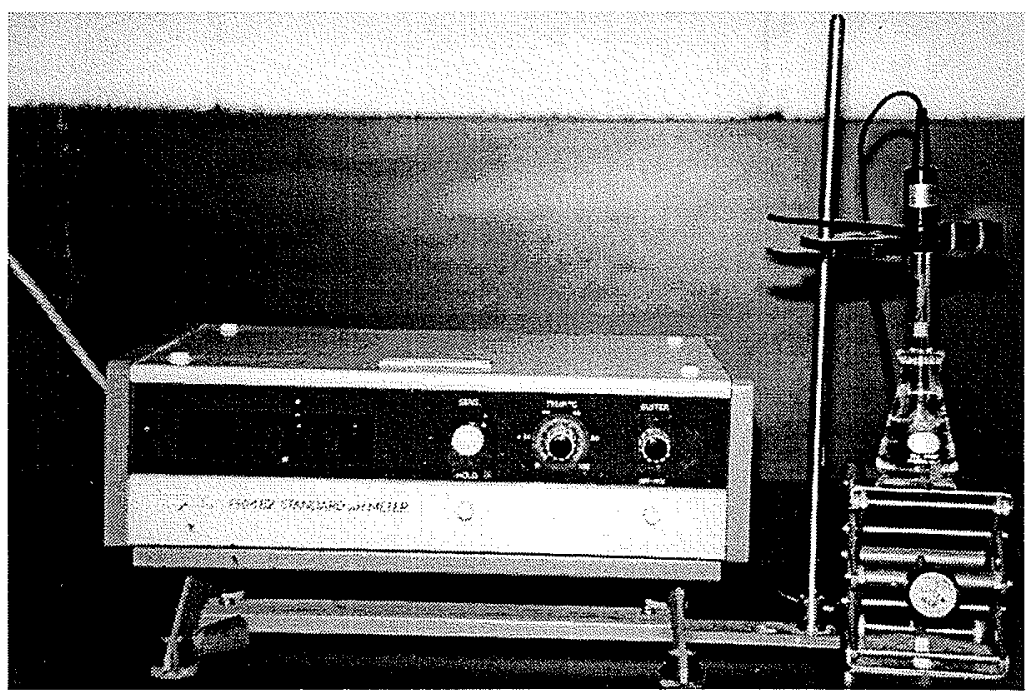

Figure 21: Fluoride electrode setup

The electrode was calibrated using a series of standard solutions made from the serial dilution of $\mathrm{NaF}$ in de-ionized, distilled water. The standard solutions were of the following concentrations (in ppm): $1000,100,10,1,0.6,0.3$ and 0.1 . Using these 
standard solutions, a calibration curve of parts per million (ppm) vs. millivolts $(\mathrm{mV})$ was plotted on semi-logarithmic graph paper (Fox, 1990). A new calibration curve was plotted at the beginning of each session. The ion-specific electrode operates on the principle that a potential develops across the electrode's membrane, and the relationship between this potential and fluoride ion activity is governed by the Nernst equation:

$$
\begin{aligned}
& \mathbf{E}=\mathbf{E}^{\circ}-\mathrm{S} \log \mathbf{A} \\
& E=\text { measured electrode potential } \\
& E^{\circ}=\text { constant, sum of several system potentials } \\
& S=\text { electrode slope } \\
& A=\text { fluoride ion activity }
\end{aligned}
$$

The ideal Nernstian equation slope is $-58 \mathrm{mV}$ per decade increase in fluoride ion activity (at $20^{\circ} \mathrm{C}$ ), except at very low fluoride concentrations (Rix, 1999; from McNeill, 2000).

For fluoride measurement, the $1 \mathrm{~mL}$ sample solution was transferred into a $5 \mathrm{~mL}$ polyethylene test cup (Nalgene, Rochester, NY). An equal amount ( $1 \mathrm{~mL}$ ) of TISAB II (Orion Research Inc., Beverly, MA) was added to each sample, and then allowed to adjust to room temperature (from McNeill, 2000). Since the fluoride ion-selective electrode is sensitive to changes in $\mathrm{pH}$, TISAB (Total Ionic Strength Adjustment Buffer) must be added to any water specimen to hold the $\mathrm{pH}$ of the specimen between 5.0 and 5.5. TISAB frees $\mathrm{F}^{-}$ions bound to hydrogen, and eliminates hydroxyl ion interference, enabling accurate measurement of total fluoride content (Fox, 1990). The electrode was rinsed thoroughly with de-ionized, distilled water and placed in the sample solution. The electrode was allowed to stabilize before measurements were taken. The electrode was 
rinsed thoroughly with de-ionized, distilled water between each measurement. Using the calibration curve described previously, the concentration of each sample (ppm) was determined from the $\mathrm{mV}$ reading given on the $\mathrm{pH}$ meter. (from McNeill, 2000)

\subsubsection{Fluoride Measurement Schedule}

In the preceding part of the study, fluoride release measurements were taken for all samples at 6 hours, 24 hours, 3 days, 7 days, 14 days, 21 days, 1 month, 2 months, 3 months, 4 months, 5 months and 6 months. For the present study, each of the four sample groups (Fuji Ortho ${ }^{\mathrm{TM}}$ LC, Assure ${ }^{\mathrm{TM}}$, Python ${ }^{\mathrm{TM}}$ and Transbond ${ }^{\mathrm{TM}} \mathrm{XT}$ ) was divided in half, leaving eight groups of five samples each (see chart below).

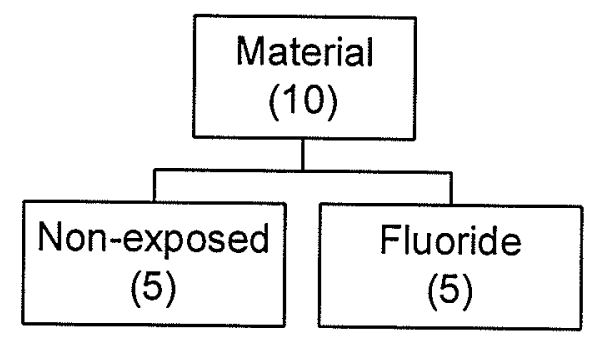

The "non-exposed" group of each material had fluoride-release measurements taken at days: 546 (18 months), 637 (21 months), 730 (24 months), 821 (27 months) and 913 (30 months) from the time of initial fabrication. At day 545 (18 months) from time of initial sample fabrication, the "fluoride" group was re-exposed (submerged) in $2 \% \mathrm{NaF}$ gel (Nupro, Dentsply Canada Ltd, Woodbridge, ON) for 4 minutes, rinsed, gently dried and replaced in de-ionized distilled water (Takahashi et al., 1993), and had measurements taken at 24 hours (day 546 from initial fabrication), 3 days (day 548), 7 days (day 552), 1 
month (day 575), 3 months (day 637), 6 months (day 730), 9 months (day 821) and 12 months (day 913) following fluoride exposure.

\subsubsection{Statistical Analysis}

The results of fluoride-release testing on days 546, 548, 552, 575, 637, 730, 821 and 913 for the fluoride exposed samples, and on days 546, 637, 730, 821 and 913 for the nonexposed samples, were each analyzed using a two-tailed repeated measures analysis of variance (ANOVA) at the 5\% significance level to determine whether significant differences in fluoride-release rates existed between the different sample groups and within each group over time for both the fluoride-exposed and non-exposed samples (Hassard, 1991).

\subsection{Experimental Method - Part II}

\subsubsection{Preparation of Specimens}

Thirty tooth-bracket specimens were fabricated using human premolars extracted for orthodontic reasons. Each tooth was removed from the de-ionized distilled water storage medium and dried gently. The crown of each tooth was cleaned with fluoride-free

pumice (Preppies ${ }^{\top M}$, Whip Mix Corporation, Louisville, KY) using a slow-speed prophylaxis cup. 


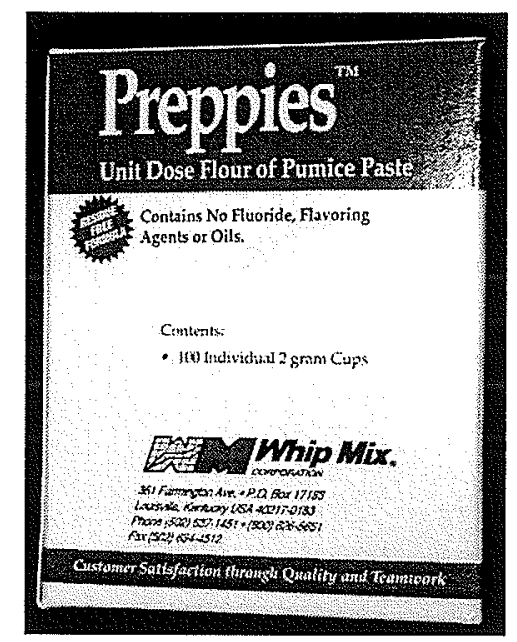

Figure 22: Preppies $^{\top M}$ pumice paste

For the bonding procedure, a template was fabricated from paraffin wax to limit the bonding materials to the bracket base area. As such, a hole was cut in the paraffin wax to the dimension of the orthodontic bracket base, and was kept in place throughout the bonding procedure.

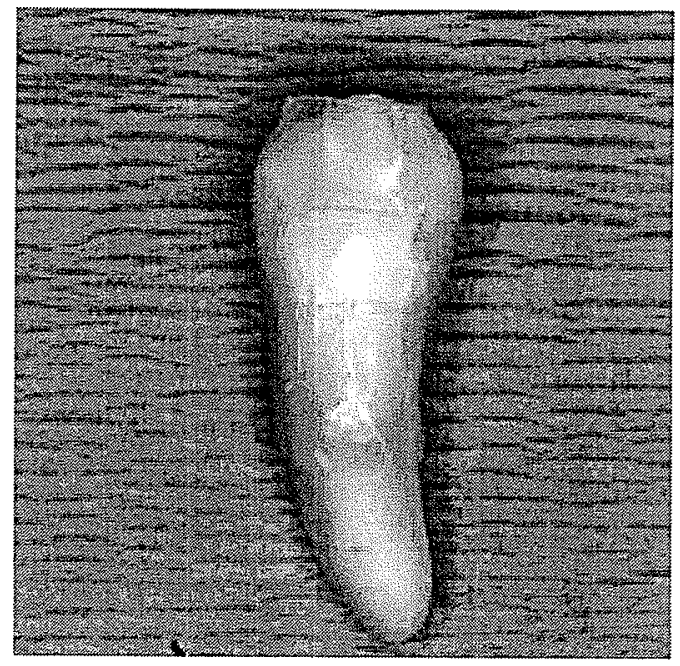

Figure 23: Buccal view of paraffin wax template on tooth 


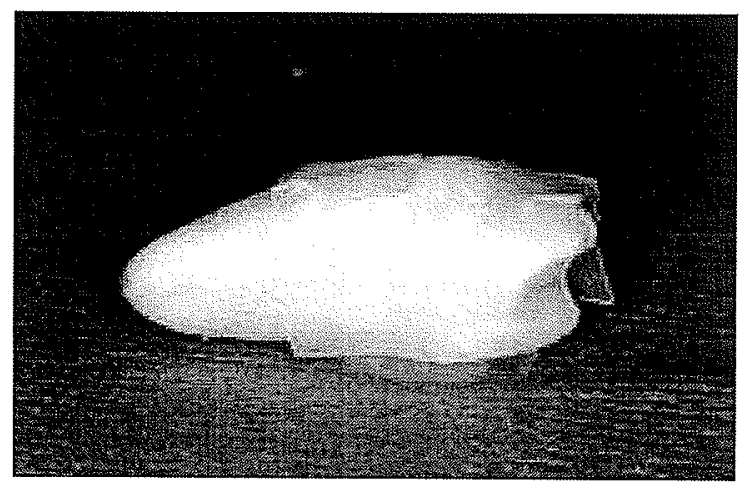

Figure 24: Lateral view of paraffin wax template on tooth

Ten teeth were bonded with pre-adjusted edgewise orthodontic brackets (American

Orthodontics, Sheboygan, WI) for each of the bonding materials (Assure ${ }^{T M}$, Quick Cure ${ }^{T M}$ and Transbond ${ }^{\top M} \mathrm{XT}$ ) according to manufacturers' instructions. The template was placed on the tooth, which was then prepared with the appropriate etching and bonding materials. The bracket base was coated with bonding resin and placed on the tooth within the defined bonding area. To minimize further residual excess bonding material, a dental explorer was used to clean around the bracket base before curing the material (Monteith et al., 1999).

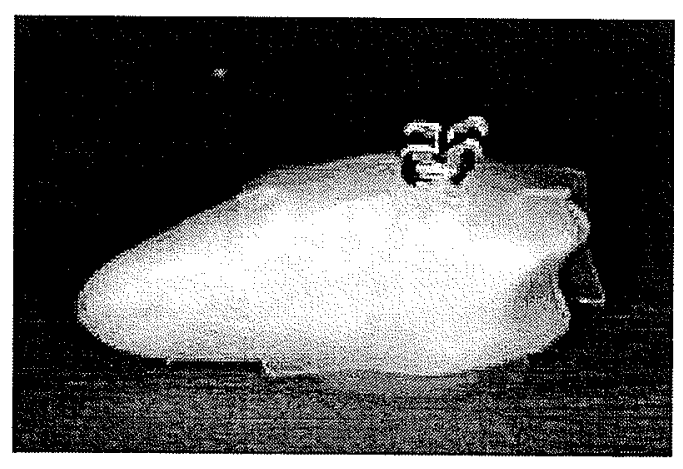

Figure 25: Bracket bonded with paraffin wax template in place

Each sample was then cured with an Ortholux ${ }^{\top M}$ Curing Light (3M Unitek ${ }^{\top M}$, Monrovia, CA). The surface area of exposed material around the bracket base periphery was 
calculated using the formula $\mathrm{A}=1 \mathrm{x}$ ht, where length was the perimeter of each bracket base and height was the thickness of material at the bracket periphery estimated at 0.01 $\mathrm{cm}(\operatorname{Rix}, 2000)$. The calculated surface area for material exposed at the bracket base periphery was $0.01185 \mathrm{~cm}^{2}$.

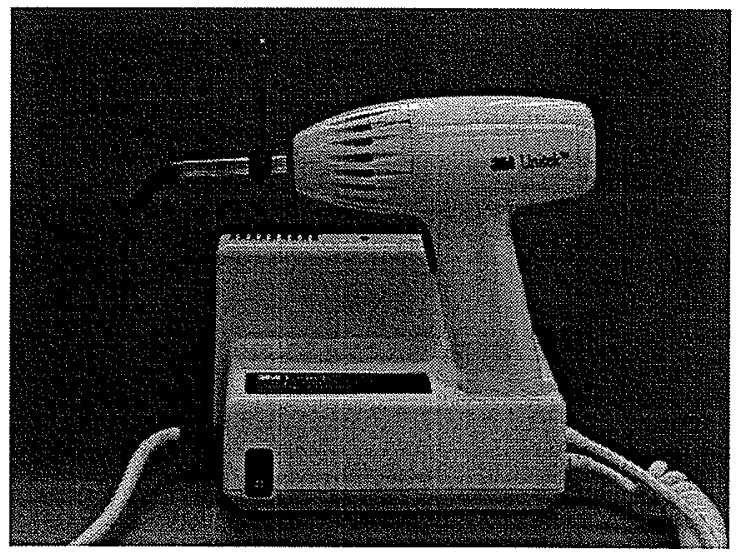

\section{Figure 26: Ortholux ${ }^{\top M}$ Light-Curing Unit}

After light curing, each tooth was coated with a layer of fluoride-free varnish to prevent leaching of fluoride from tooth material for the duration of the experiment. The varnish was applied with a brush to the tooth, coming as close as possible to the edge of the bracket without coating the bracket or bonding resin (Monteith et al., 1999).

\subsubsection{Assure AM $^{T M}$}

10 teeth were randomly chosen for bonding with Assure ${ }^{\mathrm{TM}}$ (Reliance Orthodontic Products Inc., Itasca, IL) according to manufacturer's instructions. Reliance etching agent ( $37 \%$ phosphoric acid) was placed on the bonding area for 30 seconds. The etching agent was then rinsed thoroughly with water for 10 seconds and dried thoroughly so that a frosty white appearance was evident. Assure ${ }^{T M}$ sealant was then applied to the prepared 
area of each tooth. Assure ${ }^{\mathrm{TM}}$ paste was then applied and worked into the bracket base using a spatula, and the bracket was pressed into position on the tooth. Excess material was removed using a dental explorer, and the paste was cured with the Ortholux ${ }^{\mathrm{TM}}$ ( $3 \mathrm{M}$ Unitek $^{\mathrm{TM}}$, Monrovia, CA) light-curing unit for 20 seconds from the incisal edge and 10 - seconds from the gingival edge.

\subsubsection{Quick Cure ${ }^{\top M}$}

10 teeth were randomly chosen for bonding with Quick Cure ${ }^{\top M}$ (Reliance Orthodontic Products Inc., Itasca, IL) according to manufacturer's instructions. Reliance etching agent was placed on the tooth bonding area for 30 seconds. Using an air/water syringe the tooth was rinsed thoroughly for 10 seconds and dried until a frosty white appearance was seen. Assure ${ }^{T M}$ sealant was generously applied to the tooth, allowed to sit for 10 seconds, lightly dried with air for 5 seconds and light cured for 10 seconds. Quick $\mathrm{Cure}^{\mathrm{TM}}$ paste was applied and worked into the bracket base and the bracket pressed into position on the tooth. Each bracket was cured with the Ortholux ${ }^{\top \mathrm{M}}$ (3M Unitek ${ }^{\mathrm{TM}}$, Monrovia, CA) light-curing unit for 5 seconds from the incisal and 5 seconds from the gingival edges.

\subsubsection{Transbond ${ }^{T M} X T$}

10 teeth were randomly chosen for bonding with Transbond ${ }^{T M}$ XT (3M Unitek ${ }^{\top M}$, Monrovia, CA) according to manufacturer's instructions. 34\% phosphoric acid etch (Dentsply Canada, Woodbridge, ON) was placed on the tooth for 15 seconds, rinsed thoroughly with water and dried thoroughly. A thin coat of light cure adhesive primer 
was applied to the etched area. Adhesive was applied to the bracket base and the bracket was seated on the tooth. The adhesive was then light cured with the Ortholux ${ }^{\mathrm{TM}}$ (3M Unitek $^{\mathrm{TM}}$, Monrovia, CA) light-curing unit for 10 seconds from the incisal edge and 10 seconds from the gingival edge.

\subsubsection{Specimen Storage}

De-ionized distilled water was the storage medium used for storing the tooth-bracket samples (McNeill, 2000). Water was added to glass jars with an automatic pipette (Brinkman Dispensette $5 \mathrm{~mL}$, Westbury, NY). The bonded teeth were placed into the water, ensuring that the bracket and crown of the tooth were submerged in the water. For days 1 and 3, $5 \mathrm{~mL}$ of water was placed in each jar. From day 7 on, $2.5 \mathrm{~mL}$ of water was used to allow more accurate fluoride measurement. The jars were placed in an incubator at $37^{\circ} \mathrm{C}$ and $100 \%$ relative humidity for reasons discussed in section 3.2.2. Again, to prevent cumulative measurement of fluoride, the storage solutions were changed 24 hours before measurement (Cooley et al., 1989).

\subsubsection{Measurement of Fluoride Release}

\subsubsection{Fluoride Electrode Calibration and Use}

A new fluoride detection procedure was used for part II of this study, incorporating more modern fluoride detection equipment. Fluoride levels in de-ionized distilled water were measured with a fluoride ion-specific combination electrode (Orion model 96-09, Orion Research Inc., Beverly, MA) attached to a pH/ISE/ORP measurement system 
(Sensorlink ${ }^{\mathrm{TM}}$ PCM700, Orion Research Inc., Beverly, MA) and a laptop computer (IBM Thinkpad I Series, IBM Corporation, Armonk, NY). When not in use, the electrode was stored as per manufacturer instructions. The electrode was calibrated at each measurement session with a series of standard solutions created from the serial dilution of $1000 \mathrm{ppm} \mathrm{NaF}$. The standard solutions were of the following concentrations (in ppm): $1000,100,10,1,0.6,0.3,0.1$. The Orion computer software calculated an appropriate calibration curve of parts per million (ppm) vs. millivolts $(\mathrm{mV})$ based on the standard samples. For samples collected on days 1 and 3 , the $5 \mathrm{~mL}$ samples were added to $0.5 \mathrm{~mL}$ TISAB III buffer, for reasons discussed in section 3.2.3.1. For samples collected at day 7, 1 month, 3 months and 6 months, $2.5 \mathrm{~mL}$ of de-ionized distilled water was combined with $0.25 \mathrm{~mL}$ of TISAB III. TISAB III is a concentrated version of the buffer, so the amount of buffer is only $1 / 10$ the volume of the sampled being measured. The sample was allowed to reach room temperature before measurement.

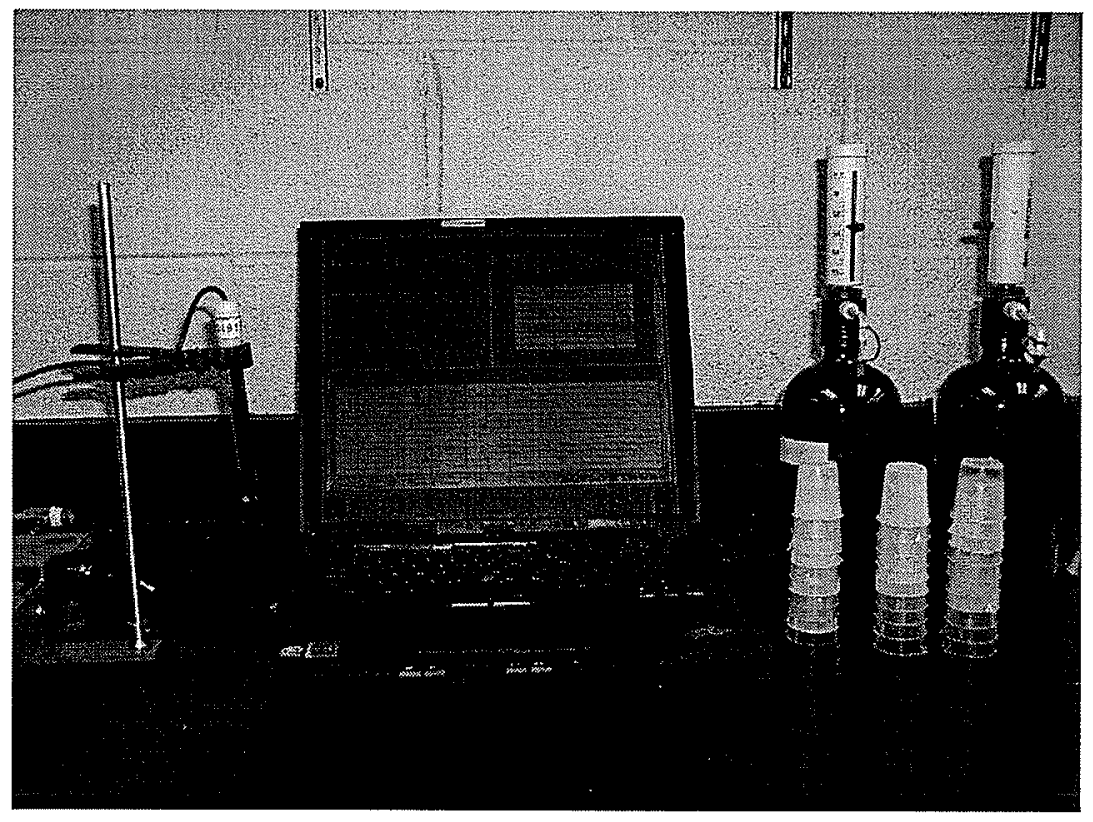

Figure 27: Fluoride measurement apparatus 


\subsubsection{Fluoride Measurement Schedule}

After fabrication and immersion in deionized distilled water, fluoride-release

measurements were taken on day 1 ( 24 hours), day 3 , day 7 , day 30 ( 1 month), day 90 ( 3

months) and day 180 (6 months). Storage water was changed 24 hours prior to testing to avoid cumulative measurement of fluoride release (Cooley et al., 1989).

\subsubsection{Statistical Analysis}

The results of fluoride-release testing on days $1,3,7,30,90$ and 180 were analyzed using a two-tailed repeated measures analysis of variance (ANOVA) at the $5 \%$ significance level to determine whether significant differences in fluoride-release rates existed among the different sample groups and within each group over time (Hassard, 1991). 


\title{
Chapter 4
}

\author{
Results
}

\subsection{Long-term Fluoride Release}

\subsubsection{Overall Pattern}

Fuji Ortho ${ }^{\mathrm{TM}}$ LC always released the highest levels of fluoride, followed by Python ${ }^{\mathrm{TM}}$ and Assure $^{\top M}$. The control material, Transbond ${ }^{T M} \mathrm{XT}$, never released detectable levels of fluoride. The long-term fluoride release rates for all materials are found in Table 1. The fluoride release measurements for individual samples can be found in Appendix 1 . 
Table 1: Long-term fluoride release rates (mean \pm S.E., $n=5$ )

\begin{tabular}{|c|c|c|c|c|c|}
\hline \multirow{2}{*}{ Material } & \multicolumn{5}{|c|}{ Fluoride Release $\left(\mu \mathrm{g} / \mathrm{cm}^{2} /\right.$ day $)$} \\
\hline & $\begin{array}{c}\text { Day } 546^{*} \\
\text { (18 months) }\end{array}$ & $\begin{array}{c}\text { Day } 637 \\
\text { (21 months) }\end{array}$ & $\begin{array}{c}\text { Day } 730 \\
\text { (24 months) }\end{array}$ & $\begin{array}{c}\text { Day } 821 \\
\text { (27 months) }\end{array}$ & $\begin{array}{c}\text { Day } 913 \\
\text { (30 months) }\end{array}$ \\
\hline \multirow[b]{2}{*}{ Fuji Ortho ${ }^{T M}$ LC } & $11.04 \pm 0.27$ & $10.45 \pm 0.040$ & $10.18 \pm 0.071$ & $10.15 \pm 0.052$ & $10.33 \pm 0.031$ \\
\hline & a A & a A & a A & a $A$ & a A \\
\hline \multirow[b]{2}{*}{ Python $^{\top \mathrm{M}}$} & $8.09 \pm 0.21$ & $5.79 \pm 0.43$ & $4.47 \pm 0.20$ & $6.19 \pm 0.36$ & $6.77 \pm 0.21$ \\
\hline & b A & b B C & b B & $\mathrm{bCC}$ & $\mathrm{b} A \mathrm{C}$ \\
\hline \multirow[b]{2}{*}{ Assure $^{\mathrm{Tu}}$} & $7.68 \pm 0.65$ & $4.62 \pm 0.79$ & $1.04 \pm 0.14$ & $1.21 \pm 0.23$ & $4.83 \pm 0.20$ \\
\hline & $\mathrm{bA}$ & $\mathrm{bB}$ & $\mathrm{c} \mathrm{C}$ & $\mathrm{c} \mathrm{C}$ & c B \\
\hline \multirow[t]{2}{*}{ Transbond $^{\mathrm{TM}} \mathrm{XT}$} & $\begin{array}{l}\text { ND (Non- } \\
\text { detectable) }\end{array}$ & ND & ND & ND & ND \\
\hline & $\mathrm{c} \mathrm{A}$ & $\mathrm{cA}$ & c A & c A & $\mathrm{d} \mathrm{A}$ \\
\hline
\end{tabular}

The same small letters in a column indicate no statistically significant difference in means.

The same large letters in a row indicate no statistically significant difference in means.

* - Indicates number of days since initial fabrication of the samples.

( ) - Parentheses indicate corresponding months since initial fabrication of samples. 


\subsubsection{Fuji Ortho ${ }^{T M}$ LC Fluoride Release Rates}

Fuji Ortho ${ }^{\top M}$ LC released statistically similar levels of fluoride at all time points (days $546,637,730,821$ and 913) ( $p>0.05)$. Descriptive statistics of mean fluoride release rates and standard errors for Fuji Ortho ${ }^{\mathrm{TM}} \mathrm{LC}$ are found in Table 2 and Figure 28.

Table 2: Fuji Ortho ${ }^{\mathrm{TM}}$ LC long-term fluoride release rate descriptive statistics

\begin{tabular}{|c|c|c|c|c|}
\hline Day & Adhesive & $n$ & $\begin{array}{l}\text { Mean Fluoride Release } \\
\left(\mu \mathrm{g} \mathrm{F} / \mathrm{cm}^{2} / \text { day }\right)\end{array}$ & $\begin{array}{c}\mathrm{SE} \\
\left(\mu \mathrm{g} \mathrm{F} / \mathrm{cm}^{2} / \text { day }\right)\end{array}$ \\
\hline 546 & Fuji Ortho ${ }^{\top M}$ LC & 5 & 11.04 & 0.27 \\
\hline 637 & Fuji Ortho ${ }^{T M}$ LC & 5 & 10.45 & 0.040 \\
\hline 730 & Fuji Ortho ${ }^{\text {TM }}$ LC & 5 & 10.18 & 0.071 \\
\hline 821 & Fuji Ortho ${ }^{T M}$ LC & 5 & 10.15 & 0.052 \\
\hline 913 & Fuji Ortho ${ }^{T M}$ LC & 5 & 10.33 & 0.031 \\
\hline
\end{tabular}

\section{Fuji Long-Term Fluoride Release}

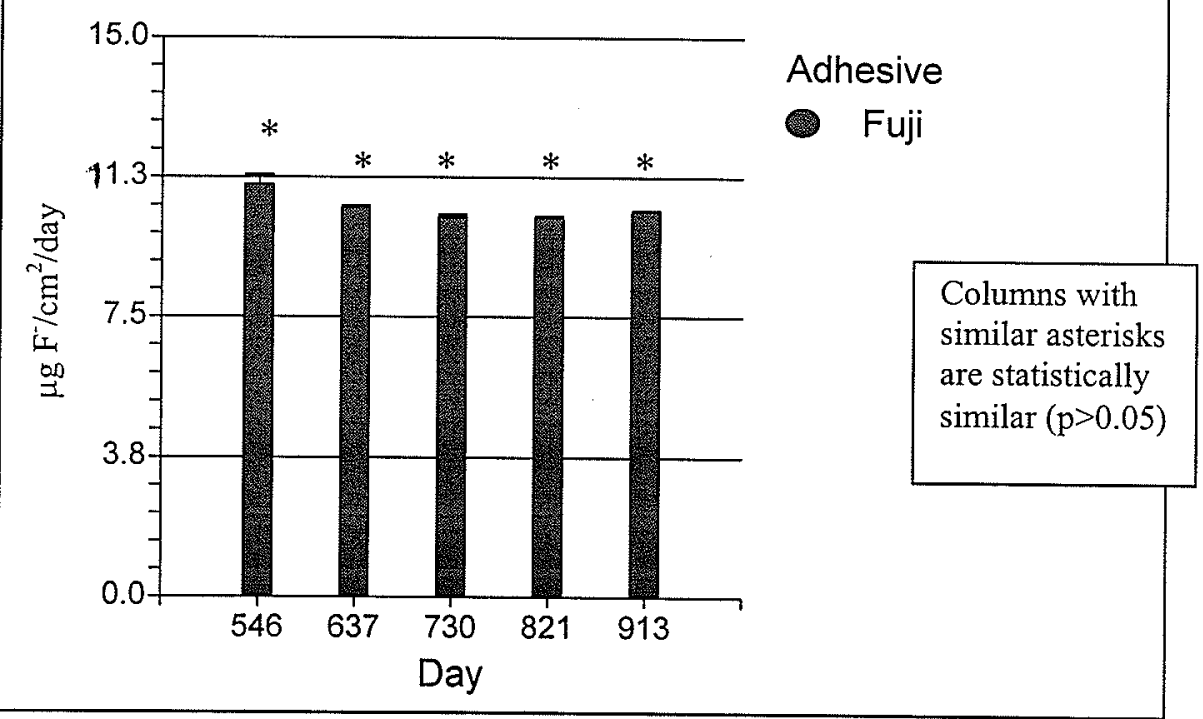

Figure 28: Fuji Ortho ${ }^{\mathrm{TM}}$ LC long-term fluoride release rates. Error bars indicate standard error. 


\subsubsection{Python ${ }^{\mathrm{TM}}$ Fluoride Release Rates}

Python $^{\mathrm{TM}}$ released $8.09 \pm 0.21 \mu \mathrm{g} \mathrm{F} / \mathrm{cm}^{2} /$ day on day 546 , followed by a statistically significant decrease to levels of $5.79 \pm 0.43 \mu \mathrm{g} \mathrm{F} / \mathrm{cm}^{2} /$ day on day 637 and $4.47 \pm 0.20 \mu \mathrm{g}$ $\mathrm{F} / \mathrm{cm}^{2} /$ day on day $730(\mathrm{p}<0.0001)$. This was followed a statistically significant increase $(\mathrm{p}<0.0001)$ in fluoride release to $6.19 \pm 0.36 \mu \mathrm{g} \mathrm{F} / \mathrm{cm}^{2} /$ day on day 821 and $6.77 \pm 0.21$ $\mu \mathrm{g} \mathrm{F} / \mathrm{cm}^{2} /$ day on day 913 . The fluoride release values on days 821 and 913 were statistically similar ( $>00.05$ ), but only day 913 had fluoride release values similar to the initial measurement on day 546 ( $p>0.05)$. Descriptive statistics of mean fluoride release rates and standard errors for Python ${ }^{\mathrm{TM}}$ are found in Table 3 and Figure 29.

Table 3: Python ${ }^{\top M}$ long-term fluoride release rate descriptive statistics

\begin{tabular}{|c|c|c|c|c|}
\hline Day & Adhesive & $\mathrm{n}$ & $\begin{array}{c}\text { Mean Fluoride Release } \\
\left(\mu \mathrm{g} \mathrm{F}^{\prime} / \mathrm{cm}^{2} / \text { day }\right)\end{array}$ & $\begin{array}{c}\mathrm{SE} \\
\left(\mu \mathrm{g} \mathrm{F} / \mathrm{cm}^{2} / \text { day }\right)\end{array}$ \\
\hline 546 & Python $^{\top \mathrm{M}}$ & 5 & 8.09 & 0.21 \\
\hline 637 & Python $^{\top \mathrm{M}}$ & 5 & 5.79 & 0.43 \\
\hline 730 & Python $^{\top \mathrm{M}}$ & 5 & 4.47 & 0.20 \\
\hline 821 & Python $^{\top \mathrm{M}}$ & 5 & 6.19 & 0.36 \\
\hline 913 & Python $^{\mathrm{M}}$ & 5 & 6.77 & 0.21 \\
\hline
\end{tabular}

\section{Python Long-Term Fluoride Release}

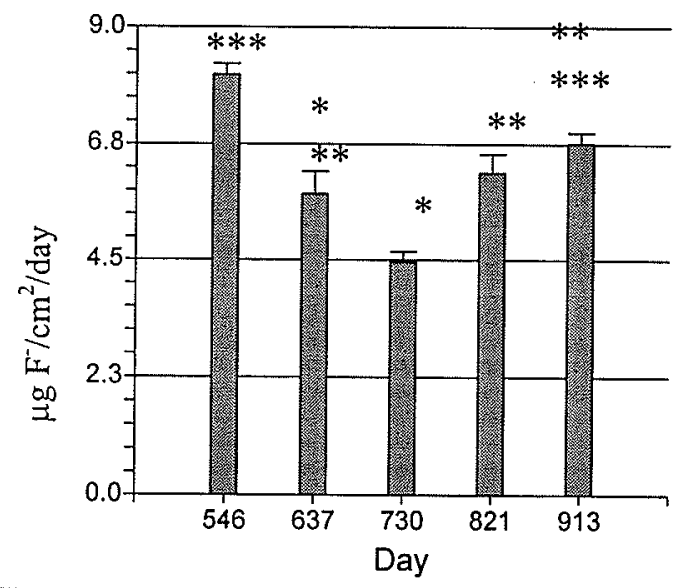

Adhesive

Python

Columns with similar asterisks are statistically similar $(\mathrm{p}>0.05)$

Figure 29: Python ${ }^{\mathrm{TM}}$ long-term fluoride release rates. Error bars indicate standard error. 


\subsubsection{Assure ${ }^{\mathrm{TM}}$ Fluoride Release Rates}

Assure $^{\mathrm{TM}}$ showed statistically significant decreases in fluoride release levels from $7.68 \pm$ $0.65 \mu \mathrm{g} \mathrm{F} / \mathrm{cm}^{2} /$ day (day 546) to $4.62 \pm 0.79 \mu \mathrm{g} \mathrm{F} / \mathrm{cm}^{2} /$ day (day 637) and from $4.62 \pm$ $0.79 \mu \mathrm{g} \mathrm{F} / \mathrm{cm}^{2} /$ day (day 637) to $1.04 \pm 0.14 \mu \mathrm{g} \mathrm{F}^{-} / \mathrm{cm}^{2} /$ day (day 730$)(\mathrm{p}<0.001)$. Fluoride release levels of Assure ${ }^{\top M}$ were statistically similar on day $730(1.04 \pm 0.14 \mu \mathrm{g} \mathrm{F}$ $/ \mathrm{cm}^{2} /$ day) and day $821\left(1.21 \pm 0.23 \mu \mathrm{g} \mathrm{F}^{-} / \mathrm{cm}^{2} /\right.$ day $)(\mathrm{p}>0.05)$. There was a statistically significant increase in fluoride release from day 821 to day $913\left(4.83 \pm 0.20 \mu \mathrm{g} \mathrm{F}^{-}\right.$ $/ \mathrm{cm}^{2} /$ day $)(\mathrm{p}<0.001)$ to a level similar to day $637(\mathrm{p}>0.05)$. Descriptive statistics of mean fluoride release rates and standard errors for Assure ${ }^{\mathrm{TM}}$ are found in Table 4 and Figure 30.

Table 4: Assure ${ }^{\mathrm{TM}}$ long-term fluoride release rate descriptive statistics

\begin{tabular}{|c|c|c|c|c|}
\hline Day & Adhesive & $\mathrm{N}$ & $\begin{array}{c}\text { Mean Fluoride Release } \\
\left(\mu \mathrm{g} \mathrm{F}^{\prime} / \mathrm{cm}^{2} / \text { day }\right)\end{array}$ & $\begin{array}{c}\mathrm{SE} \\
\left(\mu \mathrm{g} \mathrm{F} / \mathrm{cm}^{2} / \text { day }\right)\end{array}$ \\
\hline 546 & Assure $^{T \mathrm{M}}$ & 5 & 7.68 & 0.65 \\
\hline 637 & Assure $^{T \mathrm{M}}$ & 5 & 4.62 & 0.79 \\
\hline 730 & Assure $^{\top \mathrm{M}}$ & 5 & 1.04 & 0.14 \\
\hline 821 & Assure $^{\top \mathrm{M}}$ & 5 & 1.21 & 0.23 \\
\hline 913 & Assure $^{\mathrm{T}}$ & 5 & 4.83 & 0.20 \\
\hline
\end{tabular}

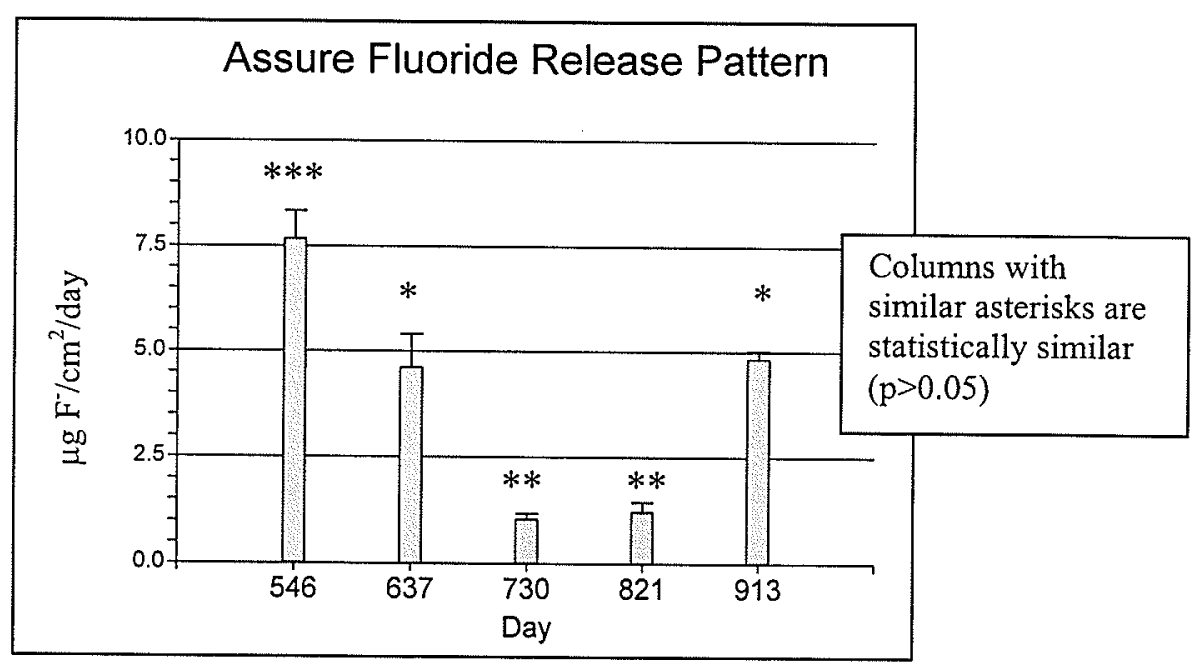

Figure 30: Assure ${ }^{T M}$ long-term fluoride release rates. Error bars indicate standard error. 


\subsubsection{Transbond ${ }^{\top M}$ XT Fluoride Release Rates}

Transbond $^{\mathrm{TM}} \mathrm{XT}$ did not release detectable levels of fluoride at any point during the measurement period. Descriptive statistics of mean fluoride release rates and standard errors for Transbond ${ }^{\mathrm{TM}}$ XT are found in Table 5 and Figure 31.

Table 5: Transbond ${ }^{\top M}$ XT long-term fluoride release rate descriptive statistics

\begin{tabular}{|c|c|c|c|c|}
\hline Day & Adhesive & $n$ & $\begin{array}{c}\text { Mean Fluoride Release } \\
\left(\mu \mathrm{g} \mathrm{F} / \mathrm{cm}^{2} / \text { day }\right)\end{array}$ & $\begin{array}{c}\mathrm{SE} \\
\left(\mu \mathrm{g} \mathrm{F} / \mathrm{cm}^{2} / \text { day }\right)\end{array}$ \\
\hline 546 & Transbond $^{T M} X T$ & 5 & ND & ND \\
\hline 637 & Transbond $^{\mathrm{TM}} \mathrm{XT}$ & 5 & ND & ND \\
\hline 730 & Transbond $^{\mathrm{TM}} \mathrm{XT}$ & 5 & ND & ND \\
\hline 821 & Transbond $^{\mathrm{TM}} \mathrm{XT}$ & 5 & ND & ND \\
\hline 913 & Transbond $^{\mathrm{TM}} \mathrm{XT}$ & 5 & ND & ND \\
\hline
\end{tabular}

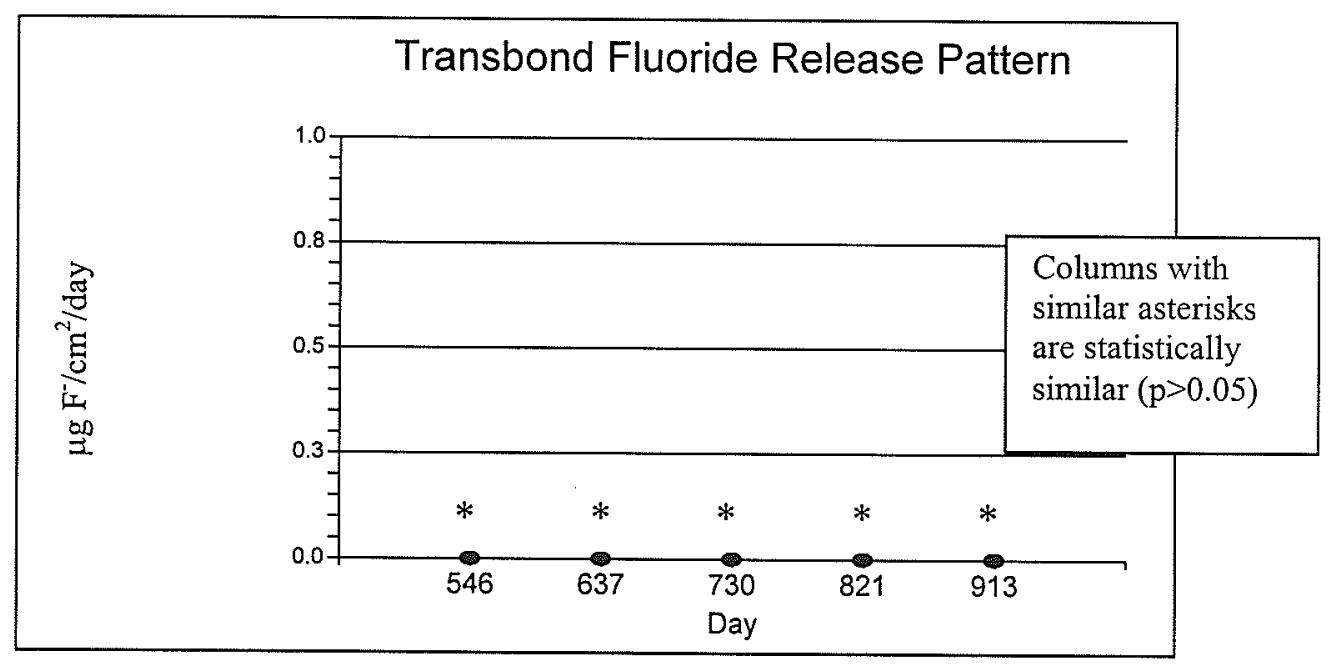

Figure 31: Transbond ${ }^{\top M}$ XT long-term fluoride release rates. Error bars indicate standard error. 


\subsubsection{Day 546 Fluoride Release Rates}

The highest mean fluoride release was from the Fuji Ortho ${ }^{\mathrm{TM}} \mathrm{LC}$ samples $(11.04 \pm 0.27$ $\mu \mathrm{g} \mathrm{F} / \mathrm{cm}^{2} /$ day). Its mean fluoride release was significantly higher $(\mathrm{p}<0.0001)$ than those

- for the other sample groups on day 546. Python ${ }^{\mathrm{TM}}\left(8.09 \pm 0.21 \mu \mathrm{g} \mathrm{F}^{-} / \mathrm{cm}^{2} /\right.$ day $)$ and Assure $^{\mathrm{TM}}\left(7.68 \pm 0.65 \mu \mathrm{g} \mathrm{\textrm {F } ^ { - }} / \mathrm{cm}^{2} /\right.$ day) showed no significant difference in their fluoride release levels $(\mathrm{p}>0.05)$. Transbond ${ }^{\top M} \mathrm{XT}$ had no detectable fluoride release and was significantly lower than all other groups $(\mathrm{p}<0.0001)$. Descriptive statistics of mean fluoride release rates and standard errors for day 546 are found in Table 6 and Figure 32 .

Table 6: Day 546 fluoride release rate descriptive statistics

\begin{tabular}{|c|c|c|c|c|}
\hline Day & Adhesive & $\mathrm{n}$ & $\begin{array}{c}\text { Mean Fluoride Release } \\
\left(\mu \mathrm{g} \mathrm{F}^{-} / \mathrm{cm}^{2} / \mathrm{day}\right)\end{array}$ & $\begin{array}{c}\text { SE } \\
\left(\mu \mathrm{g} \mathrm{F}^{-} / \mathrm{cm}^{2} / \mathrm{day}^{2}\right.\end{array}$ \\
\hline 546 & Assure $^{\top \mathrm{M}}$ & 5 & 7.68 & 0.65 \\
\hline 546 & Fuji Ortho $^{\mathrm{TM}} \mathrm{LC}$ & 5 & 11.04 & 0.27 \\
\hline 546 & Python $^{\top \mathrm{M}}$ & 5 & 8.09 & 0.21 \\
\hline 546 & Transbond $^{\top \mathrm{M}} \mathrm{XT}$ & 5 & Not Detectable (ND) & ND \\
\hline
\end{tabular}

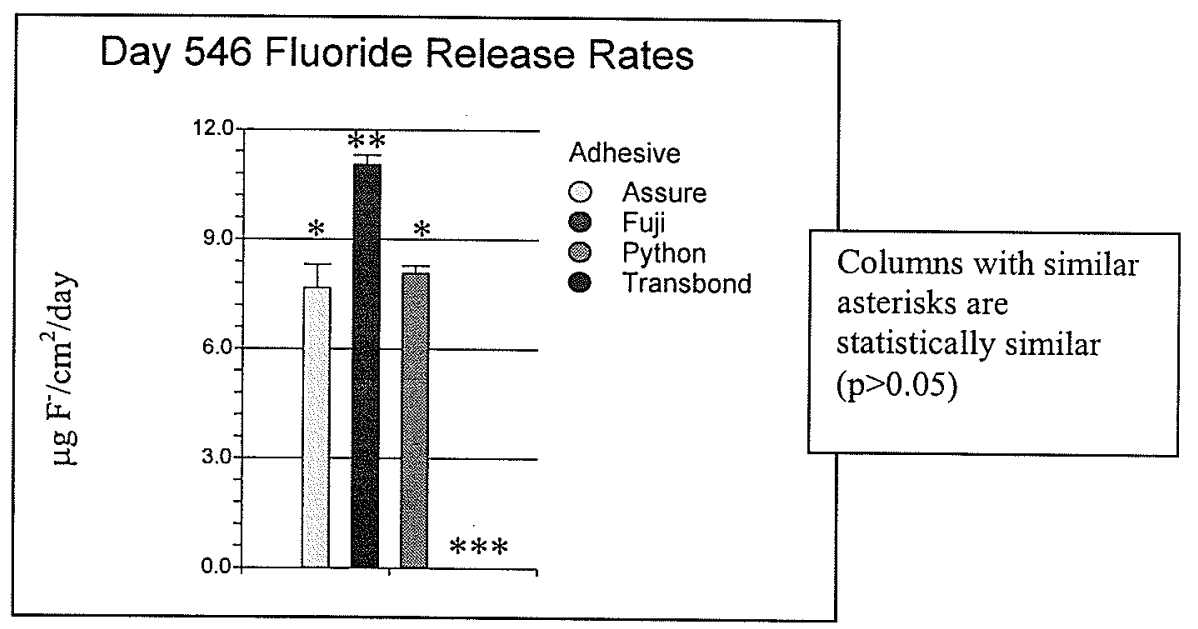

Figure 32: Day 546 fluoride release rates. Error bars indicate standard error. 


\subsubsection{Day 637 Fluoride Release Rates}

The highest mean fluoride release value was from the Fuji Ortho ${ }^{T M} \mathrm{LC}$ samples $(10.45 \pm$ $0.040 \mu \mathrm{g} \mathrm{F}^{-} / \mathrm{cm}^{2} /$ day). This was significantly higher $(\mathrm{p}<0.0001)$ than all other groups on day 637. Python ${ }^{\top M}$ released $5.79 \pm 0.43 \mu \mathrm{g} \mathrm{F} / \mathrm{cm}^{2} /$ day, which was slightly higher, but statistically similar to the $4.62 \pm 0.79 \mu \mathrm{g} \mathrm{F} / \mathrm{cm}^{2} /$ day released by Assure ${ }^{T M}(\mathrm{p}>0.05)$. Transbond ${ }^{\mathrm{TM}} \mathrm{XT}$ did not release detectable levels of fluoride, and was significantly lower than all other groups on day $637(\mathrm{p}<0.0001)$. Descriptive statistics of mean fluoride release rates and standard errors for day 637 are found in Table 7 and Figure 33.

Table 7: Day 637 fluoride release rate descriptive statistics

\begin{tabular}{|c|c|c|c|c|}
\hline Day & Adhesive & $\mathrm{n}$ & $\begin{array}{c}\text { Mean Fluoride Release } \\
\left(\mu \mathrm{g} \mathrm{F}^{-} / \mathrm{cm}^{2} / \text { day }\right)\end{array}$ & $\begin{array}{c}\text { SE } \\
\left(\mu \mathrm{g} \mathrm{F}^{-} / \mathrm{cm}^{2} / \text { day }\right)\end{array}$ \\
\hline 637 & Assure & 4.62 & 0.79 \\
\hline 637 & Fuji Ortho ${ }^{\mathrm{TM}}$ LC & 5 & 10.45 & 0.040 \\
\hline 637 & Python $^{\mathrm{TM}}$ & 5 & 5.79 & 0.43 \\
\hline 637 & Transbond $^{\mathrm{TM}} \mathrm{XT}$ & 5 & ND & ND \\
\hline
\end{tabular}

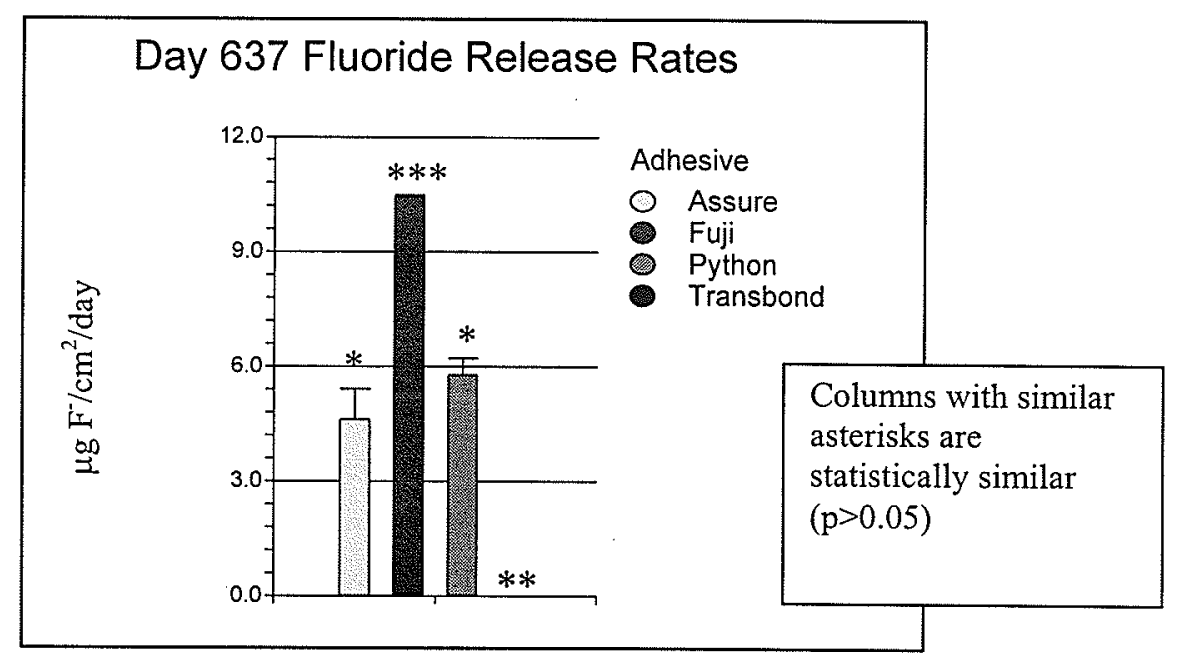

Figure 33: Day 637 fluoride release rates. Error bars indicate standard error. 


\subsubsection{Day 730 Fluoride Release Rates}

On day 730 , the fluoride release rate from Fuji Ortho ${ }^{T M} \mathrm{LC}\left(10.18 \pm 0.071 \mu \mathrm{g} \mathrm{F}^{-} / \mathrm{cm}^{2} /\right.$ day $)$ was significantly higher than the Python ${ }^{\mathrm{TM}}$ fluoride release rate $\left(4.47 \pm 0.20 \mu \mathrm{g} \mathrm{F^{- }}\right.$ $/ \mathrm{cm}^{2} /$ day $)(\mathrm{p}<0.0001)$. Release from Python $^{\top \mathrm{M}}$ was significantly higher than from $\operatorname{Assure}^{T M}\left(1.04 \pm 0.14 \mu \mathrm{g} \mathrm{F} / \mathrm{cm}^{2} /\right.$ day) and Transbond ${ }^{\top M} \mathrm{XT}$ (non-detectable) $(\mathrm{p}<0.0001)$ which were statistically similar $(\mathrm{p}>0.05)$. Descriptive statistics of mean fluoride release rates and standard errors for day 730 are found in Table 8 and Figure 34.

Table 8: Day 730 fluoride release rate descriptive statistics

\begin{tabular}{|c|c|c|c|c|}
\hline Day & Adhesive & $\mathrm{n}$ & $\begin{array}{c}\text { Mean Fluoride Release } \\
\left(\mu \mathrm{g} \mathrm{F} / \mathrm{cm}^{2} / \text { day }\right)\end{array}$ & $\begin{array}{c}\text { SE } \\
\left(\mu g \mathrm{~F}^{-} / \mathrm{cm}^{2} / \text { day }\right)\end{array}$ \\
\hline 730 & Assure $^{T M}$ & 5 & 1.04 & 0.14 \\
\hline 730 & Fuji Ortho ${ }^{\mathrm{TM}} \mathrm{LC}$ & 5 & 10.18 & 0.071 \\
\hline 730 & Python ${ }^{\mathrm{TM}}$ & 5 & 4.47 & 0.20 \\
\hline 730 & Transbond $^{T M} \mathrm{XT}$ & 5 & ND & ND \\
\hline
\end{tabular}

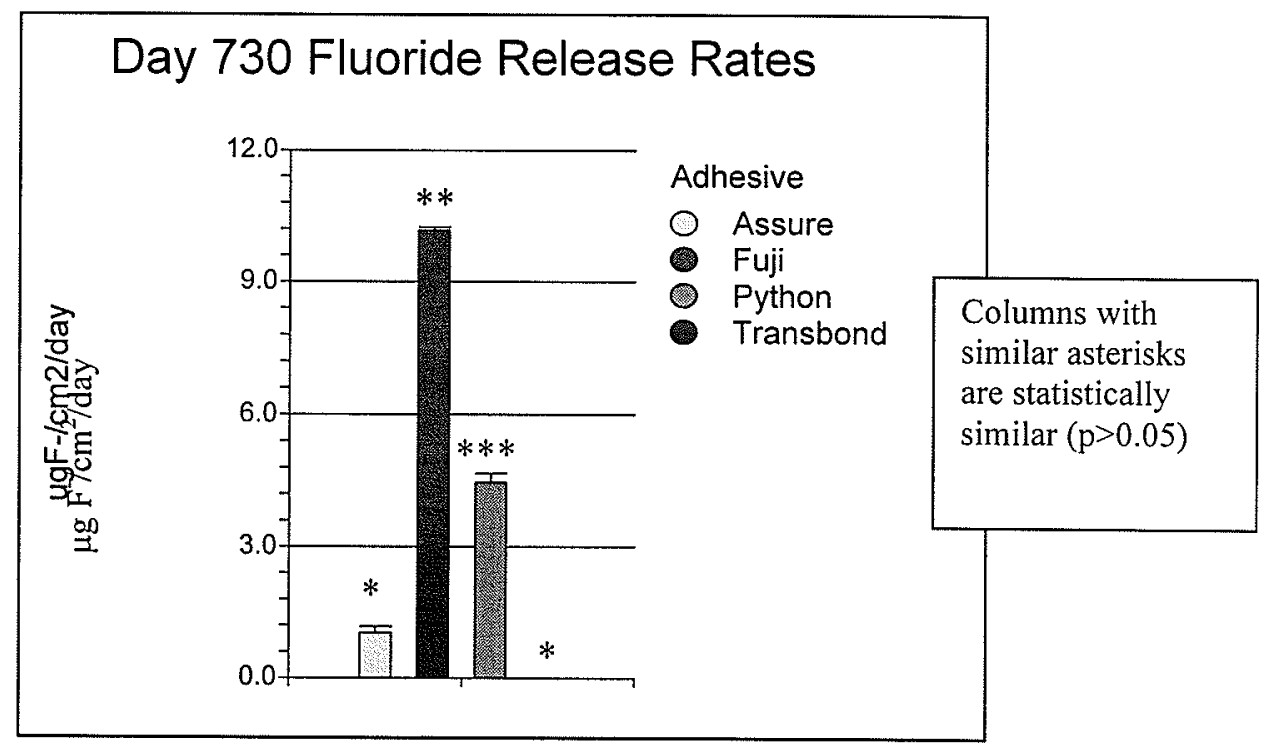

Figure 34: Day 730 fluoride release rates. Error bars indicate standard error. 


\subsubsection{Day 821 Fluoride Release Rates}

On day 821, the highest mean fluoride release rate was from Fuji Ortho ${ }^{\mathrm{TM}} \mathrm{LC}(10.15 \pm$ $0.052 \mu \mathrm{g} \mathrm{F} / \mathrm{cm}^{2} /$ day), which was significantly higher than the other groups $(\mathrm{p}<0.0001)$. Python $^{\mathrm{TM}}\left(6.19 \pm 0.36 \mu \mathrm{g} \mathrm{F} / \mathrm{cm}^{2} /\right.$ day) had a mean fluoride release rate significantly higher $(\mathrm{p}<0.0001)$ than Assure ${ }^{T M}\left(1.21 \pm 0.23 \mu \mathrm{g} \mathrm{F}^{\top} / \mathrm{cm}^{2} /\right.$ day) and Transbond ${ }^{T M} \mathrm{XT}$ (nondetectable), which were statistically similar $(p>0.05)$. Descriptive statistics of mean fluoride release rates and standard errors for day 821 are found in Table 9 and Figure 35.

Table 9: Day 821 fluoride release rate descriptive statistics

\begin{tabular}{|c|c|c|c|c|}
\hline Day & Adhesive & $n$ & $\begin{array}{c}\text { Mean Fluoride Release } \\
\left(\mu \mathrm{g} \mathrm{F} / \mathrm{cm}^{2} / \text { day }\right)\end{array}$ & $\begin{array}{c}\text { SE } \\
\left(\mu \mathrm{g} \mathrm{F}^{-} / \mathrm{cm}^{2} / \text { day }\right)\end{array}$ \\
\hline 821 & Assure $^{T M}$ & 5 & 1.21 & 0.23 \\
\hline 821 & Fuji Ortho ${ }^{T M}$ LC & 5 & 10.15 & 0.052 \\
\hline 821 & Python $^{T M}$ & 5 & 6.19 & 0.36 \\
\hline 821 & Transbond $^{\mathrm{TM}} \mathrm{XT}$ & 5 & ND & ND \\
\hline
\end{tabular}

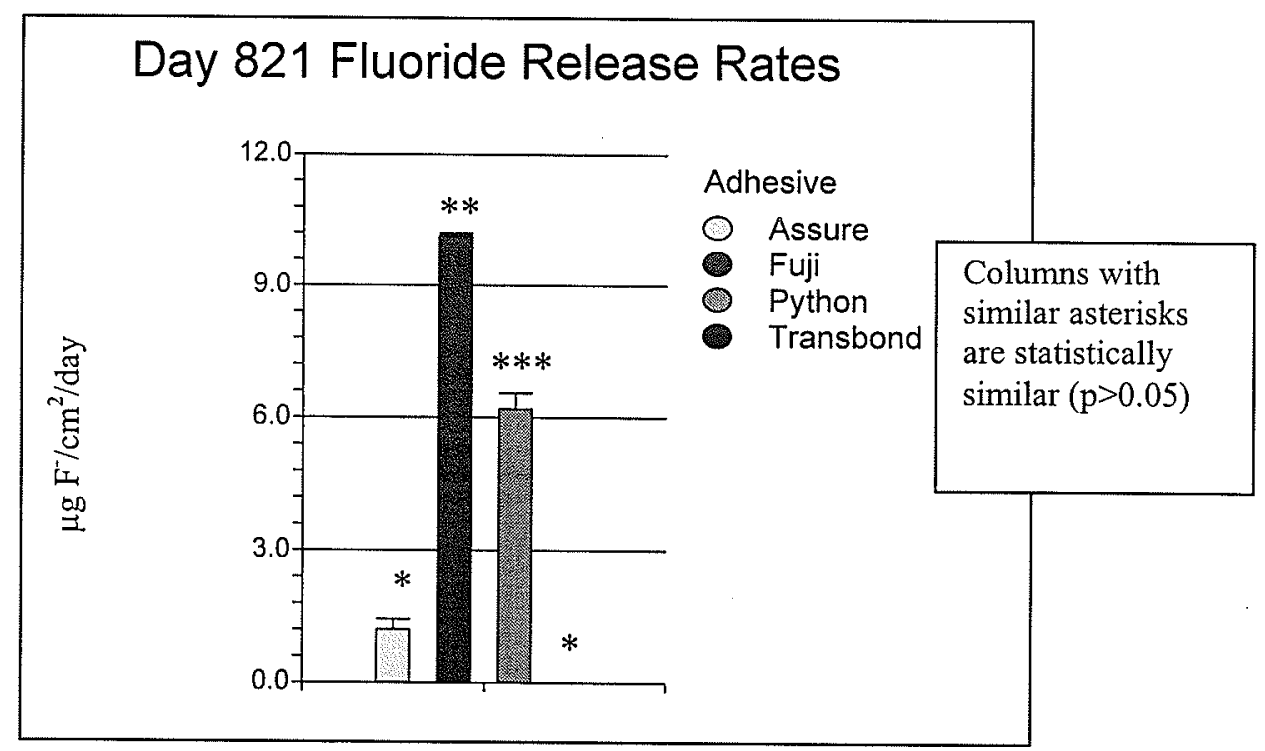

Figure 35: Day 821 fluoride release rates. Error bars indicate standard error. 


\subsubsection{Day 913 Fluoride Release Rates}

All groups had significantly different fluoride release rates on day 913 ( $p<0.0001)$. Fuji Ortho $^{\mathrm{TM}} \mathrm{LC}$ had the highest fluoride release rate $\left(10.33 \pm 0.031 \mu \mathrm{g} \mathrm{F} / \mathrm{cm}^{2} / \mathrm{day}\right)$, followed by Python ${ }^{T M}\left(6.77 \pm 0.21 \mu \mathrm{g} \mathrm{F} / \mathrm{cm}^{2} /\right.$ day), Assure ${ }^{T M}\left(4.83 \pm 0.20 \mu \mathrm{g} \mathrm{F}^{-} / \mathrm{cm}^{2} /\right.$ day $)$ and Transbond $^{\mathrm{TM}} \mathrm{XT}$ (non-detectable fluoride release rate). Descriptive statistics of mean fluoride release rates and standard errors for day 913 are found in Table 10 and Figure 36.

Table 10: Day 913 fluoride release rate descriptive statistics

\begin{tabular}{|c|c|c|c|c|}
\hline Day & Adhesive & $\mathrm{n}$ & $\begin{array}{c}\text { Mean Fluoride Release } \\
\left(\mu \mathrm{g} \mathrm{F}^{-} / \mathrm{cm}^{2} / \text { day }\right)\end{array}$ & $\begin{array}{c}\text { SE } \\
\left(\mu \mathrm{g} \mathrm{F}^{-} / \mathrm{cm}^{2} / \text { day }\right)\end{array}$ \\
\hline 913 & Assure & & \\
\hline 913 & Fuji Ortho $^{\mathrm{TM}} \mathrm{LC}$ & 5 & 4.83 & 0.20 \\
\hline 913 & Python $^{\top \mathrm{M}}$ & 5 & 10.33 & 0.031 \\
\hline 913 & Transbond $^{\mathrm{TM}} \mathrm{XT}$ & 5 & 6.77 & 0.21 \\
\hline
\end{tabular}

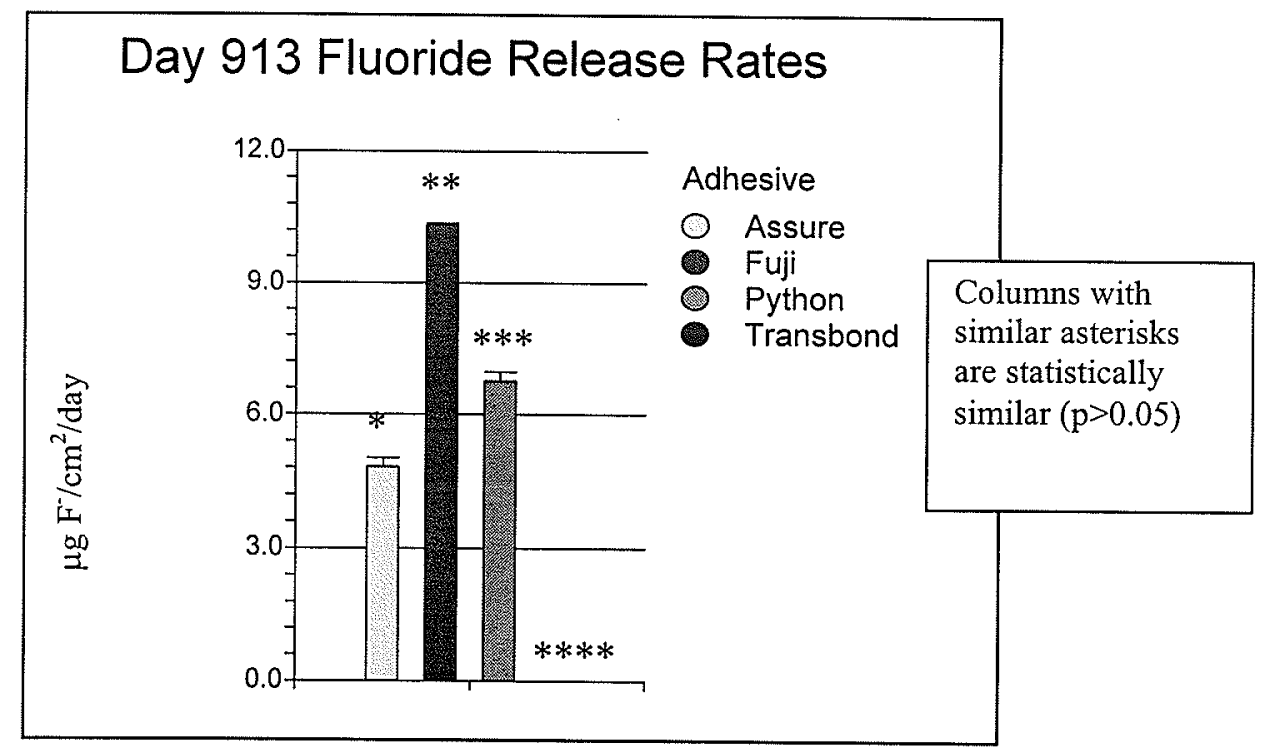

Figure 36: Day 913 fluoride release rates. Error bars indicate standard error. 


\subsection{Fluoride Release from Samples Re-exposed to Fluoride}

\subsubsection{Overall Pattern}

All materials showed a decrease in fluoride release following the first day of postfluoride exposure. On all days except day 546, Fuji Ortho ${ }^{\mathrm{TM}}$ LC released the most fluoride, followed in decreasing order by Python ${ }^{T M}>$ Assure $^{T M}>$ Transbond $^{T M} X T$. On day 546, Fuji Ortho ${ }^{T M}$ LC released the most fluoride, followed by Assure ${ }^{T M}>$ Python $^{T M}>$ Transbond ${ }^{\mathrm{TM}} \mathrm{XT}$. The overall pattern of fluoride release for all materials can be seen in Table 11. The fluoride release measurements for individual samples are found in Appendix 2. 
Table 11: Fluoride re-release rates following fluoride exposure (mean \pm S.E., $n=5$ )

\begin{tabular}{|c|c|c|c|c|c|c|c|c|}
\hline \multirow{2}{*}{ Material } & \multicolumn{8}{|c|}{ Fluoride Release $\left(\mu \mathrm{g} / \mathrm{cm}^{2} /\right.$ day $)$} \\
\hline & $\begin{array}{l}\text { Day } 546^{*} \\
(1 \text { day })^{* *}\end{array}$ & $\begin{array}{l}\text { Day } 548 \\
\text { (3 days) }\end{array}$ & $\begin{array}{l}\text { Day } 552 \\
\text { (7 days) } \\
\end{array}$ & $\begin{array}{c}\text { Day } 575 \\
\text { (1 month) }\end{array}$ & $\begin{array}{c}\text { Day } 637 \\
\text { (3 months) }\end{array}$ & $\begin{array}{c}\text { Day } 730 \\
(6 \text { months }) \\
\end{array}$ & $\begin{array}{c}\text { Day } 821 \\
\text { (9 months) }\end{array}$ & $\begin{array}{c}\text { Day } 913 \\
\text { (12 months) }\end{array}$ \\
\hline $\begin{array}{l}\text { Fuji Ortho }{ }^{\text {TM }} \\
\text { LC }\end{array}$ & $\begin{array}{c}92.34 \pm 1.48 \\
\text { a A } \\
\end{array}$ & $\begin{array}{c}12.57 \pm 2.18 \\
\mathrm{a} \mathrm{B}\end{array}$ & $\begin{array}{c}9.51 \pm 0.099 \\
\text { a B } \\
\end{array}$ & $\begin{array}{c}10.06 \pm 0.072 \\
\mathrm{a} \mathrm{B}\end{array}$ & $\begin{array}{c}10.14 \pm 0.064 \\
\text { a B }\end{array}$ & $\begin{array}{c}10.06 \pm 0.043 \\
\text { a B }\end{array}$ & $\begin{array}{c}10.20 \pm 0.043 \\
\text { a B }\end{array}$ & $\begin{array}{c}10.33 \pm 0.020 \\
\text { a B }\end{array}$ \\
\hline Python $^{\mathrm{TM}}$ & $\begin{array}{c}36.60 \pm 5.19 \\
\text { b A }\end{array}$ & $\begin{array}{c}5.85 \pm 0.36 \\
\text { a b B } \\
\end{array}$ & $\begin{array}{c}1.87 \pm 0.33 \\
\text { b B } \\
\end{array}$ & $\begin{array}{c}3.68 \pm 0.38 \\
\text { a b B } \\
\end{array}$ & $\begin{array}{c}5.79 \pm 0.22 \\
\text { a b B } \\
\end{array}$ & $\begin{array}{c}5.40 \pm 0.18 \\
\text { a b B } \\
\end{array}$ & $\begin{array}{c}6.68 \pm 0.39 \\
\text { a b B } \\
\end{array}$ & $\begin{array}{c}7.23 \pm 0.24 \\
\text { a b B } \\
\end{array}$ \\
\hline Assure $^{\mathrm{TM}}$ & $\begin{array}{c}63.40 \pm 4.68 \\
\mathrm{c} \mathrm{A} \\
\end{array}$ & $\begin{array}{c}2.90 \pm 0.88 \\
\text { b B } \\
\end{array}$ & $\begin{array}{c}0.66 \pm 0.085 \\
\text { b B } \\
\end{array}$ & $\begin{array}{c}0.86 \pm 0.16 \\
\text { b B } \\
\end{array}$ & $\begin{array}{c}3.27 \pm 0.64 \\
\text { a b B } \\
\end{array}$ & $\begin{array}{c}1.28 \pm 0.24 \\
\text { b B }\end{array}$ & $\begin{array}{c}1.20 \pm 0.19 \\
\text { b B } \\
\end{array}$ & $\begin{array}{c}4.40 \pm 0.46 \\
\text { a b B }\end{array}$ \\
\hline $\begin{array}{c}\text { Transbond }^{\text {TM }} \\
\text { XT } \\
\end{array}$ & $\begin{array}{c}5.94 \pm 1.24 \\
\mathrm{~d} \mathrm{~A} \\
\end{array}$ & $\begin{array}{c}0.043 \pm 0.043 \\
\text { b A }\end{array}$ & $\begin{array}{l}\text { ND } \\
\text { b A } \\
\end{array}$ & $\begin{array}{c}0.021 \pm 0.021 \\
\text { b A }\end{array}$ & $\begin{array}{c}0.026 \pm 0.026 \\
\text { b A }\end{array}$ & $\begin{array}{l}\text { ND } \\
\text { b A } \\
\end{array}$ & $\begin{array}{l}\text { ND } \\
\text { b A }\end{array}$ & $\begin{array}{l}\text { ND } \\
\text { b A }\end{array}$ \\
\hline
\end{tabular}

The same small letters in a column indicate no statistically significant difference in means.

The same large letters in a row indicate no statistically significant difference in means.

* - Indicates number of days since initial fabrication of the samples.

** - Indicates number of days following exposure to fluoride. 


\subsubsection{Fuji Ortho ${ }^{\mathrm{TM}}$ LC Fluoride Re-Release Rates}

Fluoride release was highest on day 546 (92.34 $\pm 1.48 \mu \mathrm{g} \mathrm{F} / \mathrm{cm}^{2} /$ day), immediately following fluoride exposure. This was significantly higher than at all other time points $(\mathrm{p}<0.0001)$ and decreased to $12.57 \pm 2.18 \mu \mathrm{g} \mathrm{F} / \mathrm{cm}^{2} /$ day on day 548 . The fluoride release was not significantly different on days $548,552,575,637,730,821$ and 913 $(\mathrm{p}>0.05)$. Descriptive statistics of mean fluoride release rates and standard errors for Fuji Ortho $^{\mathrm{TM}} \mathrm{LC}$ are found in Table 12 and Figure 37.

Table 12: Fuji Ortho ${ }^{\mathrm{TM}}$ LC fluoride re-release rate descriptive statistics

\begin{tabular}{|c|c|c|c|c|}
\hline Day & Adhesive & $\mathrm{n}$ & $\begin{array}{l}\text { Mean Fluoride Release } \\
\left(\mu \mathrm{g} \mathrm{F}^{-} / \mathrm{cm}^{2} / \text { day }\right)\end{array}$ & 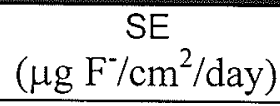 \\
\hline 546 & Fuji Ortho ${ }^{\text {TM }}$ LC & 5 & 92.34 & 1.48 \\
\hline 548 & Fuji Ortho'M LC & 5 & 12.57 & 2.18 \\
\hline 552 & Fuji Ortho ${ }^{\top M}$ LC & 5 & 9.51 & 0.099 \\
\hline 575 & Fuji Ortho ${ }^{T M}$ LC & 5 & 10.06 & 0.072 \\
\hline 637 & Fuji Ortho ${ }^{T M}$ LC & 5 & 10.14 & 0.064 \\
\hline 730 & Fuji Ortho ${ }^{\top \mathrm{M}} \mathrm{LC}$ & 5 & 10.06 & 0.043 \\
\hline 821 & Fuji Ortho ${ }^{\mathrm{TM}}$ LC & 5 & 10.20 & 0.043 \\
\hline 913 & Fuji Ortho' ${ }^{T M}$ LC & 5 & 10.33 & 0.020 \\
\hline
\end{tabular}

\section{Fuji Ortho LC Fluoride Release Rates}

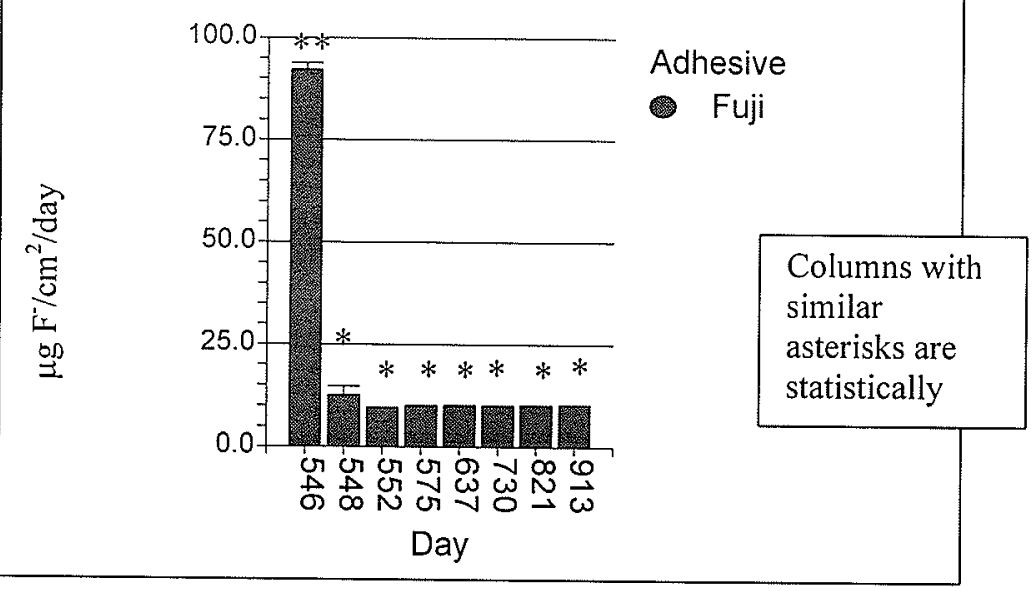

Figure 37: Fuji Ortho ${ }^{T M}$ LC fluoride re-release rates. Error bars indicate standard error. 


\subsubsection{Python ${ }^{\mathrm{TM}}$ Fluoride Re-Release Rates}

Python $^{\text {TM }}$ released $36.60 \pm 5.19 \mu \mathrm{g} \mathrm{F}^{-} / \mathrm{cm}^{2} /$ day, which was significantly more than at any other time point $(\mathrm{p}<0.0001)$. On days $548,552,575,637,730,821$ and 913 , Python ${ }^{\mathrm{TM}}$ had statistically similar fluoride release rates $(p>0.05)$. Descriptive statistics of mean fluoride release rates and standard errors for Python ${ }^{\mathrm{TM}}$ are found in Table 13 and Figure 38.

Table 13: Python ${ }^{\mathrm{TM}}$ fluoride re-release rate descriptive statistics

\begin{tabular}{|c|c|c|c|c|}
\hline Day & Adhesive & $\mathrm{n}$ & $\begin{array}{c}\text { Mean Fluoride Release } \\
\left(\mu \mathrm{g} \mathrm{F} / \mathrm{cm}^{2} / \text { day }\right)\end{array}$ & 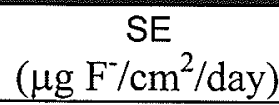 \\
\hline 546 & Python $^{T M}$ & 5 & 36.60 & 5.19 \\
\hline 548 & Python $^{T M}$ & 5 & 5.85 & 0.36 \\
\hline 552 & Python $^{T M}$ & 5 & 1.87 & 0.33 \\
\hline 575 & Python $^{T M}$ & 5 & 3.68 & 0.38 \\
\hline 637 & Python $^{T M}$ & 5 & 5.79 & 0.22 \\
\hline 730 & Python $^{T M}$ & 5 & 5.40 & 0.18 \\
\hline 821 & Python $^{\mathrm{TM}}$ & 5 & 6.68 & 0.39 \\
\hline 913 & Python ${ }^{\top M}$ & 5 & 7.23 & 0.24 \\
\hline
\end{tabular}

\section{Python Long-Term Fluoride Release}

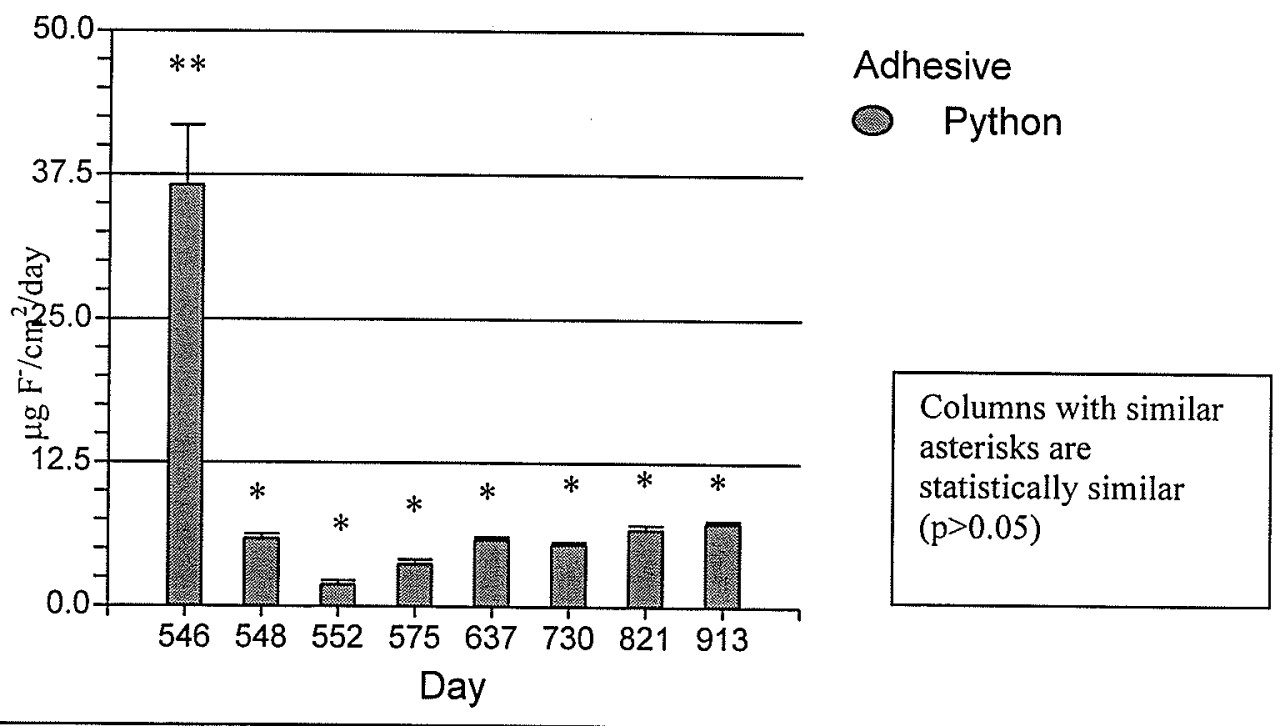

Figure 38: Python ${ }^{\mathrm{TM}}$ fluoride re-release rates. Error bars indicate standard error. 


\subsubsection{Assure ${ }^{T M}$ Fluoride Re-Release Rates}

Assure $^{T M}$ had a significantly higher fluoride release rate on day $546\left(63.40 \pm 4.68 \mu \mathrm{g} \mathrm{F}^{-}\right.$ $/ \mathrm{cm}^{2} /$ day $)$ than at any other time point $(\mathrm{p}<0.0001)$. The fluoride release rates on days $548,552,575,637,730,821$ and 913 were statistically similar ( $p>0.05)$. Descriptive statistics of mean fluoride release rates and standard errors for Assure ${ }^{T M}$ are found in Table 14 and Figure 39.

Table 14: Assure $^{\mathrm{TM}}$ fluoride re-release rate descriptive statistics

\begin{tabular}{|c|l|c|c|c|}
\hline Day & Adhesive & $n$ & $\begin{array}{c}\text { Mean Fluoride Release } \\
\left(\mu \mathrm{g} \mathrm{F}^{-} / \mathrm{cm}^{2} / \text { day }\right)\end{array}$ & $\begin{array}{c}\text { SE } \\
\left(\mu \mathrm{g} \mathrm{F}^{-} / \mathrm{cm}^{2} / \text { day }\right)\end{array}$ \\
\hline 546 & Assure $^{\mathrm{TM}}$ & 5 & 63.40 & 4.68 \\
\hline 548 & Assure $^{\mathrm{TM}}$ & 5 & 2.90 & 0.88 \\
\hline 552 & Assure $^{\mathrm{TM}}$ & 5 & 0.66 & 0.085 \\
\hline 575 & Assure $^{\mathrm{TM}}$ & 5 & 0.86 & 0.16 \\
\hline 637 & Assure $^{\mathrm{TM}}$ & 5 & 3.27 & 0.64 \\
\hline 730 & Assure $^{\mathrm{TM}}$ & 5 & 1.28 & 0.24 \\
\hline 821 & Assure $^{\mathrm{TM}}$ & 5 & 1.20 & 0.19 \\
\hline 913 & Assure $^{\mathrm{TM}}$ & 5 & 4.40 & 0.46 \\
\hline
\end{tabular}

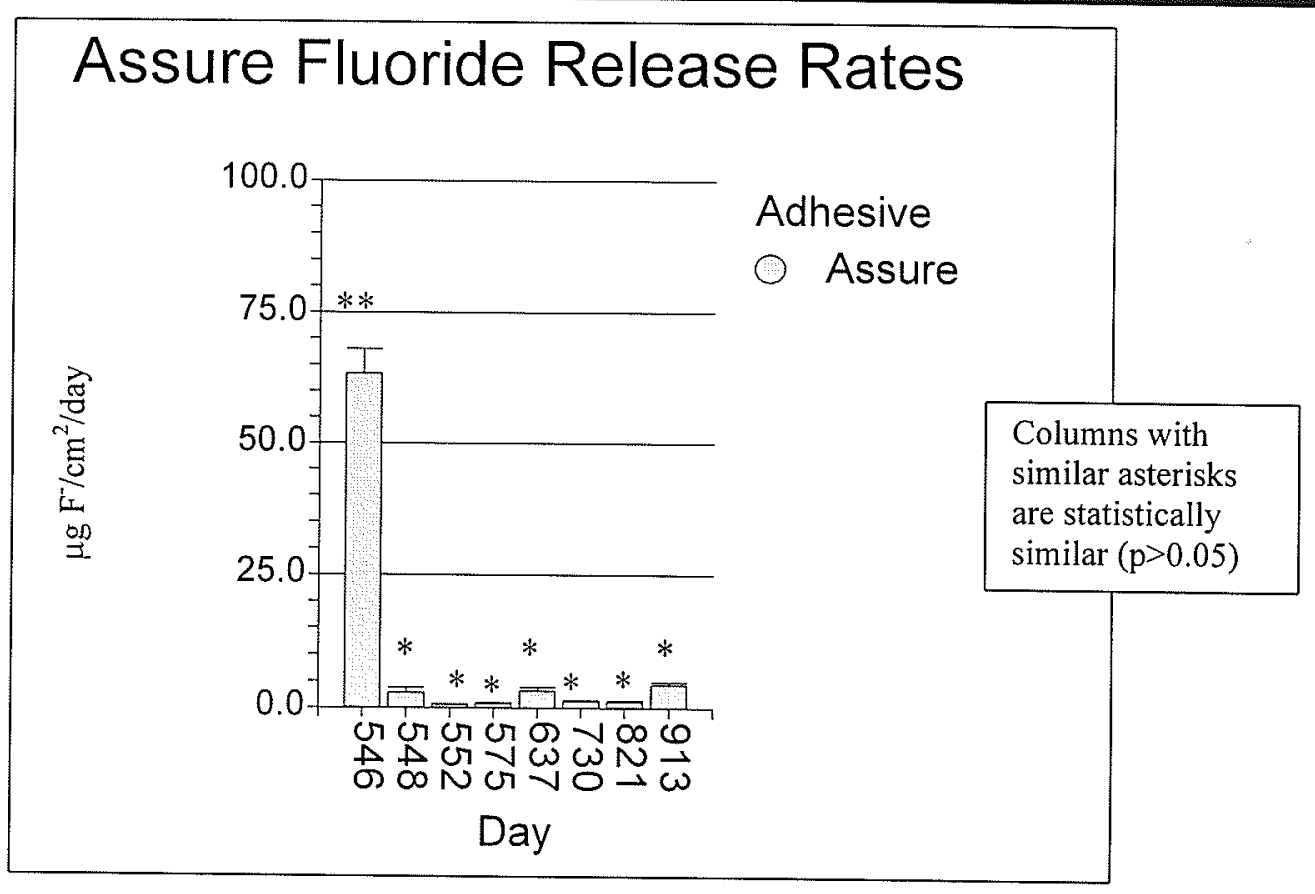

Figure 39: Assure ${ }^{\mathrm{TM}}$ fluoride re-release rates. Error bars indicate standard error. 


\subsubsection{Transbond ${ }^{\top M}$ XT Fluoride Re-Release Rates}

The highest fluoride release rate for Transbond ${ }^{\top M}$ XT was on day $546\left(5.94 \pm 1.24 \mu \mathrm{g} \mathrm{F}^{-}\right.$ $/ \mathrm{cm}^{2} /$ day $)$. Detectable fluoride release rates were also seen on day $548(0.043 \pm 0.043 \mu \mathrm{g}$ $\mathrm{F}^{-} / \mathrm{cm}^{2} /$ day $)$, day $575\left(0.021 \pm 0.021 \mu \mathrm{g} \mathrm{F} / \mathrm{cm}^{2} /\right.$ day $)$ and day $637(0.026 \pm 0.026 \mu \mathrm{g} \mathrm{F}$ $/ \mathrm{cm}^{2} /$ day). On the remaining days fluoride release was non-detectable. However, at all time points the fluoride release rates were statistically similar $(\mathrm{p}>0.05)$. Descriptive statistics of mean fluoride release rates and standard errors for Transbond ${ }^{\top \mathrm{M}} \mathrm{XT}$ are found in Table 15 and Figure 40.

Table 15: Transbond ${ }^{T M} \mathrm{XT}$ fluoride re-release rate descriptive statistics

\begin{tabular}{|c|c|c|c|c|}
\hline Day & Adhesive & $\mathrm{n}$ & $\begin{array}{c}\text { Mean Fluoride Release } \\
\left(\mu \mathrm{g} \mathrm{F} / \mathrm{cm}^{2} / \text { day }\right)\end{array}$ & $\begin{array}{c}\mathrm{SE} \\
\left(\mu \mathrm{g} \mathrm{F}^{-} / \mathrm{cm}^{2} / \text { day }\right)\end{array}$ \\
\hline 546 & Transbond $^{\top M} X T$ & 5 & 5.94 & 1.24 \\
\hline 548 & Transbond ${ }^{T M} X T$ & 5 & 0.043 & 0.043 \\
\hline 552 & Transbond $^{\mathrm{TM}} \mathrm{XT}$ & 5 & ND & ND \\
\hline 575 & Transbond $^{\mathrm{TM}} \mathrm{XT}$ & 5 & 0.021 & 0.021 \\
\hline 637 & Transbond $^{T M} \mathrm{XT}$ & 5 & 0.026 & 0.026 \\
\hline 730 & Transbond $^{T M} X T$ & 5 & ND & ND \\
\hline 821 & Transbond $^{\mathrm{TM}} \mathrm{XT}$ & 5 & ND & ND \\
\hline 913 & Transbond ${ }^{\mathrm{TM}} \mathrm{XT}$ & 5 & ND & ND \\
\hline
\end{tabular}




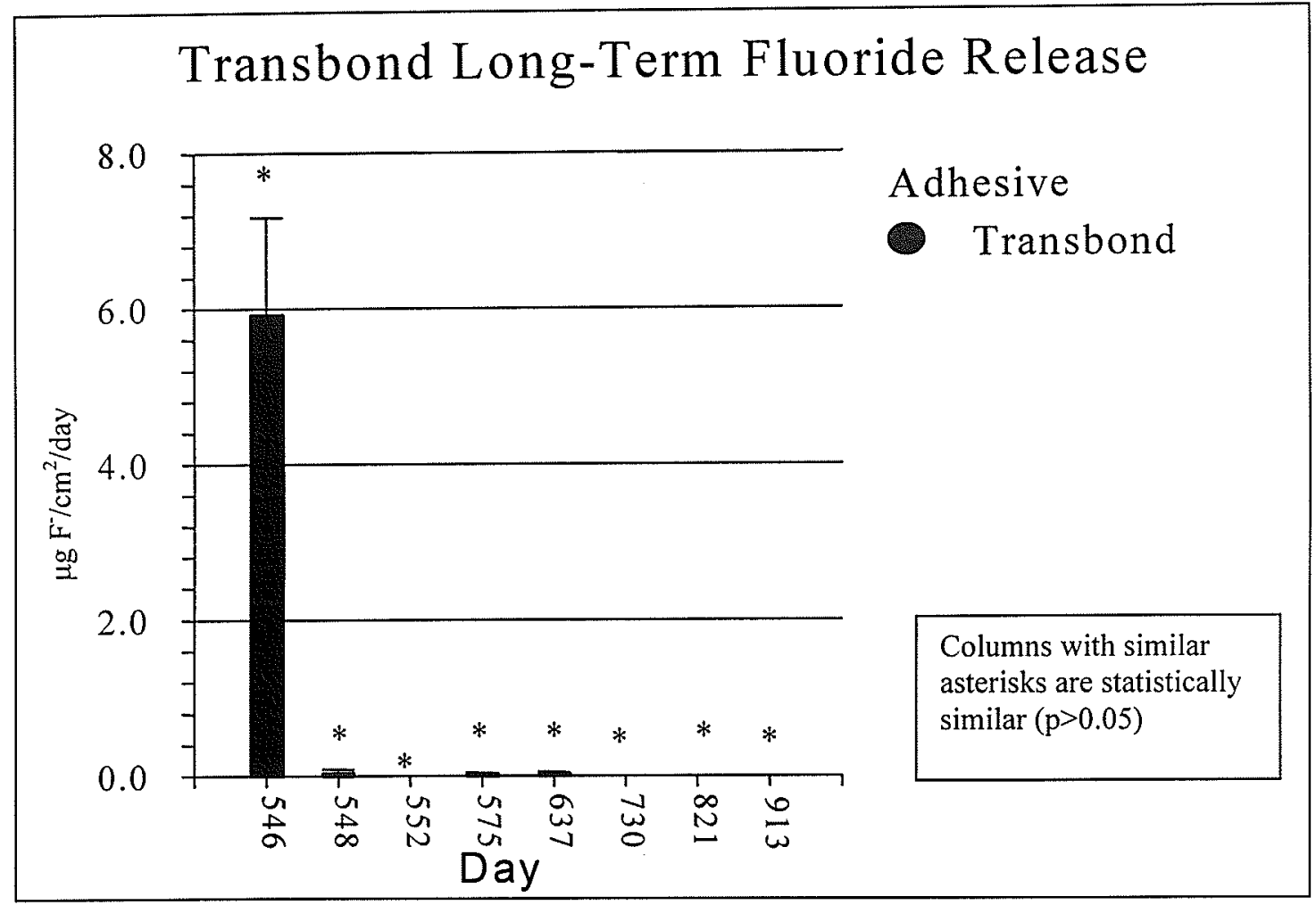

Figure 40: Transbond ${ }^{\mathrm{TM}}$ XT fluoride re-release rates. Error bars indicate standard error.

\subsubsection{Day 546 Fluoride Re-release Rates}

The fluoride release rates for each of the materials were significantly different on day 546 ( $<<0.0001)$. Fuji Ortho ${ }^{\mathrm{TM}} \mathrm{LC}$ had the highest fluoride release rate $\left(92.34 \pm 1.48 \mu \mathrm{g} \mathrm{F}^{-}\right.$ $/ \mathrm{cm}^{2} /$ day), followed by Assure ${ }^{\mathrm{TM}}\left(63.40 \pm 4.68 \mu \mathrm{g} \mathrm{F}^{-} / \mathrm{cm}^{2} /\right.$ day $)$, Python $^{\mathrm{TM}}(36.60 \pm 5.19 \mu \mathrm{g}$ $\mathrm{F}^{*} / \mathrm{cm}^{2} /$ day) and Transbond ${ }^{\mathrm{TM}} \mathrm{XT}\left(5.94 \pm 1.24 \mu \mathrm{g} \mathrm{F} / \mathrm{cm}^{2} /\right.$ day $)$. Descriptive statistics of mean fluoride release rates and standard errors for day 546 are found in Table 16 and Figure 41 . 
Table 16: Day 546 fluoride re-release rate descriptive statistics

\begin{tabular}{|c|c|c|c|c|}
\hline Day & Adhesive & $\mathrm{n}$ & $\begin{array}{c}\text { Mean Fluoride Release } \\
\left(\mu \mathrm{g} \mathrm{F}^{-} / \mathrm{cm}^{2} / \text { day }\right)\end{array}$ & $\begin{array}{c}\text { SE } \\
\left(\mu \mathrm{g} \mathrm{F}^{-} / \mathrm{cm}^{2} / \text { day }\right)\end{array}$ \\
\hline 546 & Fuji Ortho $^{\top \mathrm{M}} \mathrm{LC}$ & 5 & 92.34 & 1.48 \\
\hline 546 & Python $^{\top \mathrm{M}}$ & 5 & 36.60 & 5.19 \\
\hline 546 & Assure $^{\mathrm{M}}$ & 5 & 63.40 & 4.68 \\
\hline 546 & Transbond $^{\top \mathrm{M}} \mathrm{XT}$ & 5 & 5.94 & 1.24 \\
\hline
\end{tabular}

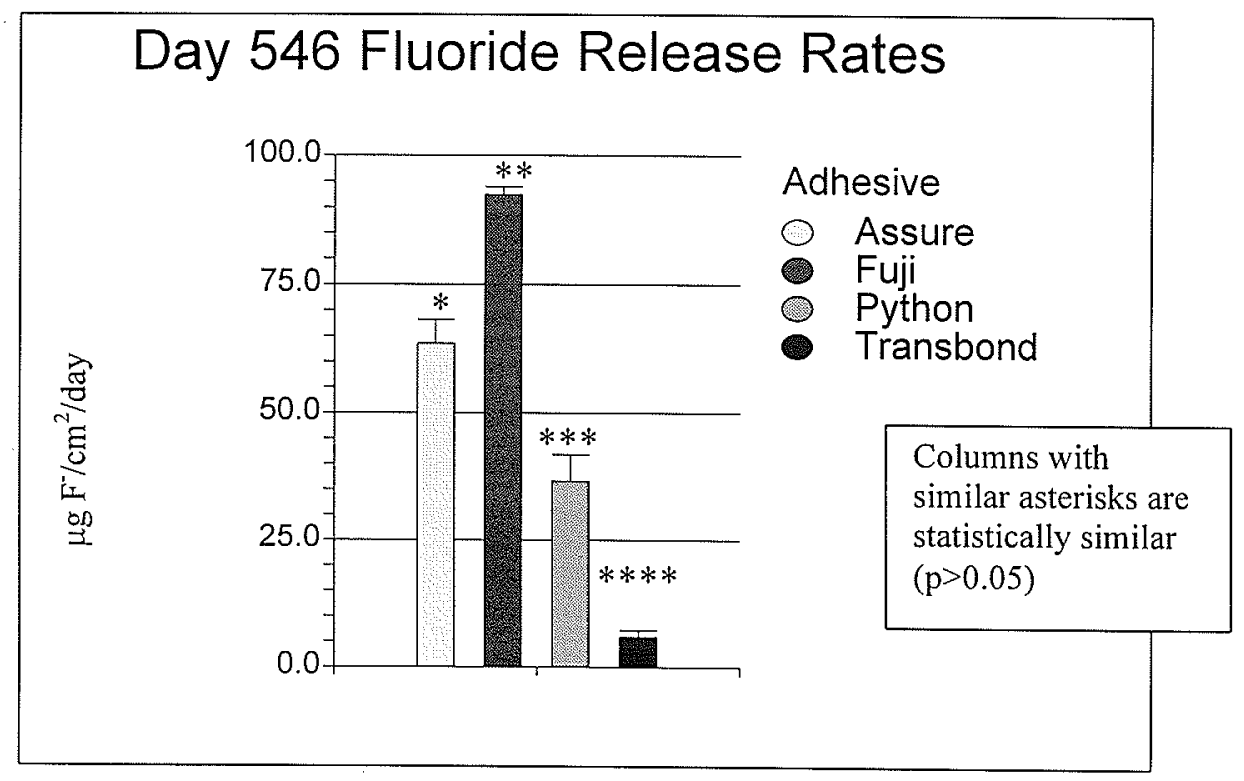

Figure 41: Day 546 fluoride re-release rates. Error bars indicate standard error.

\subsubsection{Day 548 Fluoride Re-release Rates}

Fuji Ortho ${ }^{\mathrm{TM}} \mathrm{LC}$ had the highest fluoride release rate $\left(12.57 \pm 2.18 \mu \mathrm{g} \mathrm{F} / \mathrm{cm}^{2} /\right.$ day $)$, which was statistically similar to the fluoride release rate of Python ${ }^{\mathrm{TM}}\left(5.85 \pm 0.36 \mu \mathrm{g} \mathrm{F^{- }}\right.$ $/ \mathrm{cm}^{2} /$ day) ( $\left.\mathrm{p}>0.05\right)$, but significantly higher than Assure $^{\top \mathrm{M}}\left(2.90 \pm 0.88 \mu \mathrm{g} \mathrm{F} / \mathrm{cm}^{2} /\right.$ day $)$ and Transbond ${ }^{\top M}$ XT $\left(0.043 \pm 0.043 \mu \mathrm{g} \mathrm{F} / \mathrm{cm}^{2} /\right.$ day $)(\mathrm{p}<0.0001)$. However, the fluoride release rates of Python $^{\top M}$, Assure ${ }^{\top M}$ and Transbond ${ }^{\top M}$ XT were statistically similar $(p>0.05)$. Descriptive statistics of mean fluoride release rates and standard errors for day 546 are found in Table 17 and Figure 42. 
Table 17: Day 548 fluoride re-release rate descriptive statistics

\begin{tabular}{|c|c|c|c|c|}
\hline Day & Adhesive & $\mathrm{N}$ & $\begin{array}{c}\text { Mean Fluoride Release } \\
\left(\mu \mathrm{g} \mathrm{F}^{-} / \mathrm{cm}^{2} / \text { day }\right)\end{array}$ & $\begin{array}{c}\text { SE } \\
\left(\mu \mathrm{g} \mathrm{F}^{-} / \mathrm{cm}^{2} / \text { day }\right)\end{array}$ \\
\hline 548 & Fuji Ortho $^{\text {TM } \mathrm{LC}}$ & 5 & 12.57 & 2.18 \\
\hline 548 & Python $^{\top \mathrm{M}}$ & 5 & 5.85 & 0.36 \\
\hline 548 & Assure $^{\mathrm{TM}}$ & 5 & 2.90 & 0.88 \\
\hline 548 & Transbond $^{\top \mathrm{M}} \mathrm{XT}$ & 5 & 0.043 & 0.043 \\
\hline
\end{tabular}

\section{Day 548 Fluoride Release Rates}

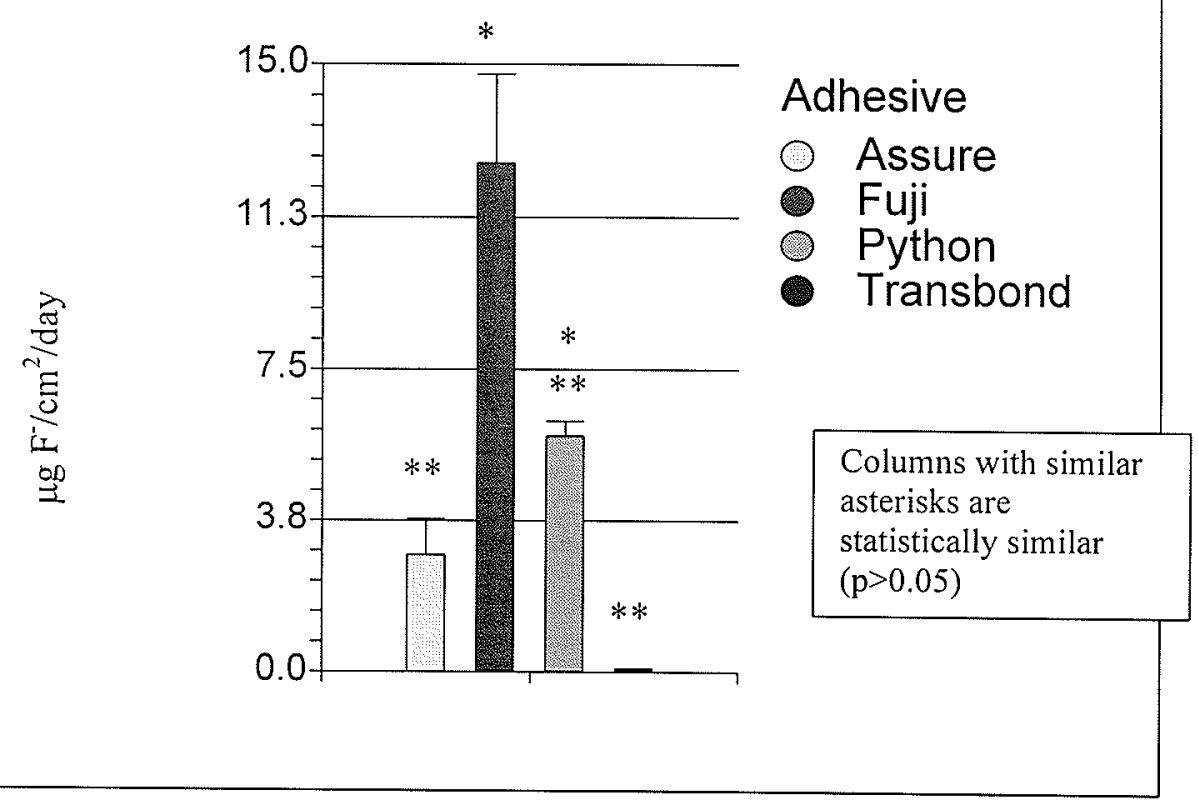

Figure 42: Day 548 fluoride re-release rates. Error bars indicate standard error.

\subsubsection{Day 552 Fluoride Re-release Rates}

Fuji Ortho ${ }^{T M}$ LC had a significantly higher fluoride release rate $\left(9.51 \pm 0.099 \mu \mathrm{g} \mathrm{F}^{-}\right.$ $/ \mathrm{cm}^{2} /$ day) than all the other groups $(\mathrm{p}<0.0001)$. Python ${ }^{\mathrm{TM}}$, Assure $^{\mathrm{TM}}$ and Fuji Ortho ${ }^{\mathrm{TM}} \mathrm{LC}$ had similar fluoride release rates on day $552(\mathrm{p}>0.05)$. Descriptive statistics of mean fluoride release rates and standard errors for day 552 are found in Table 18 and Figure 43. 
Table 18: Day 552 fluoride re-release rate descriptive statistics

\begin{tabular}{|c|c|c|c|c|}
\hline Day & Adhesive & $\mathrm{n}$ & $\begin{array}{c}\text { Mean Fluoride Release } \\
\left(\mu \mathrm{g} \mathrm{F}^{-} / \mathrm{cm}^{2} / \text { day }\right)\end{array}$ & $\begin{array}{c}\mathrm{SE} \\
\left(\mu \mathrm{g} \mathrm{F}^{-} / \mathrm{cm}^{2} / \text { day }\right)\end{array}$ \\
\hline 552 & Fuji Ortho ${ }^{\top \mathrm{M}} \mathrm{LC}$ & 5 & 9.51 & 0.099 \\
\hline 552 & Python $^{\top \mathrm{M}}$ & 5 & 1.87 & 0.33 \\
\hline 552 & Assure $^{\mathrm{TM}}$ & 5 & 0.66 & 0.085 \\
\hline 552 & Transbond $^{\mathrm{TM}} \mathrm{XT}$ & 5 & $\mathrm{ND}$ & $\mathrm{ND}$ \\
\hline
\end{tabular}

\section{Day 552 Fluoride Release Rates}

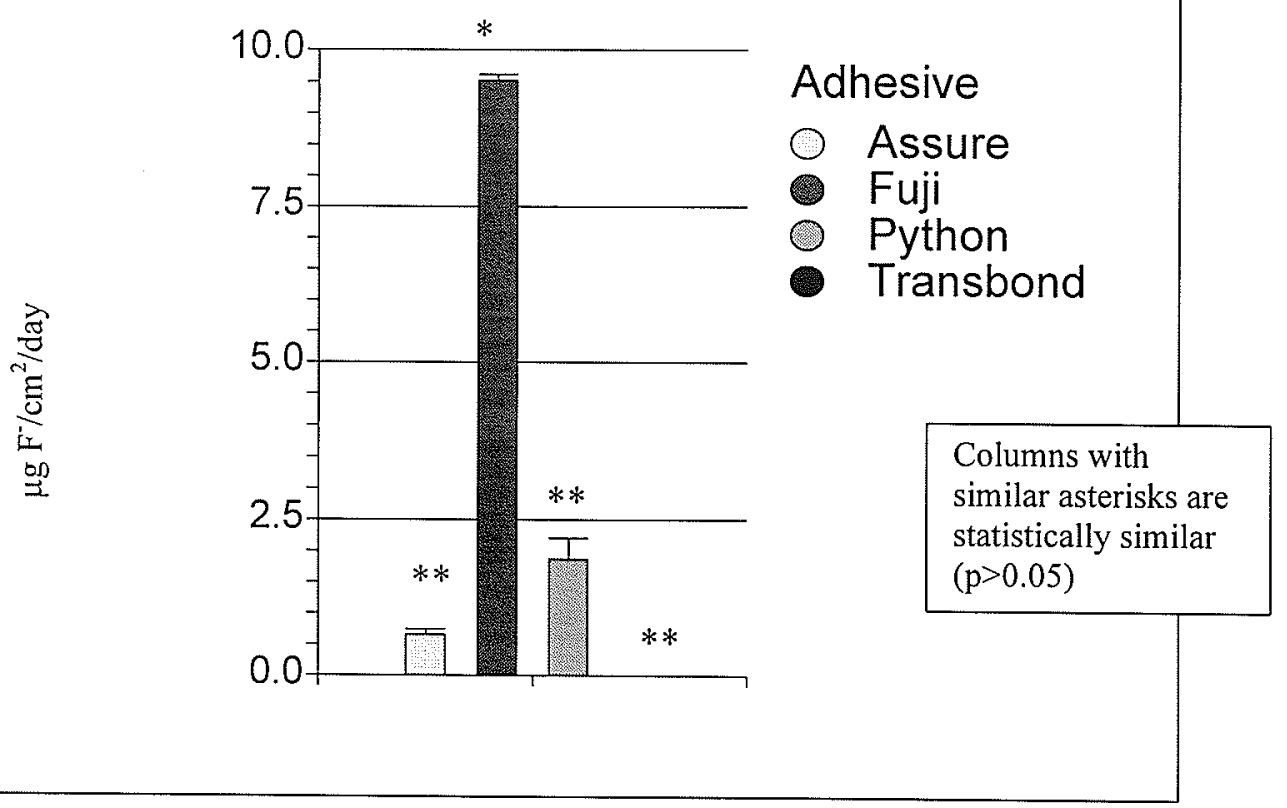

Figure 43: Day 552 fluoride re-release rates. Error bars indicate standard error.

\subsubsection{Day 575 Fluoride Re-release Rates}

Fuji Ortho ${ }^{\mathrm{TM}} \mathrm{LC}$ had the highest fluoride release rate on day $575\left(10.06 \pm 0.072 \mu \mathrm{g} \mathrm{F^{- }}\right.$ $/ \mathrm{cm}^{2} /$ day). Python ${ }^{\mathrm{TM}}$ had a lower fluoride release rate of $3.68 \pm 0.38 \mu \mathrm{g} \mathrm{F}^{-} / \mathrm{cm}^{2} /$ day, but was statistically similar to Fuji Ortho ${ }^{\mathrm{TM}} \mathrm{LC}(\mathrm{p}>0.05)$. Statistically similar fluoride release rates were found for Assure ${ }^{\mathrm{TM}}\left(0.86 \pm 0.16 \mu \mathrm{g} \mathrm{F}^{*} / \mathrm{cm}^{2} /\right.$ day $)$ and Transbond ${ }^{\mathrm{TM}} \mathrm{XT}(0.021 \pm$ $0.021 \mu \mathrm{g} \mathrm{F} / \mathrm{cm}^{2} /$ day) $(\mathrm{p}>0.05)$, and were significantly lower than Fuji Ortho ${ }^{\mathrm{TM}} \mathrm{LC}$ $(\mathrm{p}<0.0001)$. Rates for Python ${ }^{\mathrm{TM}}$, Assure ${ }^{\mathrm{TM}}$ and Transbond ${ }^{\mathrm{TM}} \mathrm{XT}$ were statistically similar 
$(p>0.05)$. Descriptive statistics of mean fluoride release rates and standard errors for day 575 are found in Table 19 and Figure 44.

Table 19: Day 575 fluoride re-release rate descriptive statistics

\begin{tabular}{|c|c|c|c|c|}
\hline Day & Adhesive & $n$ & $\begin{array}{c}\text { Mean Fluoride Release } \\
\left(\mu \mathrm{g} \mathrm{F} / \mathrm{cm}^{2} / \text { day }\right)\end{array}$ & $\begin{array}{c}\mathrm{SE} \\
\left(\mu \mathrm{g} \mathrm{F} / \mathrm{cm}^{2} / \text { day }\right)\end{array}$ \\
\hline 575 & Fuji Ortho' $^{T M} \mathrm{LC}$ & 5 & 10.06 & 0.072 \\
\hline 575 & Python $^{\mathrm{TM}}$ & 5 & 3.68 & 0.38 \\
\hline 575 & Assure & 0.86 & 0.16 \\
\hline 575 & Transbond $^{T M} \mathrm{XT}$ & 5 & 0.021 & 0.021 \\
\hline
\end{tabular}

\section{Day 575 Fluoride Release Rates}

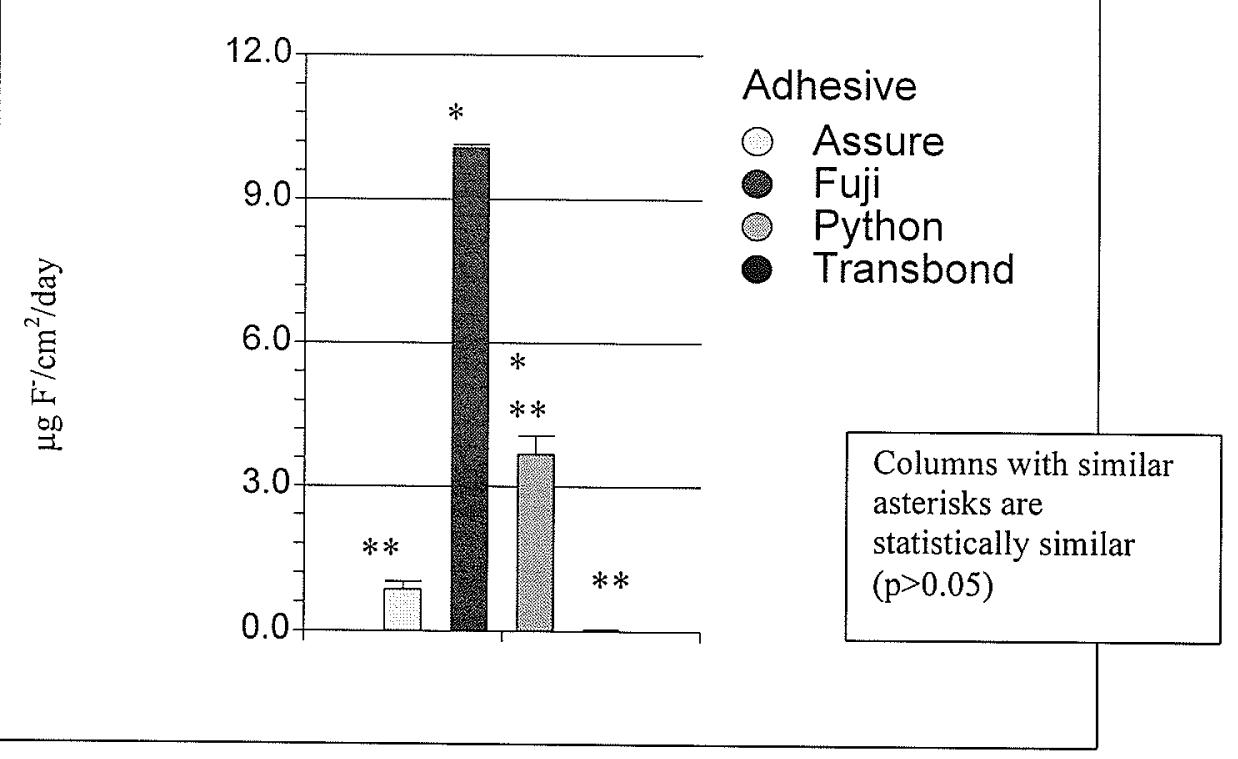

Figure 44: Day 575 fluoride re-release rates. Error bars indicate standard error.

\subsubsection{Day 637 Fluoride Re-release Rates}

The fluoride release rates for Fuji Ortho ${ }^{\mathrm{TM}} \mathrm{LC}\left(10.14 \pm 0.064 \mu \mathrm{g} \mathrm{F} / \mathrm{cm}^{2} /\right.$ day $)$ and Transbond ${ }^{\mathrm{TM}} \mathrm{XT}\left(0.026 \pm 0.026 \mu \mathrm{g} \mathrm{F} / \mathrm{cm}^{2} /\right.$ day $)$ were significantly different $(\mathrm{p}<0.0001)$. The release rates for Fuji Ortho ${ }^{\mathrm{TM}} \mathrm{LC}$, Python ${ }^{\mathrm{TM}}\left(5.79 \pm 0.22 \mu \mathrm{g} \mathrm{F} / \mathrm{cm}^{2} /\right.$ day) and Assure ${ }^{\mathrm{TM}}$ 
$\left(3.27 \pm 0.64 \mu \mathrm{g} \mathrm{F} / \mathrm{cm}^{2} /\right.$ day) were similar $(\mathrm{p}>0.05)$, and Python $^{T M}$, Assure ${ }^{T M}$ and Transbond ${ }^{T M} X T$ were similar $(\mathrm{p}>0.05)$. Descriptive statistics of mean fluoride release rates and standard errors are found in Table 20 and Figure 45.

Table 20: Day 637 fluoride re-release rate descriptive statistics

\begin{tabular}{|c|c|c|c|c|}
\hline Day & Adhesive & $\mathrm{n}$ & $\begin{array}{c}\text { Mean Fluoride Release } \\
\left(\mu \mathrm{g} \mathrm{F}^{-} / \mathrm{cm}^{2} / \text { day }\right)\end{array}$ & $\begin{array}{c}\mathrm{SE} \\
\left(\mu \mathrm{g} \mathrm{F}^{-} / \mathrm{cm}^{2} / \text { day }\right)\end{array}$ \\
\hline 637 & Fuji Ortho ${ }^{\mathrm{TM}} \mathrm{LC}$ & 5 & 10.14 & 0.064 \\
\hline 637 & Python $^{\mathrm{TM}}$ & 5 & 5.79 & 0.22 \\
\hline 637 & Assure $^{\mathrm{TM}}$ & 5 & 3.27 & 0.64 \\
\hline 637 & Transbond $^{\mathrm{TM}} \mathrm{XT}$ & 5 & 0.026 & 0.026 \\
\hline
\end{tabular}

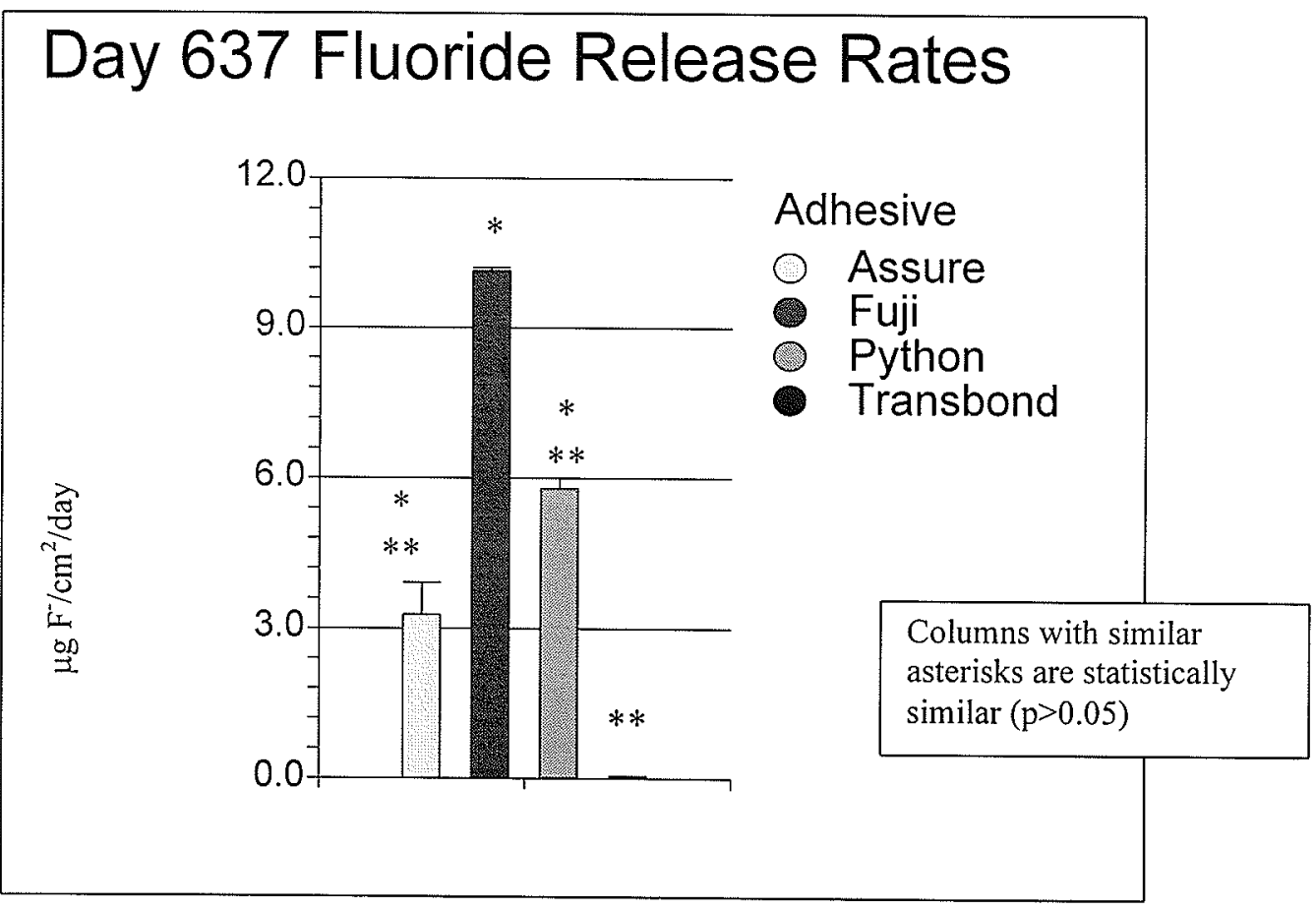

Figure 45: Day 637 fluoride re-release rates. Error bars indicate standard error.

\subsubsection{Day 730 Fluoride Re-release Rates}

The fluoride releases rate for Fuji Ortho ${ }^{\top M} \mathrm{LC}\left(10.06 \pm 0.043 \mu \mathrm{g} \mathrm{F}^{-} / \mathrm{cm}^{2} /\right.$ day $)$ were significantly higher than those for Assure ${ }^{\mathrm{TM}}\left(1.28 \pm 0.24 \mu \mathrm{g} \mathrm{F} / \mathrm{cm}^{2} /\right.$ day $)$ and Transbond ${ }^{\mathrm{TM}}$ 
$\mathrm{XT}(\mathrm{ND})(\mathrm{p}<0.0001)$. The fluoride release rate for Python $^{\mathrm{TM}}$ was $5.40 \pm 0.18 \mu \mathrm{g} \mathrm{F}$ $/ \mathrm{cm}^{2} /$ day, which was statistically similar to all other groups $(\mathrm{p}>0.05)$. Descriptive statistics of mean fluoride release rates and standard errors for day 730 are found in Table 21 and Figure 46.

Table 21: Day 730 fluoride re-release rate descriptive statistics

\begin{tabular}{|c|c|c|c|c|}
\hline Day & Adhesive & $\mathrm{n}$ & $\begin{array}{c}\text { Mean Fluoride Release } \\
\left(\mu \mathrm{g} \mathrm{F}^{-} / \mathrm{cm}^{2} / \text { day }\right)\end{array}$ & $\begin{array}{c}\mathrm{SE} \\
\left(\mu \mathrm{g} \mathrm{F}^{-} / \mathrm{cm}^{2} / \text { day }\right)\end{array}$ \\
\hline 730 & Fuji Ortho ${ }^{T M} \mathrm{LC}$ & 5 & 10.06 & 0.043 \\
\hline 730 & Python $^{T M}$ & 5 & 5.40 & 0.18 \\
\hline 730 & Assure & 5 & 1.28 & 0.24 \\
\hline 730 & Transbond $^{T M} \mathrm{XT}$ & 5 & $\mathrm{ND}$ & $\mathrm{ND}$ \\
\hline
\end{tabular}

\section{Day 730 Fluoride Release Rates}

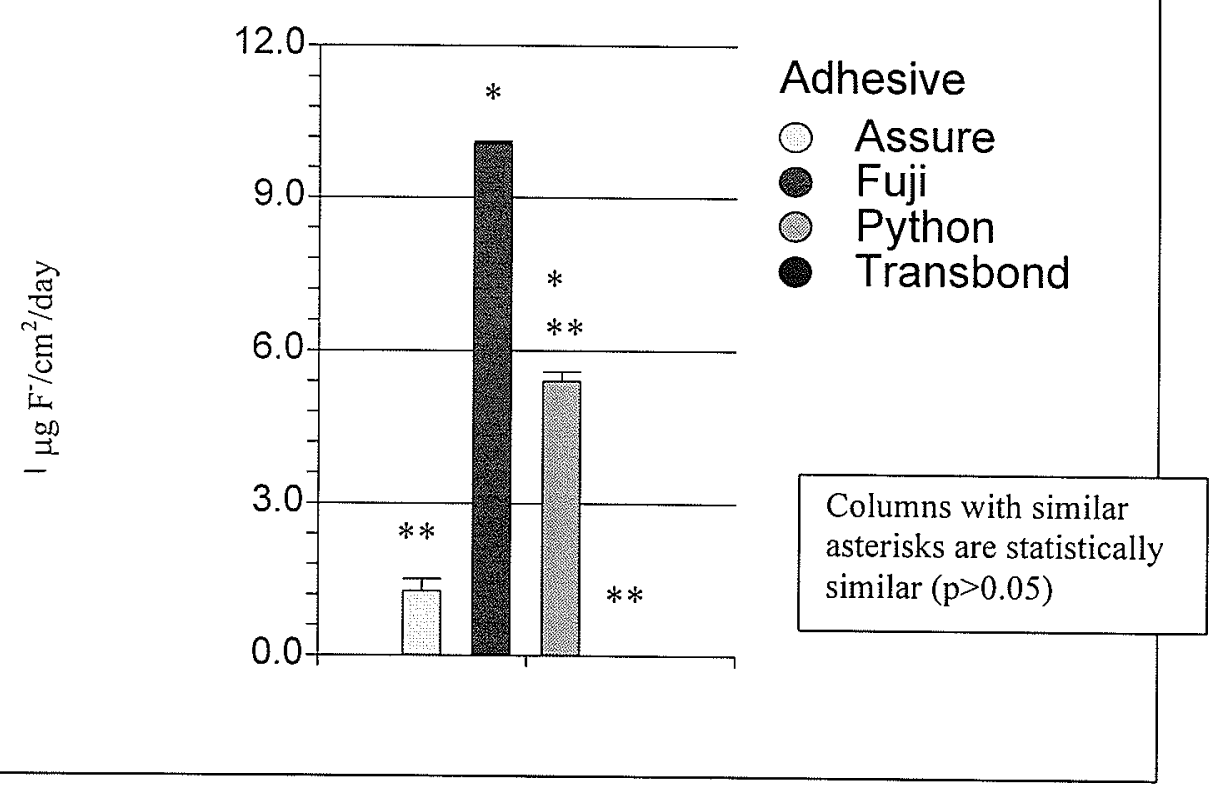

Figure 46: Day 730 fluoride re-release rates. Error bars indicate standard error. 


\subsubsection{Day 821 Fluoride Re-release Rates}

The fluoride release rate for Fuji Ortho ${ }^{T M} \mathrm{LC}\left(10.20 \pm 0.043 \mu \mathrm{g} \mathrm{F} / \mathrm{cm}^{2} /\right.$ day) was significantly higher than those for Assure ${ }^{\mathrm{TM}}\left(1.20 \pm 0.19 \mu \mathrm{g} \mathrm{F}^{-} / \mathrm{cm}^{2} /\right.$ day $)$ and Transbond ${ }^{\mathrm{TM}}$ $\mathrm{XT}(\mathrm{ND})(\mathrm{p}<0.0001)$. The fluoride release rate for Python ${ }^{\top \mathrm{M}}$ was $6.68 \pm 0.39 \mu \mathrm{g} \mathrm{F}^{-}$ $/ \mathrm{cm}^{2} /$ day, which was statistically similar to all other groups ( $>0.05$ ). Descriptive statistics of mean fluoride release rates and standard errors for day 821 are found in Table 22 and Figure 47.

Table 22: Day 821 fluoride re-release rate descriptive statistics

\begin{tabular}{|c|c|c|c|c|}
\hline Day & Adhesive & $\mathrm{n}$ & $\begin{array}{c}\text { Mean Fluoride Release } \\
\left(\mu \mathrm{g} \mathrm{F}^{-} / \mathrm{cm}^{2} / \text { day }\right)\end{array}$ & $\begin{array}{c}\text { SE } \\
\left(\mu \mathrm{g} \mathrm{F}^{-} / \mathrm{cm}^{2} / \text { day }\right)\end{array}$ \\
\hline 821 & Fuji Ortho $^{\text {TM }} \mathrm{LC}$ & 5 & 10.20 & 0.043 \\
\hline 821 & Python $^{\mathrm{M}}$ & 5 & 6.68 & 0.39 \\
\hline 821 & Assure & & \\
\hline $\mathrm{MM}$ & 5 & 1.20 & 0.19 \\
\hline 821 & Transbond $^{\text {TM }}$ XT & 5 & ND & ND \\
\hline
\end{tabular}

\section{Day 821 Fluoride Release Rates}

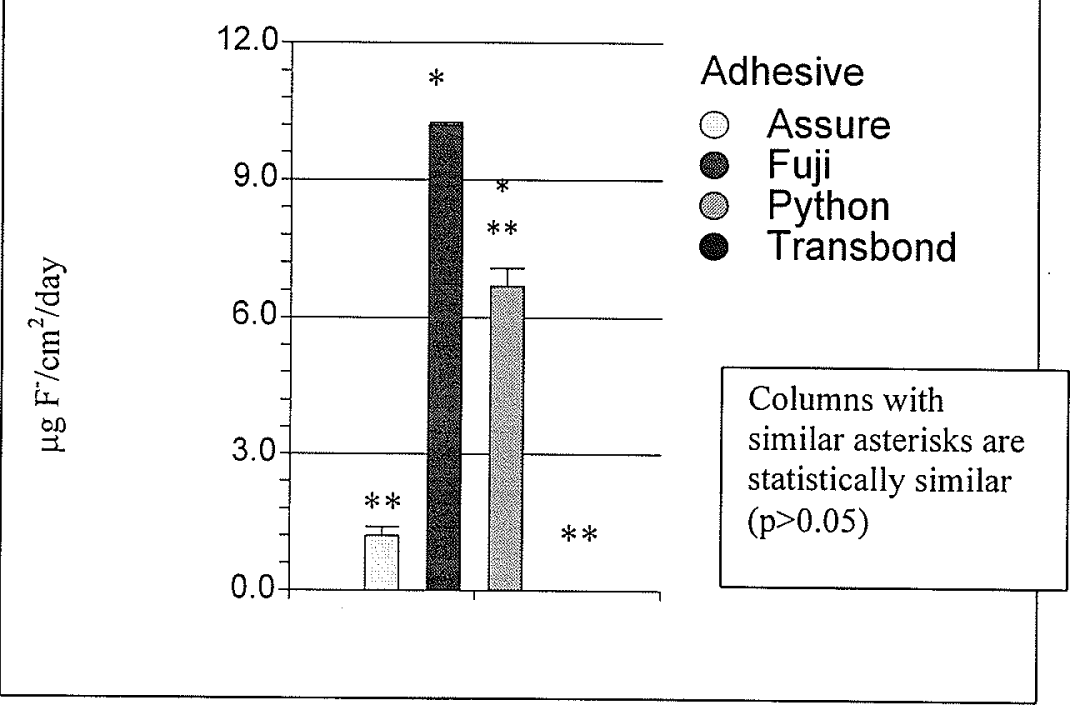

Figure 47: Day 821 fluoride re-release rates. Error bars indicate standard error. 


\subsubsection{Day 913 Fluoride Re-release Rates}

The fluoride release rate for Fuji Ortho' ${ }^{\text {TM }} \mathrm{LC}\left(10.33 \pm 0.020 \mu \mathrm{g} \mathrm{F} / \mathrm{cm}^{2} /\right.$ day $)$ was significantly higher than that of Transbond ${ }^{\top M} X T(N D)(p<0.0001)$. The fluoride release rate was $7.23 \pm 0.24 \mu \mathrm{g} \mathrm{F}^{-} / \mathrm{cm}^{2} /$ day for Python ${ }^{\top \mathrm{M}}$, and $4.40 \pm 0.46 \mu \mathrm{g} \mathrm{F} / \mathrm{cm}^{2} /$ day for Assure $^{\top M}$, neither of which were significantly different from any other group ( $\left.p>0.05\right)$. Descriptive statistics of mean fluoride release rates and standard errors for day 913 are found in Table 23 and Figure 48.

Table 23: Day 913 fluoride re-release rate descriptive statistics

\begin{tabular}{|c|c|c|c|c|}
\hline Day & Adhesive & $\mathrm{n}$ & $\begin{array}{c}\text { Mean Fluoride Release } \\
\left(\mu \mathrm{g} \mathrm{F} / \mathrm{cm}^{2} / \text { day }\right)\end{array}$ & $\begin{array}{c}\text { SE } \\
\left(\mu \mathrm{g} \mathrm{F}^{-} / \mathrm{cm}^{2} / \text { day }\right)\end{array}$ \\
\hline 913 & Fuji Ortho ${ }^{T M}$ LC & 5 & 10.33 & 0.020 \\
\hline 913 & Python ${ }^{\mathrm{TM}}$ & 5 & 7.23 & 0.24 \\
\hline 913 & Assure $^{T M}$ & 5 & 4.40 & 0.46 \\
\hline 913 & Transbond $^{\mathrm{TM}} \mathrm{XT}$ & 5 & ND & ND \\
\hline
\end{tabular}




\section{Day 913 Fluoride Release Rates}

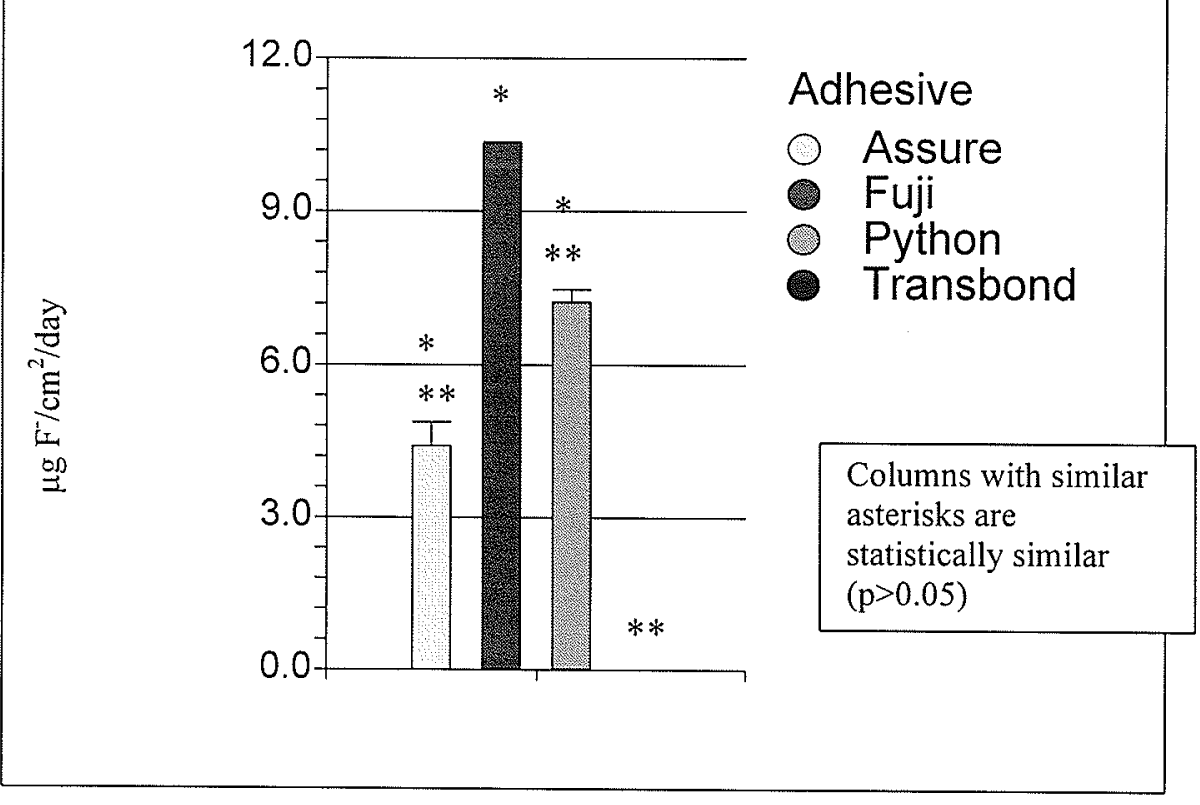

Figure 48: Day 913 fluoride re-release rates. Error bars indicate standard error.

\subsection{Fluoride Release Rates from Tooth-Bracket Model}

\subsubsection{Overall Pattern}

At all time points where detectable levels of fluoride were released, Assure ${ }^{T M}$ had the highest fluoride release rates. Assure released fluoride on days 1, 3, 7 and 30; Quick Cure $^{\mathrm{TM}}$ released fluoride only on day 1 ; and Transbond ${ }^{\mathrm{TM}} \mathrm{XT}$ never released detectable levels of fluoride. All fluoride release rates were statistically similar $(\mathrm{p}>0.05)$ except for Assure $^{\mathrm{TM}}$ on day 1 which was significantly higher $(\mathrm{p}<0.0001)$. The overall pattern of fluoride release for all materials can be seen in Table 24. The fluoride release measurements for individual samples can be found in Appendix 3. 
Table 24: Fluoride release rates for tooth-bracket model (mean \pm S.E., $n=5$ )

\begin{tabular}{|c|c|c|c|c|c|c|}
\hline \multirow{2}{*}{ Material } & \multicolumn{6}{|c|}{ Fluoride Release $\left(\mu \mathrm{g} / \mathrm{cm}^{2} /\right.$ day $)$} \\
\hline & Day $1 *$ & Day 3 & Day 7 & Day 30 & Day 90 & Day 180 \\
\hline Assure ${ }^{\mathrm{rm}}$ & $\begin{array}{c}236.39 \pm 49.14 \\
\text { a A }\end{array}$ & $\begin{array}{c}41.59 \pm 8.32 \\
\text { a B }\end{array}$ & $\begin{array}{c}14.49 \pm 7.15 \\
\text { a B }\end{array}$ & $\begin{array}{c}3.03 \pm 1.65 \\
\text { a B } \\
\end{array}$ & $\begin{array}{l}\mathrm{ND} \\
\mathrm{aB} \\
\end{array}$ & $\begin{array}{l}\mathrm{ND} \\
\mathrm{a} \mathrm{B} \\
\end{array}$ \\
\hline Quick Cure $^{\text {TM }}$ & $\begin{array}{c}10.45 \pm 6.97 \\
\text { b A }\end{array}$ & $\begin{array}{l}\text { ND } \\
\mathrm{aA} \\
\end{array}$ & $\begin{array}{l}\text { ND } \\
\text { a A }\end{array}$ & $\begin{array}{l}\text { ND } \\
\text { a A }\end{array}$ & $\begin{array}{l}\text { ND } \\
\text { a A }\end{array}$ & $\begin{array}{l}\text { ND } \\
\text { a A }\end{array}$ \\
\hline Transbond $^{\mathrm{TM}} \mathrm{XT}$ & $\begin{array}{l}\mathrm{ND} \\
\mathrm{bA} \\
\end{array}$ & $\begin{array}{l}\text { ND } \\
\text { a A }\end{array}$ & $\begin{array}{l}\text { ND } \\
\text { a A }\end{array}$ & $\begin{array}{l}\text { ND } \\
\text { a A }\end{array}$ & $\begin{array}{l}\text { ND } \\
\text { a A }\end{array}$ & $\begin{array}{l}\text { ND } \\
\text { a A }\end{array}$ \\
\hline
\end{tabular}

The same small letters in a column indicate no statistically significant difference in means.

The same large letters in a row indicate no statistically significant difference in means.

* - Indicates number of days since initial fabrication of the samples. 


\subsubsection{Assure $^{T \mathrm{M}}$ Fluoride Release Rates}

The fluoride release for Assure ${ }^{T M}$ was highest on day $1\left(236.39 \pm 49.14 \mu \mathrm{g} \mathrm{F}^{-} / \mathrm{cm}^{2} /\right.$ day $)$. This was followed by significant decrease to $41.59 \pm 8.32 \mu \mathrm{g} \mathrm{F} / \mathrm{cm}^{2} /$ day on day 3 $(\mathrm{p}<0.0001)$. The levels of fluoride release for all days after day 1 (including days 3,7 , 30, 90 and 180) were statistically similar ( $>>0.05)$. Descriptive statistics of mean fluoride release rates and standard errors for Assure ${ }^{\mathrm{TM}}$ are found in Table 25 and Figure 49.

Table 25: Assure ${ }^{\mathrm{TM}}$ fluoride release rate descriptive statistics

\begin{tabular}{|c|l|c|c|c|}
\hline Day & Adhesive & $\mathrm{N}$ & $\begin{array}{c}\text { Mean Fluoride Release } \\
\left(\mu \mathrm{F} \mathrm{F}^{-} / \mathrm{cm}^{2} / \text { day }\right)\end{array}$ & $\begin{array}{c}\text { SE } \\
\left(\mu \mathrm{g} \mathrm{F} / \mathrm{cm}^{2} / \text { day }\right)\end{array}$ \\
\hline 1 & Assure $^{\mathrm{T}}$ & 10 & 236.39 & 49.14 \\
\hline 3 & Assure $^{\mathrm{M}}$ & 10 & 41.59 & 8.32 \\
\hline 7 & Assure $^{\mathrm{T}}$ & 10 & 14.49 & 7.15 \\
\hline 30 & Assure $^{\mathrm{M}}$ & 10 & 3.03 & 1.65 \\
\hline 90 & Assure $^{\mathrm{M}}$ & 10 & $\mathrm{ND}$ & $\mathrm{ND}$ \\
\hline 180 & Assure $^{\mathrm{TM}}$ & 10 & $\mathrm{ND}$ & $\mathrm{ND}$ \\
\hline
\end{tabular}




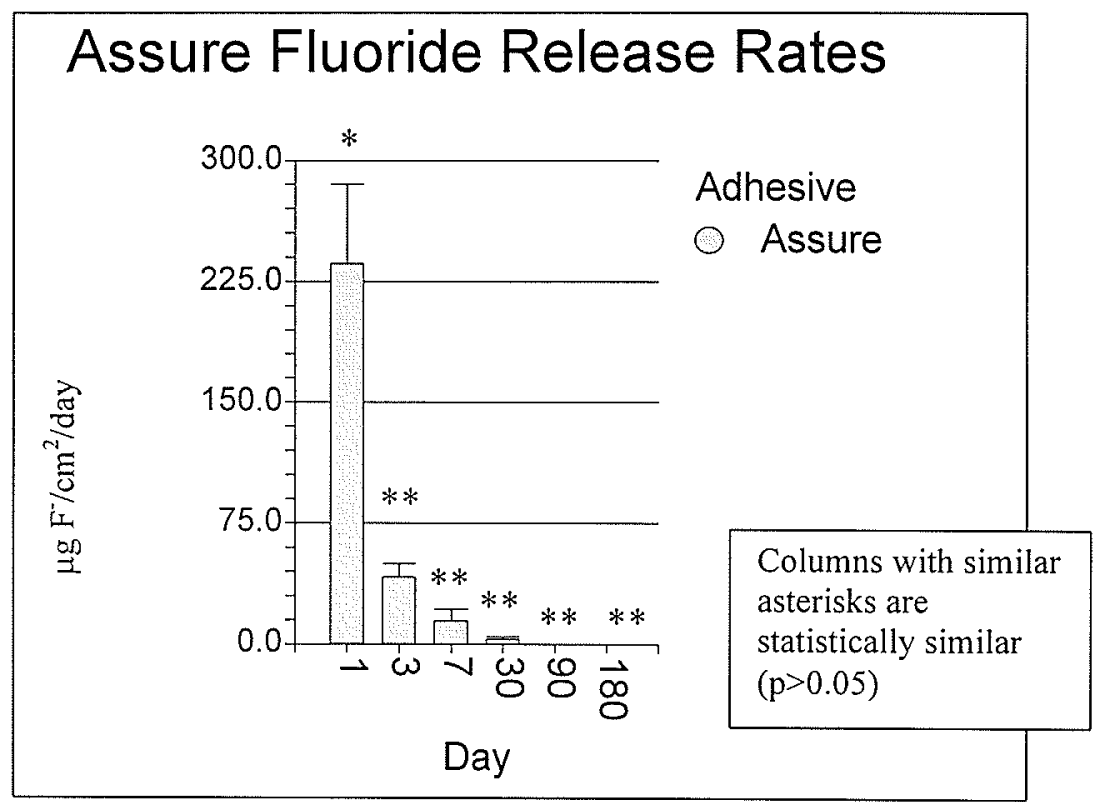

Figure 49: Assure ${ }^{\mathrm{TM}}$ fluoride release rates. Error bars indicate standard error.

\subsubsection{Quick Cure ${ }^{\mathrm{TM}}$ Fluoride Release Rates}

Quick Cure $^{T M}$ released a detectable level of fluoride on day 1 only $\left(10.45 \pm 6.97 \mu \mathrm{g} \mathrm{F}^{-}\right.$ $/ \mathrm{cm}^{2} /$ day); all time points after that had non-detectable fluoride release rates. Statistically, however, all groups were similar $(\mathrm{p}>0.05)$. Descriptive statistics of mean fluoride release rates and standard errors for Quick Cure ${ }^{\mathrm{TM}}$ are found in Table 26 and Figure 50. 
Table 26: Quick Cure ${ }^{\top M}$ fluoride release rate descriptive statistics

\begin{tabular}{|c|c|c|c|c|}
\hline Day & Adhesive & $\mathrm{N}$ & $\begin{array}{c}\text { Mean Fluoride Release } \\
\left(\mu \mathrm{g} \mathrm{F} / \mathrm{cm}^{2} / \text { day }\right)\end{array}$ & $\begin{array}{c}\mathrm{SE} \\
\left(\mu \mathrm{g} \mathrm{F} / \mathrm{cm}^{2} / \text { day }\right)\end{array}$ \\
\hline 1 & Quick Cure $^{T M}$ & 10 & 10.45 & 6.97 \\
\hline 3 & Quick Cure $^{\top M}$ & 10 & ND & ND \\
\hline 7 & Quick Cure $^{T M}$ & 10 & ND & ND \\
\hline 30 & Quick Cure $^{\top \mathrm{M}}$ & 10 & ND & ND \\
\hline 90 & Quick Cure $^{T \mathrm{M}}$ & 10 & ND & ND \\
\hline 180 & Quick Cure $^{T M}$ & 10 & $\mathrm{ND}$ & $\mathrm{ND}$ \\
\hline
\end{tabular}

\section{Quick Cure Long-Term Fluoride Release}

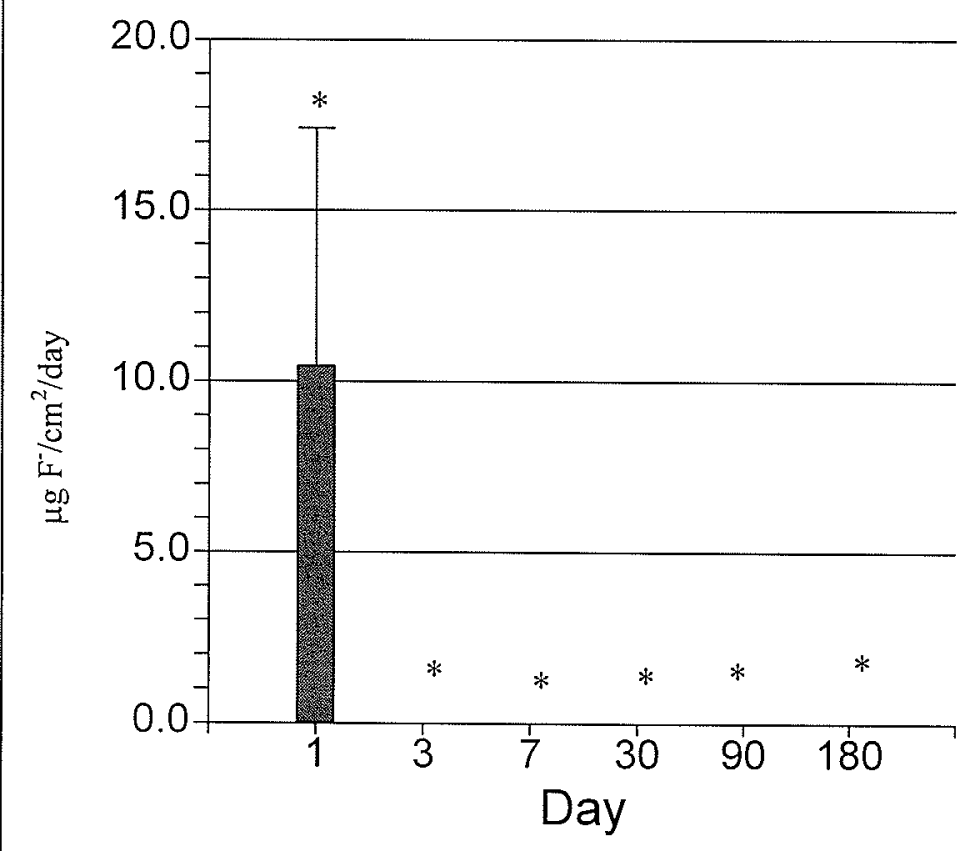

Adhesive

- QuickCure

Columns with similar asterisks are

statistically similar

$(p>0.05)$

Figure 50: Quick Cure ${ }^{\top M}$ fluoride release rates. Error bars indicate standard error.

\subsubsection{Transbond ${ }^{T M}$ XT Fluoride Release Rates}

Transbond ${ }^{T M} \mathrm{XT}$ did not release detectable levels of fluoride at any time point; therefore, all groups were statistically similar $(\mathrm{p}>0.05)$. Descriptive statistics of mean fluoride 
release rates and standard errors for Transbond ${ }^{\top M} \mathrm{XT}$ are found in Table 27 and Figure 51.

Table 27: Transbond ${ }^{\mathrm{TM}}$ XT fluoride release rate descriptive statistics

\begin{tabular}{|c|c|c|c|c|}
\hline Day & Adhesive & $\mathrm{N}$ & $\begin{array}{c}\text { Mean Fluoride Release } \\
\left(\mu \mathrm{g} \mathrm{F} / \mathrm{cm}^{2} / \text { day }\right)\end{array}$ & $\begin{array}{c}\mathrm{SE} \\
\left(\mu \mathrm{g} \mathrm{F}^{-} / \mathrm{cm}^{2} / \text { day }\right)\end{array}$ \\
\hline 1 & Transbond $^{\top \mathrm{M}} \mathrm{XT}$ & 10 & ND & ND \\
\hline 3 & Transbond $^{\top M} X T$ & 10 & ND & ND \\
\hline 7 & Transbond $^{\top \mathrm{M}} \mathrm{XT}$ & 10 & ND & ND \\
\hline 30 & Transbond $^{\mathrm{TM}} \mathrm{XT}$ & 10 & ND & ND \\
\hline 90 & Transbond $^{\mathrm{TM}} \mathrm{XT}$ & 10 & ND & ND \\
\hline 180 & Transbond $^{T M} X T$ & 10 & ND & ND \\
\hline
\end{tabular}

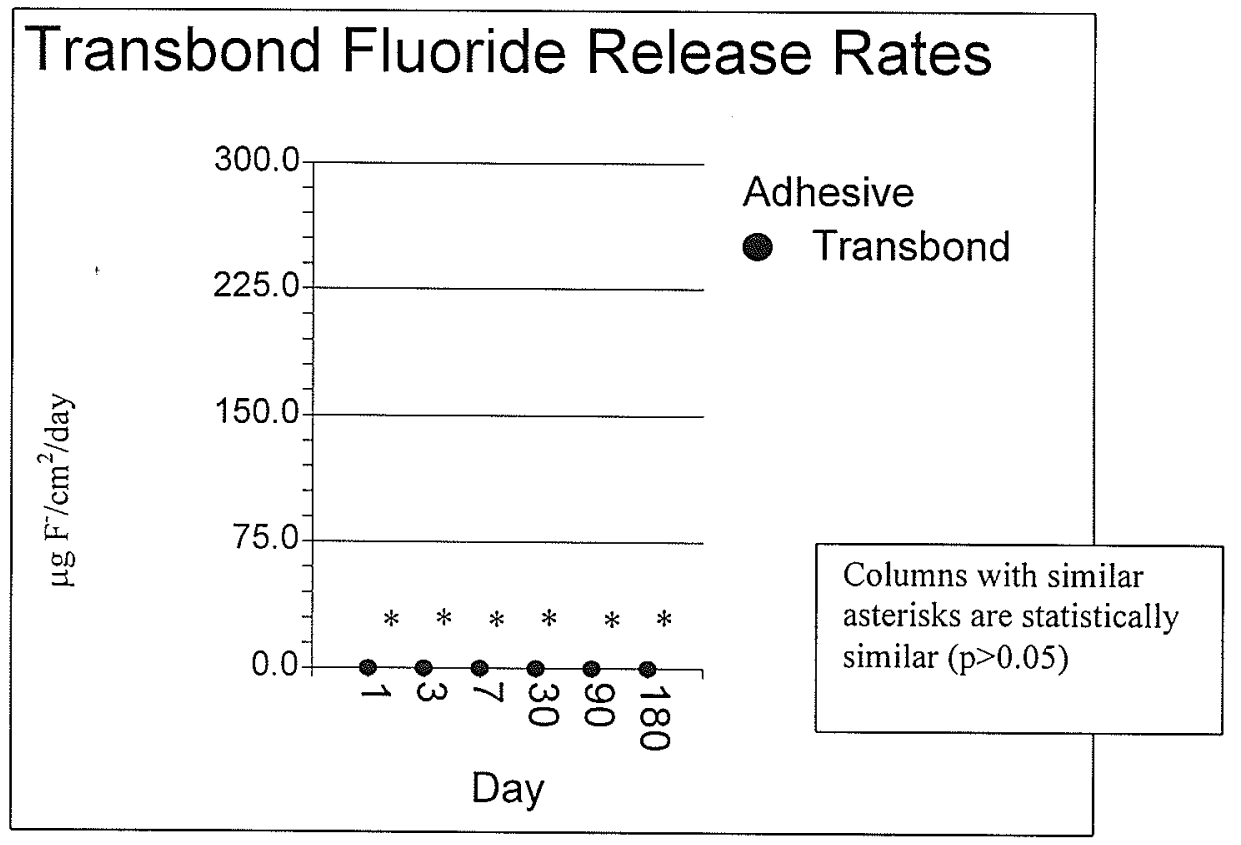

Figure 51: Transbond ${ }^{\mathrm{TM}}$ XT fluoride release rates. Error bars indicate standard error.

\subsubsection{Day 1 Fluoride Release Rates}

The fluoride release rate for Assure ${ }^{\mathrm{TM}}\left(236.39 \pm 49.14 \mu \mathrm{g} \mathrm{F} / \mathrm{cm}^{2} /\right.$ day) was significantly more than those for all other groups $(p<0.0001)$. Quick Cure ${ }^{T M}$ had a fluoride release rate 
statistically similar to Transbond ${ }^{\top M} X T(p>0.05)$, which did not release detectable levels of fluoride. Descriptive statistics of mean fluoride release rates and standard errors for Transbond ${ }^{\top \mathrm{M}} \mathrm{XT}$ are found in Table 28 and Figure 51.

Table 28: Day 1 fluoride release rate descriptive statistics

\begin{tabular}{|c|c|c|c|c|}
\hline Day & Adhesive & $\mathrm{N}$ & $\begin{array}{c}\text { Mean Fluoride Release } \\
\left(\mu \mathrm{g} \mathrm{F}^{*} / \mathrm{cm}^{2} / \text { day }\right)\end{array}$ & $\begin{array}{c}\text { SE } \\
\left(\mu \mathrm{g} \mathrm{F}^{-} / \mathrm{cm}^{2} / \text { day }\right)\end{array}$ \\
\hline 1 & Assure $^{\mathrm{TM}}$ & 10 & 236.39 & 49.14 \\
\hline 1 & Quick Cure $^{\mathrm{TM}}$ & 10 & 10.45 & 6.97 \\
\hline 1 & Transbond $^{\mathrm{TM}} \mathrm{XT}$ & 10 & $\mathrm{ND}$ & $\mathrm{ND}$ \\
\hline
\end{tabular}

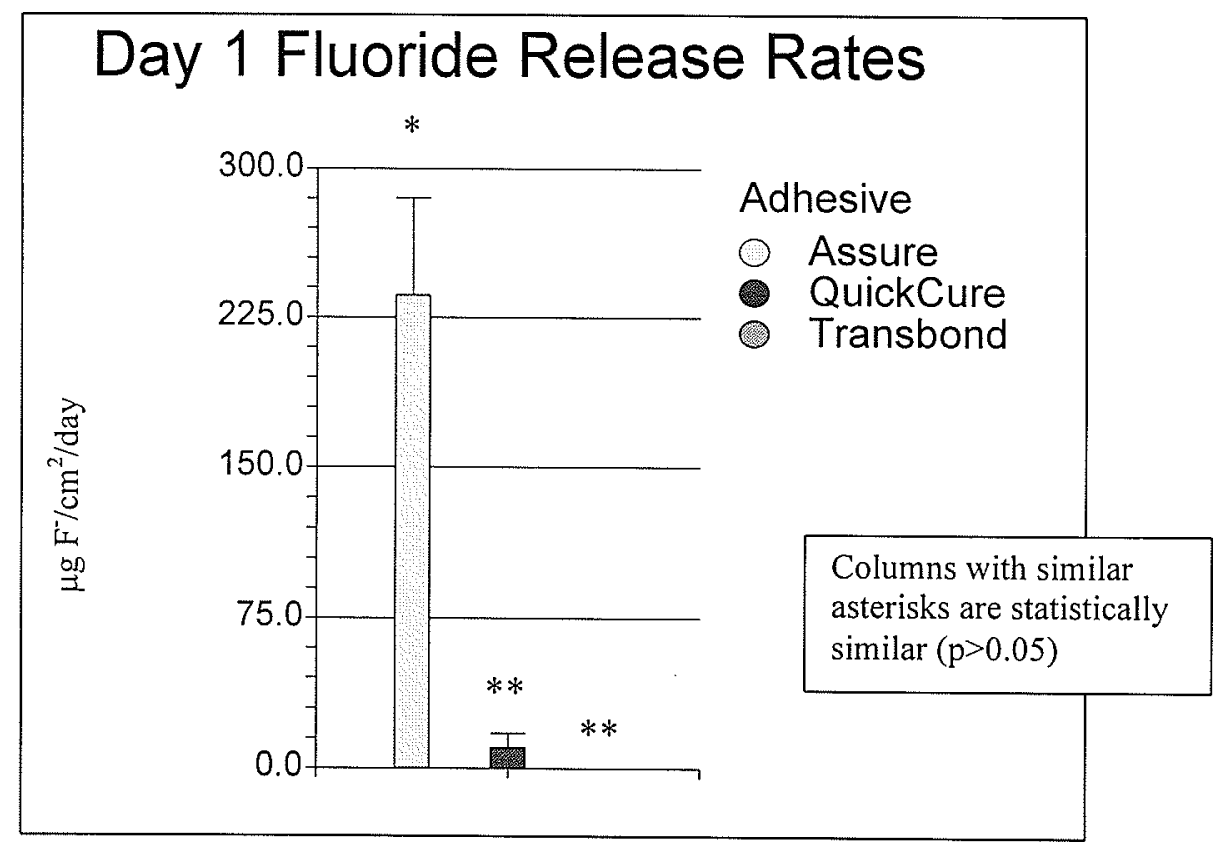

Figure 52: Day 1 fluoride release rates. Error bars indicate standard error.

\subsubsection{Day 3 Fluoride Release Rates}

Assure $^{\mathrm{TM}}$ had the only detectable fluoride release rate $\left(41.59 \pm 8.32 \mu \mathrm{g} \mathrm{F} / \mathrm{cm}^{2} /\right.$ day $)$, but it was not significantly different from those of Quick Cure ${ }^{T M}$ or Transbond ${ }^{T M} X T(p>0.05)$. 
Descriptive statistics of mean fluoride release rates and standard errors are found in Table 29 and Figure 53.

Table 29: Day 3 fluoride release rate descriptive statistics

\begin{tabular}{|c|c|c|c|c|}
\hline Day & Adhesive & $\mathrm{N}$ & $\begin{array}{c}\text { Mean Fluoride Release } \\
\left(\mu \mathrm{g} \mathrm{F}^{\top} / \mathrm{cm}^{2} / \text { day }\right)\end{array}$ & $\begin{array}{c}\text { SE } \\
\left(\mu \mathrm{g} \mathrm{F}^{-} / \mathrm{cm}^{2} / \text { day }\right)\end{array}$ \\
\hline 3 & Assure & 10 & 41.59 & 8.32 \\
\hline 3 & Quick Cure $^{\mathrm{TM}}$ & 10 & $\mathrm{ND}$ & $\mathrm{ND}$ \\
\hline 3 & Transbond $^{\mathrm{TM}} \mathrm{XT}$ & 10 & $\mathrm{ND}$ & $\mathrm{ND}$ \\
\hline
\end{tabular}

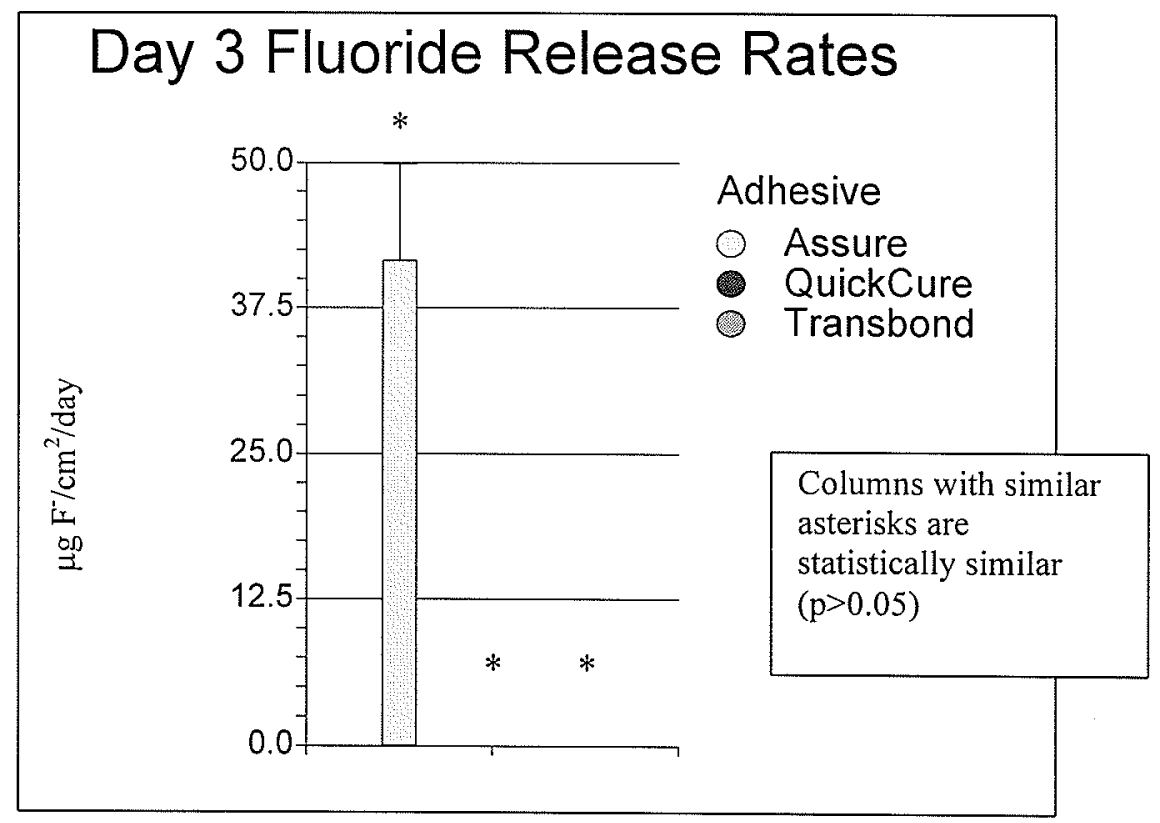

Figure 53: Day 3 fluoride release rates. Error bars indicate standard error.

\subsubsection{Day 7 Fluoride Release Rates}

Assure $^{\mathrm{TM}}$ had a fluoride release rate of $14.49 \pm 7.15 \mu \mathrm{g} \mathrm{F} / \mathrm{cm}^{2} /$ day, while Quick Cure ${ }^{\mathrm{TM}}$ and Transbond ${ }^{\mathrm{TM}}$ XT did not release detectable levels of fluoride. All groups had statistically similar fluoride release rates $(\mathrm{p}>0.05)$. Descriptive statistics of mean fluoride release rates and standard errors are found in Table 30 and Figure 54. 
Table 30: Day 7 fluoride release rate descriptive statistics

\begin{tabular}{|c|c|c|c|c|}
\hline Day & Adhesive & $\mathrm{N}$ & $\begin{array}{l}\text { Mean Fluoride Release } \\
\left(\mu \mathrm{g} \mathrm{F}^{-} / \mathrm{cm}^{2} / \text { day }\right)\end{array}$ & $\begin{array}{c}\mathrm{SE} \\
\left(\mu \mathrm{g} \mathrm{F} / \mathrm{cm}^{2} / \text { day }\right)\end{array}$ \\
\hline 7 & Assure $^{T M}$ & 10 & 14.49 & 7.15 \\
\hline 7 & Quick Cure'T & 10 & ND & ND \\
\hline 7 & Transbond ${ }^{\top M} \mathrm{XT}$ & 10 & ND & ND \\
\hline
\end{tabular}

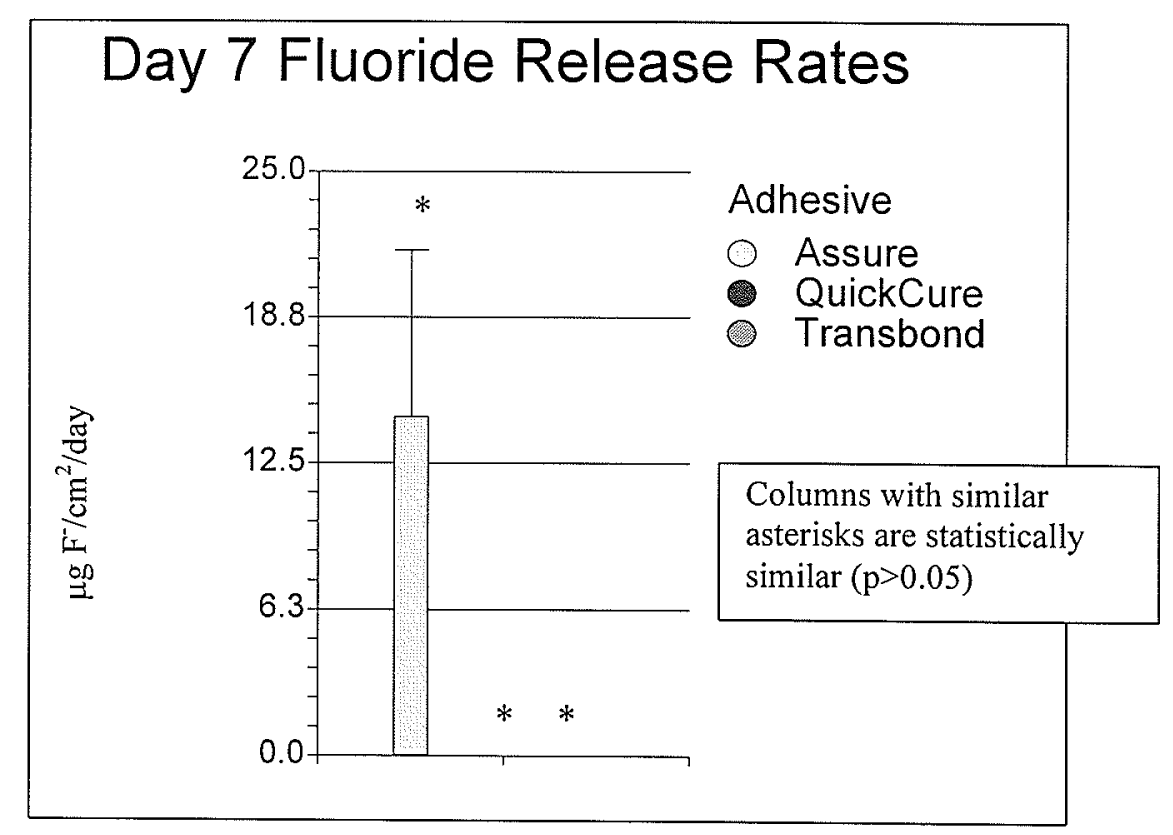

Figure 54: Day 7 fluoride release rates. Error bars indicate standard error.

\subsubsection{Day 30 Fluoride Release Rates}

Assure $^{\top M}$ had a fluoride release rate of $3.03 \pm 1.65 \mu \mathrm{g} \mathrm{F}^{-} / \mathrm{cm}^{2} /$ day, while Quick Cure ${ }^{\top \mathrm{M}}$ and Transbond ${ }^{\mathrm{TM}} \mathrm{XT}$ did not release detectable levels of fluoride. All groups had statistically similar rates of fluoride release $(\mathrm{p}>0.05)$. Descriptive statistics of mean fluoride release rates and standard errors are found in Table 31 and Figure 55. 
Table 31: Day 30 fluoride release rate descriptive statistics

\begin{tabular}{|c|c|c|c|c|}
\hline Day & Adhesive & $\mathrm{N}$ & $\begin{array}{c}\text { Mean Fluoride Release } \\
\left(\mu \mathrm{g} \mathrm{F}^{*} / \mathrm{cm}^{2} / \text { day }\right)\end{array}$ & $\begin{array}{c}\text { SE } \\
\left(\mu \mathrm{g} \mathrm{F}^{-} / \mathrm{cm}^{2} / \text { day }\right)\end{array}$ \\
\hline 30 & Assure $^{\top M}$ & 10 & 3.03 & 1.65 \\
\hline 30 & Quick Cure $^{T M}$ & 10 & $\mathrm{ND}$ & $\mathrm{ND}$ \\
\hline 30 & Transbond $^{\top M} \mathrm{XT}$ & 10 & $\mathrm{ND}$ & $\mathrm{ND}$ \\
\hline
\end{tabular}

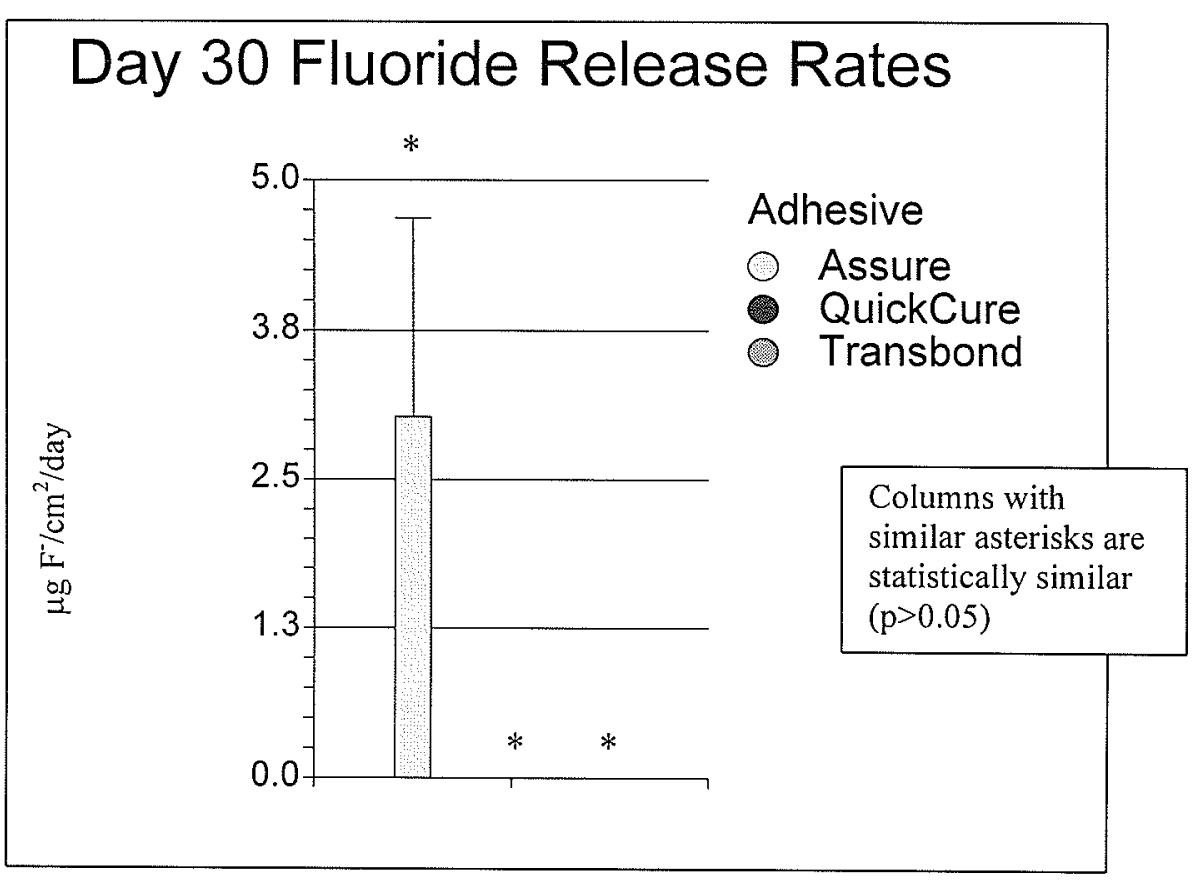

Figure 55: Day 30 fluoride release rates. Error bars indicate standard error.

\subsubsection{Day 90 Fluoride Release Rates}

None of the materials (Assure ${ }^{T M}$, Quick Cure $^{T M}$ or Transbond ${ }^{T M} \mathrm{XT}$ ) had detectable fluoride release rates on day 90, making all groups statistically similar. Descriptive statistics of mean fluoride release rates and standard errors are found in Table 32 and Figure 56. 
Table 32: Day 90 fluoride release rate descriptive statistics

\begin{tabular}{|c|c|c|c|c|}
\hline Day & Adhesive & $n$ & $\begin{array}{l}\text { Mean Fluoride Release } \\
\left(\mu \mathrm{g} \mathrm{F}^{-} / \mathrm{cm}^{2} / \text { day }\right)\end{array}$ & $\begin{array}{c}\mathrm{SE} \\
\left(\mu \mathrm{g} \mathrm{F} / \mathrm{cm}^{2} / \text { day }\right)\end{array}$ \\
\hline 90 & Assure ${ }^{T M}$ & 10 & ND & ND \\
\hline 90 & Quick Cure $^{T M}$ & 10 & ND & ND \\
\hline 90 & Transbond $^{\mathrm{TM}} \mathrm{XT}$ & 10 & ND & ND \\
\hline
\end{tabular}

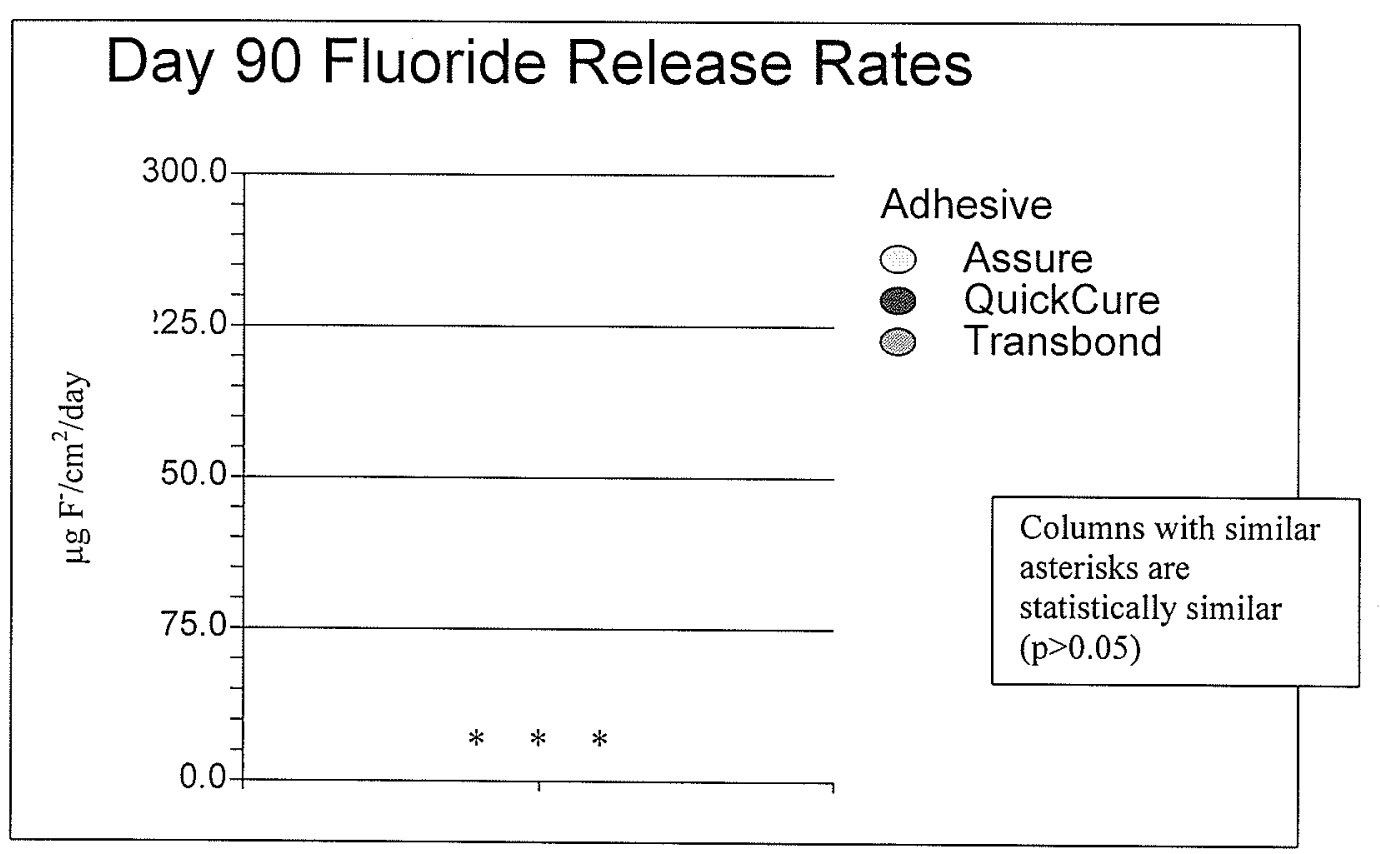

Figure 56: Day 90 fluoride release rates. Error bars indicate standard error.

\subsubsection{Day 180 Fluoride Release Rates}

None of the materials (Assure ${ }^{T M}$, Quick Cure ${ }^{T M}$ or Transbond ${ }^{T M}$ XT) had detectable fluoride release rates on day 90, making all groups statistically similar. Descriptive statistics of mean fluoride release rates and standard errors are found in Table 33 and Figure 57. 
Table 33: Day 180 fluoride release rate descriptive statistics

\begin{tabular}{|c|c|c|c|c|}
\hline Day & Adhesive & $\mathrm{n}$ & $\begin{array}{l}\text { Mean Fluoride Release } \\
\left(\mu \mathrm{g} \mathrm{F}^{-} / \mathrm{cm}^{2} / \text { day }\right)\end{array}$ & $\begin{array}{c}\mathrm{SE} \\
\left(\mu \mathrm{g} \mathrm{F}^{-} / \mathrm{cm}^{2} / \text { day }\right)\end{array}$ \\
\hline 180 & Assure $^{T M}$ & 10 & ND & ND \\
\hline 180 & Quick Cure $^{\mathrm{TM}}$ & 10 & ND & ND \\
\hline 180 & Transbond $^{\mathrm{TM}} \mathrm{XT}$ & 10 & ND & ND \\
\hline
\end{tabular}

\section{Day 180 Fluoride Release Rates}

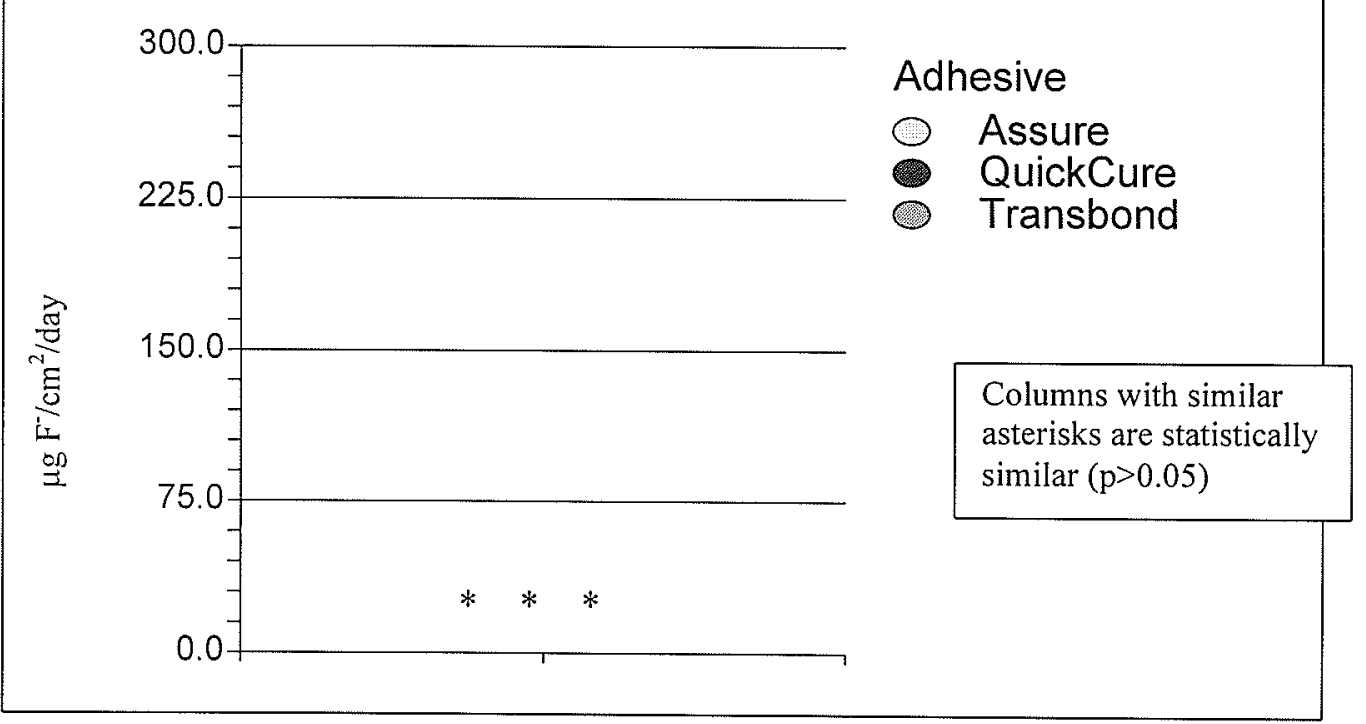

Figure 57: Day 180 fluoride release rates. Error bars indicate standard error. 


\section{Chapter 5}

\section{$\underline{\text { Discussion }}$}

\subsection{Long-Term Fluoride Release}

Many analyses of different materials for up to 3 to 6 month durations (Cooley et al., 1989; Wiltshire and Janse van Rensburg, 1995; Young et al., 1996; Monteith et al., 1998; McNeill et al., 2001) have shown that fluoride-releasing bonding materials have an initial releasing "burst effect" in the first 24 hours. This reaches stable levels by the second week (Wiltshire and Janse van Rensburg, 1995; Ashcraft et al., 1997, McNeill et al., 2001), although fluoride release over a comparable term of orthodontic treatment times (e.g. 2 to 3 years) requires further evaluation.

The current investigation was the continuation of a previous 6-month study (McNeill et al., 2001), where the fluoride release rates (in $\mu \mathrm{g} \mathrm{F} / \mathrm{cm}^{2} /$ day) in distilled water at day 183 were reported as follows: Fuji Ortho ${ }^{\mathrm{TM}} \mathrm{LC}(3.8 \pm 1.46)$, $^{\text {Assure }}{ }^{\mathrm{TM}}(3.1 \pm 1.01)$, Python $^{\mathrm{TM}}$ $(2.6 \pm 1.02)$ and Transbond $^{\mathrm{TM}} \mathrm{XT}(0.1 \pm 0.03)$ (McNeill et al., 2001). These values were surprisingly lower than the release rates (in $\mu \mathrm{g} \mathrm{F} / \mathrm{cm}^{2} /$ day) found at the day 546 measurement of the current study for the respective materials: Fuji Ortho ${ }^{\mathrm{TM}}$ LC $(11.04 \pm$ 0.27), Assure $^{\mathrm{TM}}(7.68 \pm 0.65)$, Python $^{\mathrm{TM}}(8.09 \pm 0.21)$ and Transbond ${ }^{\mathrm{TM}} \mathrm{XT}$ (non- 
detectable). However, when McNeill et al. (2001) measured the fluoride release rate from Assure ${ }^{\text {Tw }}$ after one year, the fluoride release rate had increased to $10.8 \pm 0.77 \mu \mathrm{g} \mathrm{F}$ $/ \mathrm{cm}^{2} /$ day, a value which was higher than the day 546 measurement in the current study. McNeill (2000) hypothesized that long-term storage in a small volume of water for 6 months resulted in fluoride diffusion from the center of the matrix to the periphery, which created a constant fluoride concentration throughout the sample. It is likely that a similar phenomenon occurred in the present study with a 6-month storage prior to the first measurement.

Other studies have shown long-term fluctuations in fluoride release rates. Temin and Csuros (1988) studied the long-term fluoride release from a fluoridated composite restorative material. Using discs $1.75 \times 20 \mathrm{~mm}$ in deionized water, they reported a fluoride release rate of $0.35 \mu \mathrm{g} \mathrm{F} / \mathrm{cm}^{2} /$ day at day $246,0.20 \mu \mathrm{g} \mathrm{F} / \mathrm{cm}^{2} /$ day at day 410 and $0.19 \mu \mathrm{g} \mathrm{F} / \mathrm{cm}^{2} /$ day at day 1591. As in the current study, Temin and Csuros (1988) showed the long-term fluoride release rates fluctuated with time. Wiltshire and Janse van Rensburg (1995) measured the fluoride release rate from FluorEver OBA, a light-cured orthodontic adhesive, using sample sizes $\left(0.94 \mathrm{~cm}^{2}\right)$ and immersion conditions identical to those used in this study. They found that the release rate fluctuated between 0.35 and $0.5 \mu \mathrm{g} \mathrm{F} / \mathrm{cm}^{2} /$ day from week 17 to week 85 , with a final measurement of $0.508 \mu \mathrm{g} \mathrm{F}^{-}$ $/ \mathrm{cm}^{2} /$ day at 21.5 months. This is lower than the rates found for any of the fluoridereleasing materials at any time in this study (Assure ${ }^{\mathrm{TM}}$, Python $^{\mathrm{TM}}$ and Fuji Ortho ${ }^{\mathrm{TM}} \mathrm{LC}$ ), the lowest of which was Assure ${ }^{\mathrm{TM}}$ on day $730\left(1.04 \pm 0.14 \mu \mathrm{g} \mathrm{F} / \mathrm{cm}^{2} /\right.$ day $)$. Grobler et al. (1998) found a significant increase in fluoride release rates for several materials from day 
60 to day 200. The changes in fluoride release rates (in $\mu \mathrm{g} \mathrm{F}^{*} / \mathrm{cm}^{2} /$ day) were as follows: Advance hybrid increased from 0.20 to 0.51 , Fuji II LC increased from 0.14 to 0.34 , Vitremer increased from 0.12 to 0.26 and Dyract ${ }^{\circledR}$ increased from 0.05 to 0.17 .

Fluctuations in fluoride release rates seem to occur with long time periods between measurements, possibly reflecting two fluoride elution processes (Grobler et al., 1998; Tay and Braden, 1988). There is an initial rapid surface process with high and rapid fluoride release that equilibrates after a time, followed by a slow bulk diffusion process that continues for at least 2.5 years (Tay and Braden, 1988). Grobler et al. (1998) felt that fluctuations in fluoride release reported in their study were probably due to the time of exposure to water and the diffusion of water into the materials, resulting in the release of fluoride from the bulk of the materials. This slow bulk diffusion may also explain the long-term fluoride release pattern seen in the present study.

In the present study, fluoride was released from Fuji Ortho ${ }^{T M}$ LC, Assure ${ }^{\mathrm{TM}}$ and Python ${ }^{\mathrm{T} M}$ on days $546,613,730,821$ and 913 . Transbond ${ }^{\text {TM }}$ XT never released sufficient fluoride to meet the detection threshold of the fluoride ion-specific electrode (i.e. less than $0.1 \mu \mathrm{g} \mathrm{F}^{-}$ $/ \mathrm{cm}^{2} /$ day). At all time points Fuji Ortho ${ }^{\mathrm{TM}} \mathrm{LC}$ had significantly greater fluoride release rates than the other materials $(\mathrm{p}<0.0001)$, followed in order of magnitude by Python $^{\mathrm{T} M}>$ Assure $^{\mathrm{TM}}>$ Transbond $^{\mathrm{TM}}$ XT. These results are supported by those of Monteith et al. (1999) who found that the amount of fluoride released by a resin-modified glass-ionomer (Vitremer ${ }^{\circledR}$ ) was greater than that from Dyract ${ }^{\circledR}$ Ortho (a polyacid-modified composite) using three different models. Monteith et al. (1999) found the mean cumulative 
concentration of fluoride released from Vitremer ${ }^{\circledR}$ was: unvarnished discs $3 \mathrm{~mm}$ in diameter and $1.5 \mathrm{~mm}$ in height $(25.69 \pm 1.52 \mathrm{ppm})$, varnished discs with half the surface area $(18.99 \pm 0.83 \mathrm{ppm})$, and tooth-bracket model $(8.92 \pm 2.80 \mathrm{ppm})$. By contrast, the mean cumulative concentration of fluoride released from Dyract ${ }^{\circledR}$ Ortho was: unvarnished discs $(6.42 \pm 1.00 \mathrm{ppm})$, varnished discs $(5.19 \pm 0.83 \mathrm{ppm})$ and toothbracket model (1.48 $\pm 0.57 \mathrm{ppm}$ ) (Monteith et al., 1999). Vermeersch et al. (2001) also found that polyacid-modified composite resin materials released less fluoride than resinmodified glass-ionomer cements. Fuji II LC (a resin-modified glass-ionomer cement) had a mean cumulative fluoride release rate of $0.62 \pm 0.13 \mu \mathrm{g} / \mathrm{mm}^{2}$ at 7 days and $1.86 \pm$ $0.38 \mu \mathrm{g} / \mathrm{mm}^{2}$ at 91 days, Vitremer ${ }^{\circledR}$ (a resin-modified glass-ionomer cement) had a mean cumulative fluoride release rate of $0.43 \pm 0.13 \mu \mathrm{g} / \mathrm{mm}^{2}$ on day 7 and $1.00 \pm 0.24 \mu \mathrm{g} / \mathrm{mm}^{2}$ on day 91 , and Dyract ${ }^{(1)}$ (a polyacid-modified composite resin) had a mean cumulative fluoride release rate of $0.08 \pm 0.03 \mu \mathrm{g} / \mathrm{mm}^{2}$ on day 7 and $0.41 \pm 0.10 \mu \mathrm{g} / \mathrm{mm}^{2}$ on day 91 . These results therefore indicate that the fluoride release rate for the resin-modified glassionomer cement (Fuji Ortho $^{T M}$ LC) was greater than those of the polyacid-modified composite resins (Assure ${ }^{\mathrm{TM}}$ and Python ${ }^{\mathrm{TM}}$ ).

The fluoride release rate for Python ${ }^{\text {TM }}$ was significantly greater than that of Assure ${ }^{T M}$ on days 730,821 and $913(\mathrm{p}<0.0001)$. All fluoride-releasing materials showed a decrease in release rates until day 730 (Python $^{\mathrm{TM}}$ and Assure $^{\mathrm{TM}}$ ) or 821 (Fuji Ortho ${ }^{\mathrm{TM}}$ LC), followed by an increase until day 913. The reason for the increase in fluoride release rates at day 913 remains unclear. On days 730 and 821 Assure $^{\text {TM }}$ had fluoride release rates of $1.04 \pm 0.14$ 
and $1.21 \pm 0.23 \mu \mathrm{g} \mathrm{F} / \mathrm{cm}^{2} /$ day. These were statistically similar to the control material Transbond $^{\mathrm{TM}} \mathrm{XT}(\mathrm{P}>0.05)$, yet offer clinically significant enamel protection. Rawls (1987 and 1995) states that to inhibit caries initiation in sound enamel in the immediate vicinity of a resin-based dental material, fluoride release should be in the range of 0.65 to $1.3 \mu \mathrm{g}$ $\mathrm{F}^{*} / \mathrm{cm}^{2} /$ day. All fluoride-releasing materials (Fuji Ortho ${ }^{\mathrm{TM}}$ LC, Assure ${ }^{\mathrm{TM}}$ and Python ${ }^{\mathrm{TM}}$ ) had long-term fluoride release rates at or above this level throughout the experiment, and so may be considered cariostatic.

Several studies have reported long-term fluoride release from various materials, although few have reported on fluoride-releasing orthodontic bonding materials. Fox (1998) studied fluoride release from a polyacid-modified composite resin $\left(\right.$ Direct $\left.^{\circledR}\right)$ and a glass ionomer cement $\left(\mathrm{Ketac}_{\mathrm{Cem}}{ }^{\circledR}\right)$, both of which are non-orthodontic bonding materials. The sample size used was $10 \mathrm{~mm} \times 10 \mathrm{~mm} \times 1 \mathrm{~mm}$, resulting in a surface area of $2.4 \mathrm{~cm}^{2}$ (for comparison, the results of the study have been converted from $\mu \mathrm{g} / \mathrm{day}$ to $\mu \mathrm{g} / \mathrm{cm}^{2} /$ day). Fox (1998) found the fluoride release rate for Direct ${ }^{\circledR}$ on day 2 was 4.1 $\mu \mathrm{g} / \mathrm{cm}^{2} /$ day, which dropped to $0.1 \mu \mathrm{g} / \mathrm{cm}^{2} /$ day by 10 weeks and stayed at that level up to 20 weeks. Ketac-Cem ${ }^{\circledR}$ had higher fluoride release rates on day $2\left(36.7 \mu \mathrm{g} / \mathrm{cm}^{2} /\right.$ day $)$, but dropped below $0.1 \mu \mathrm{g} / \mathrm{cm}^{2} /$ day at 6 weeks and remained below through week 20 . Fox (1998) found essentially no long-term fluoride release for Direct ${ }^{\circledR}$ and Ketac-Cem ${ }^{\circledR}$ as compared to the materials in the present study.

Trimpeneers et al. (1998) also studied fluoride release from orthodontic bonding resins over a long-term period of 560 days. Utilizing samples with dimensions $13 \mathrm{~mm}$ diameter 
x $1.2 \mathrm{~mm}$ thickness, they studied fluoride release rates from Light-Bond, Rely.a.Bond, Orthon, FluorEver and Ketac-Cem ${ }^{\circledR}$. Direct comparison of these results is difficult because fluoride release rates were reported in mmol/L/day. Nevertheless, FluorEver and Ketac-Cem ${ }^{\circledR}$ had a continuous, slow decline in fluoride release over the evaluation period. Fluoride release from Orthon, however, increased after a period of time to a constant higher level than those of Ketac-Cem ${ }^{\circledast}$ and FluorEver. Again, variability in fluoride release patterns was attributed to differencet kinetic processes (Trimpeneers et al., 1998).

\subsection{Fluoride Re-Release Pattern}

As discussed in section 5.1, fluoride-releasing materials show a "burst-effect" fluoride release pattern (i.e. the greatest amount of fluoride is released within the first few days of testing) (Wiltshire and Janse van Rensburg, 1995; Ashcraft et al., 1997). With a rapid decline to much lower levels, it is important to examine the usefulness of these materials as fluoride "reservoirs" during the average orthodontic treatment time of two to three years by determining the fluoride re-release pattern after exposure to additional fluoride. Fluoride exposure often occurs clinically, such as when patients receive topical fluoride applications during treatment or ingest fluoride-containing drinks or food. In agreement with previous studies (Takahashi et al., 1993; Young et al., 1996; McNeill et al., 2001),

this experiment showed a similar 'burst-effect' fluoride re-release pattern following exposure of aged samples to $2 \%$ sodium fluoride $(\mathrm{NaF})$ gel. The fluoride re-release rates 
(in $\mu \mathrm{g} \mathrm{F} / \mathrm{cm}^{2} /$ day) for Fuji Ortho ${ }^{\mathrm{TM}} \mathrm{LC}(92.34 \pm 1.48)$, Assure $^{\mathrm{TM}}(63.40 \pm 4.68)$, and Python $^{\text {TM }}(36.60 \pm 5.19)$ were much higher than the values reported by McNeill et al. (2001) for the same samples 12 months earlier (at day 183): Fuji Ortho ${ }^{\mathrm{TW}}$ LC $(3.8 \pm 1.46)$, Assure $^{\text {TM }}(3.1 \pm 1.01)$, Python $^{\text {TM }}(2.6 \pm 1.02)$ and Transbond ${ }^{\text {TM }}$ XT $(0.1 \pm 0.03)$.

The fluoride release rates were significantly greer 24 hours post-exposure (day 546) compared to subsequent measurements $(\mathrm{p}<0.0001)$. The rapid decrease in fluoride release after one day supports the findings of De Witte et al. (2000) who investigated the fluoride release profiles of mature restorative resin-modified glass-ionomer and conventional glass-ionomer cements after fluoride application. They found that conventional and resin-modified GICs could be charged with fluoride $(2 \% \mathrm{NaF}$ for 1 hour) after maturing for 21 days, and this release rate lasted for only a few days. They felt that the short-term release process seen after fluoridation was due to the kinetic processes involved. More specifically, some fluoride is free to move into the cement and is subsequently easily released by simple diffusion through the matrix, while other fluoride penetrates the GIC upon fluoridation and reacts with aluminum, calcium or other bivalent metal ions of the matrix, forming matrix-bound fluoride. The unbound fluoride would account for the short-term elution, while the matrix-bound fluoride could only be released following decomplexation and might be related to the long-term elution process. On subsequent fluoridations they found that the short-term process explained the amount of fluoride released. Less fluoride could become matrix bound because many, if not all, of the metal ions were complexed, allowing more of the fluoride to remain free within the 
matrix. Consequently, the short-term fluoride release would be more prominent with each fluoride exposure (De Witte et al., 2000).

Young et al. (1996) studied fluoride release and re-release from two fluoride-containing orthodontic adhesives (Saga Bond and VP 862), a polyacid modified composite (Tetric) and a glass-ionomer cement material $\left(\operatorname{Ketac~Fil}^{\circledR}\right)$. They found all materials had greatly increased fluoride release after exposure to $1000 \mathrm{ppm} \mathrm{NaF}$ solution, followed by a return to pre-exposure levels within 2-3 days. This pattern was similar to the present study, with the leveling-off of fluoride release rates by the third day (day 548). Young et al. (1996) also reported an increase in 'base-line' fluoride release from Ketac-Fil ${ }^{\circledR}$ with repeated fluoride exposures. The remaining materials, however, showed a trend of decreasing fluoride release in the initial 24-hour follow-up period with repeated exposures. This trend might have changed with a longer follow-up period (i.e. fluoride exposures occurred on days 33, 40 and 46). They reasoned that there was a possible reduction in 'constant' fluoride release from the materials or the surface became saturated with fluoride following several exposures (Young et al., 1996).

On day 546, Fuji Ortho ${ }^{\mathrm{TM}} \mathrm{LC}$ had the highest fluoride release rate $\left(92.34 \pm 1.48 \mu \mathrm{g} \mathrm{F}^{-}\right.$ $/ \mathrm{cm}^{2} /$ day), followed by Assure ${ }^{\mathrm{TM}}\left(63.40 \pm 4.68 \mu \mathrm{g} \mathrm{F}^{-} / \mathrm{cm}^{2} /\right.$ day), Python ${ }^{\mathrm{TM}}(36.60 \pm 5.19 \mu \mathrm{g}$ $\mathrm{F}^{*} / \mathrm{cm}^{2} /$ day $)$ and Transbond ${ }^{\mathrm{TM}} \mathrm{XT}\left(5.94 \pm 1.24 \mu \mathrm{g} \mathrm{F}^{*} / \mathrm{cm}^{2} /\right.$ day $)$. On all subsequent days the fluoride release rates (in decreasing order) were as follows: Fuji Ortho $^{\mathrm{TM}} \mathrm{LC}^{\mathrm{L}}>$ Python $^{\mathrm{TM}}>$ Assure $^{\text {TM }}>$ Transbond $^{\text {TM }}$ XT. These results are consistent with those reported by Yip and Smales (1999), who studied fluoride release and uptake by aged resin-modified glass- 
ionomers (Fuji II LC, Photac-Fil and Vitremer) and a polyacid modified resin composite (Dyract). Using samples $3 \mathrm{~mm}$ in diameter $\times 2.7 \mathrm{~mm}$ in height submerged in $2 \mathrm{~mL}$ of deionized water, fluoride release was shown to be higher for resin-modified glassionomer cements following fluoride exposure relative to the polyacid-modified resin composite. At 2 hours following exposure to $\mathrm{NaF}$, the concentration of fluoride released by the samples was as follows: Photac-Fil $(2.54 \mathrm{ppm})>$ Fuji II LC (2.28 ppm) > Vitremer $(2.10 \mathrm{ppm})>$ Dyract $(0.56 \mathrm{ppm})$. At 21 days following exposure to $\mathrm{NaF}$, the order was slightly different, but the resin-modified glass-ionomers still had the greatest concentration of fluoride release: Photac-Fil $(0.54 \mathrm{ppm})>$ Vitremer $(0.23 \mathrm{ppm})>$ Fuji II LC $(0.20 \mathrm{ppm})>\operatorname{Dyract}(0.20 \mathrm{ppm})$.

On days 548,552,575,637, 730, 821 and 913 no statistical difference was apparent in release rates (in $\mu \mathrm{g} \mathrm{F}^{-} / \mathrm{cm}^{2} /$ day) between Assure $^{\text {TM }}$ ( $2.90 \pm 0.88$ on day 548 ), Python ${ }^{\text {TM }}$ (5.85 \pm 0.36 on day 548) and the control material Transbond ${ }^{\mathrm{TM}} \mathrm{XT}(0.043 \pm 0.043$ on day 548$)$. However, as mentioned in section 5.1, the difference may be clinically significant, based on experiments determining the minimum fluoride level that offers cariostatic protection. Again using Rawls' (1995) values for significant fluoride release rates (0.65 to $1.3 \mu \mathrm{g} \mathrm{F}^{-}$ $/ \mathrm{cm}^{2} /$ day) needed to inhibit caries after fluoride exposure; all fluoride-releasing materials (Fuji Ortho ${ }^{\text {TM }}$ LC, Assure ${ }^{\mathrm{TM}}$ and Python ${ }^{\mathrm{TM}}$ ) met or exceeded this standard in the present study. 
Creanor et al. (1994) studied fluoride uptake and re-release of such glass ionomer cements as Ketac Fil ${ }^{\circledR}$, Chemfil Superior, Fuji II LC, Aquacem and Vitrebond. They immersed samples in $1 \mathrm{~L}$ of deionized water for 60 days to leach fluoride out of the materials and divided them into control and experimental groups. The experimental samples were then exposed to $1000 \mathrm{ppm} \mathrm{F}^{-}$solution daily for 20 days, when they found that the exposed samples released more ionic fluoride than the controls at all time points over the 20 days. This indicated that all five types of glass ionomer cements imbibe and re-release fluoride.

The fluoride re-release patterns seen in this experiment and other studies may be due to two different mechanisms, including: I) surface retention of fluoride and II) diffusion of fluoride into the matrix of the material. Surface retention of fluoride is supported by the results using non-fluoridated control materials. In the present study it was found that Transbond $^{\text {TM }}$ XT had greater fluoride release in the initial 24 hours post-exposure $(5.94 \pm$ $1.24 \mu \mathrm{g} \mathrm{F} / \mathrm{cm}^{2} /$ day) than at any time following, even though these differences were not significant ( $>0.05$ ). Takahashi et al. (1993) found fluoride release of $0.06 \pm 0.01$ $\mathrm{mmol} / \mathrm{L}$ in the first week post-exposure, compared with $0.01 \pm 0.01 \mathrm{mmol} / \mathrm{L}$ preexposure from a composite resin (Prisma APH). Young et al. (1996) reported that Tetric (a polyacid-modified composite) had a fluoride release of $8.5 \pm 2.62 \mathrm{mg} / \mathrm{cm}^{2} 24$ hours post-exposure, compared with $0.27 \pm 0.04 \mathrm{mg} / \mathrm{cm}^{2}$ at the initial 24 hour measurement. They felt that the increased fluoride release rate for Tetric (a polyacid modified composite) was most likely due to surface-retained fluoride; the most likely explanation 
for the increased fluoride release from Transbond ${ }^{\text {Th }}$ XT following fluoride exposure in this experiment.

Diffusion of fluoride in the matrix material is supported by fluoride re-release rates from fluoride-releasing bonding materials. For example, Takahashi et al. (1993) used 6-weekold samples to compare fluoride release following exposure to $2 \% \mathrm{NaF}, 0.2 \% \mathrm{NaF}$, $0.02 \% \mathrm{NaF}$ and distilled water (no NaF). They found that the $0.02 \%$ exposed group did not release more fluoride than controls immersed in distilled water, while the $2 \%$ and $0.2 \% \mathrm{NaF}$ exposed samples released extra fluoride during the 3 weeks post-exposure. These results illustrate that some fluoride must have diffused into the matrix material, as it could not be accounted for by washout of fluoride ions adsorbed to the surface. It is likely that for the fluoride-releasing materials used in this study, both surface adsorption and matrix diffusion of fluoride from $\mathrm{NaF}$ gel resulted in the 'burst-effect' fluoride release pattern - a significant clinical benefit for their use in orthodontics.

\subsection{Tooth-Bracket Model}

Fluoride release from orthodontic bonding materials may be important only if sufficient to provide a cariostatic benefit. According to Monteith et al. (1999), the amount of fluoride varies with the in vitro model used. Utilizing a tooth-bracket model would therefore provide valuable insight into the amount of fluoride release in vivo. The toothbracket model in this study was used to evaluate two materials that are marketed as fluoride releasing (Assure ${ }^{\mathrm{TM}}$ and Quick $\mathrm{Cure}^{\mathrm{T} M}$ ), by comparing them with a non-fluoride 
releasing control composite resin $\left(\right.$ Transbond $\left.^{\mathrm{TM}} \mathrm{XT}\right)$. As expected, Transbond $\mathrm{d}^{\mathrm{TM}} \mathrm{XT}$ did not release detectable levels of fluoride at any point in the experiment. Assure ${ }^{\mathrm{Tu}}$ released detectable levels of fluoride on days $1,3,7$ and 30 , with the fluoride release rate on day 1 being significantly greater than on subsequent days $(p<0.0001)$. On days 3,7 and 30 the mean fluoride release rates were not significantly different from the control $(\mathrm{p}>0.05)$. This may be clinically significant since they still exceeded the caries inhibitory fluoride release rates of 0.65 to $1.3 \mu \mathrm{g} \mathrm{F} / \mathrm{cm}^{2} /$ day. However, the variation in fluoride release rates between individual samples indicates that not all orthodontic brackets bonded with fluoride-releasing bonding materials may be similarly protective. Quick Cure ${ }^{\mathrm{TM}}$, meanwhile, released detectable levels only on day 1 (and this was only from 2 samples). The fluoride release rates for Quick Cure ${ }^{\text {TM }}$ were statistically similar at all time periods $(p>0.05)$. Since there are no other independent reports of fluoride release rates for Quick Cure $^{\mathrm{IM}}$ using a tooth-bracket model, it is assumed that minimal fluoride is released from this material.

There is only one reported study of fluoride release from Assure ${ }^{\mathrm{T}}$ using a tooth-bracket model (Rix et al., 2001), which showed the following release rates: day $1(89.74 \mu \mathrm{g} \mathrm{F}$ $/ \mathrm{cm}^{2} /$ day $)$, day $3\left(64.10 \mu \mathrm{g} \mathrm{F} / \mathrm{cm}^{2} /\right.$ day $)$ and day $7\left(13.46 \mu \mathrm{g} \mathrm{F} / \mathrm{cm}^{2} /\right.$ day $)$. The reported fluoride release rates in $\mu \mathrm{g} \mathrm{F}^{-} /$bracket/day up to 1 month are difficult to compare with this study because of differences in units. It is important to note, however, that Assure $^{\mathrm{TM}}$ had a release rate of $0 \mu \mathrm{g} \mathrm{F}$ /bracket/day on day 28 , revealing a similar burst-effect, followed by the trend for fluoride release rates to diminish to non-detectable levels. The current findings show a rate of $3.03 \pm 1.65 \mu \mathrm{g} \mathrm{F} / \mathrm{cm}^{2} /$ day on day 30 and non-detectable fluoride 
release on days 90 and 180. Unlike the disc samples, this indicates rebound in fluoride release rate did not occur by 6 months, probably due to the smaller amount of material used. It is possible that all fluoride had diffused out and was released by this point with the minimal amount of bonding material present.

Rix et al. (2001) also studied the fluoride release rates (in $\mu \mathrm{g} \mathrm{F} / \mathrm{cm}^{2} /$ day) for Fuji Ortho ${ }^{\mathrm{TM}}$ LC using a tooth-bracket model, and found that they were higher than those reported for Assure $^{\mathrm{TM}}$. Fuji Ortho ${ }^{\mathrm{TM}}$ LC released 157.05 on day 1 , decreasing to 26.92 on day 3 and 20.51 on day 7. It is important to note that for Assure $^{\mathrm{TM}}$ and Fuji Ortho ${ }^{\mathrm{TM}} \mathrm{LC}$, greater fluoride release rates were reported from the bracketed teeth than from discs of the same materials (Rix et al., 2001), a finding similar to this study, especially for Assure ${ }^{\mathrm{TM}}$ on day $1\left(236.39 \pm 49.14 \mu \mathrm{g} \mathrm{F}^{-} / \mathrm{cm}^{2} /\right.$ day). Large variation in fluoride release rates for the toothbracket samples may also reflect the presence of flash material around the bracket periphery, which again mimics the clinical situation where flash is quite prevalent.

Chan et al. (1990) used a tooth-bracket model to investigate fluoride release rates for FluorEver OBA. The reported fluoride release rates (in $\mu \mathrm{g} \mathrm{F} / \mathrm{cm}^{2} /$ day) as follows: day 1 $(\sim 700)$, day $3(52.6 \pm 13.2)$ and day $43(10.5 \pm 2.6)$. This was a fairly consistent pattern with Assure ${ }^{\text {TM }}$ in this study; however, FluorEver OBA had higher initial rates and a less rapid decline up to approximately one month.

Ashcraft et al. (1997) studied fluoride release from three resin-modified glass ionomer cements (Band-Lok, Zionomer and Geristore) using a tooth-bracket model. While 
comparison of results with the current study is difficult because values were reported in concentration of fluoride release (ppm), the overall pattern of release is important. They found that Bank-Lok released significantly more fluoride than the other materials on each day that fluoride was released. The concentration of fluoride released on day 1 for each material was as follows: Geristore $(1.50 \mathrm{ppm})$, Zionomer $(0.36 \mathrm{ppm})$ and Geristore $(0.50$ ppm). Both Zionomer and Geristore showed rapid decreases in fluoride ion release after initial cure to near zero ppm on day 7 (Ashcraft et al., 1997). Ghani et al. (1994) also used a tooth-bracket model to report fluoride release from orthodontic bonding composites Mirage Dual Cure ${ }^{\circledR}$ and Reliance ${ }^{\circledR}$. The experimental period only lasted for 8 days, during which the concentration of fluoride released from Mirage Dual Cure ${ }^{\circledR}$ decreased from $0.49 \pm 0.09 \mathrm{ppm}$ to $0.13 \pm 0.03 \mathrm{ppm}$, and Reliance ${ }^{\circledR}$ decreased from 0.30 $\pm 0.01 \mathrm{ppm}$ to $0.13 \pm 0.04 \mathrm{ppm}$ (Ghani et al., 1994).

In summary, using two different in vitro models, fluoride release was found to be a common phenomenon with Fuji Ortho ${ }^{\mathrm{TM}}$ LC, Assure ${ }^{\mathrm{TM}}$ and Python ${ }^{\mathrm{TM}}$. Consequently, these materials offer a potentially significant cariostatic effect in the clinical situation of bracket bonding. 


\section{Chapter 6}

\section{Conclusions and Recommendations}

\subsection{Conclusions}

From the present study, the following conclusions can be made:

- Fuji Ortho ${ }^{\mathrm{TM}} \mathrm{LC}$ had the greatest fluoride release of the materials investigated in this study.

- Fuji Ortho ${ }^{\mathrm{TM}}$ LC, Assure ${ }^{\mathrm{T} M \mathrm{M}}$ and Python ${ }^{\mathrm{TM}}$ had long-term fluoride-release rates above the range of 0.65 to $1.3 \mu \mathrm{g} \mathrm{F} / \mathrm{cm}^{2} /$ day recommended by Rawls (1987 and 1995) to inhibit caries initiation in sound enamel in the immediate vicinity of a resinbased dental material.

- Fuji Ortho ${ }^{T M} L C$, Assure $^{T M}$ and Python ${ }^{\mathrm{TM}}$ all demonstrated a 'burst-effect' pattern of fluoride re-release following exposure to $2 \%$ sodium fluoride gel. These materials had fluoride release rates that fell to low, consistent levels that were above the range of 0.65 to $1.3 \mu \mathrm{g} \mathrm{F}^{-} / \mathrm{cm}^{2} /$ day recommended by Rawls (1987 and 1995). The fluoride uptake and re-release is probably due the processes of surface adsorption and matrix diffusion of fluoride.

- Using a tooth-bracket model, Assure ${ }^{\text {TM }}$ was found to be a suitable fluoridereleasing material, as it released clinically significant levels of fluoride up to day 
30. Quick Cure ${ }^{\text {TM }}$ released fluoride at levels similar to the non-fluoride releasing control Transbond ${ }^{\mathrm{TM}} \mathrm{XT}$.

Therefore, the null hypothesis that stated:

1) Samples of resin-modified glass-ionomer (Fuji Ortho ${ }^{\mathrm{TM}} \mathrm{LC}$ ) will not release more fluoride than either polyacid-modified composite resin $\left(\right.$ Assure $^{\text {TM }}$ and Python $^{\text {IMM }}$ ) or a non-fluoride-containing composite resin (Transbond ${ }^{\text {TM }} \mathrm{XT}$ ) is rejected because Fuji Ortho ${ }^{\text {TM }}$ LC had significantly greater fluoride release rates than Python ${ }^{\text {TM }}$ or Assure $^{\mathrm{TM}}$ at all time points $(\mathrm{p}<0.0001)$.

2) Samples of resin-modified glass-ionomer (Fuji Ortho ${ }^{\text {TM }}$ LC) will not imbibe and re-release more fluoride than either polyacid-modified composite resin (Assure ${ }^{\text {TM }}$ and Python ${ }^{\mathrm{TM}}$ ) or a non-fluoride-containing composite resins (Transbond ${ }^{\mathrm{TM}} \mathrm{XT}$ ) is rejected because on day 546 Fuji Ortho ${ }^{\mathrm{TM}}$ LC released significantly more fluoride than any other material $(\mathrm{p}<0.0001)$.

3) A tooth-bracket model of either polyacid-modified composite resin (Assure ${ }^{\mathrm{TM}}$ and Quick Cure ${ }^{\mathrm{T}}$ ) will not release more fluoride than a non-fluoride-containing composite resin is rejected because Assure ${ }^{\text {Tu }}$ released significantly more fluoride on day 1 than Quick Cure ${ }^{\text {TM }}$ or Transbond ${ }^{T M}$ XT $(p<0.0001)$. 


\subsection{Recommendations}

From investigation of the literature and results of this study, the following recommendations are made:

a When bonding orthodontic attachments, materials that release fluoride should be used because they are likely to provide protection from white spot formation.

- Fuji Ortho ${ }^{T M}$ LC, Assure ${ }^{\text {TM }}$ and Python ${ }^{\text {TM }}$ have sufficient long-term fluoride release rates to reduce white spot formation and are all recommended as suitable orthodontic bonding materials.

- The use of Quick Cure ${ }^{\mathrm{TM}}$ as a fluoride-releasing bonding material cannot be recommended because detectable fluoride release rates (using a tooth-bracket model) were found only on day 1 , and these rates were not significantly different from any subsequent measurement which had non-detectable fluoride release rates.

\subsection{Future Research}

Future research of fluoride releasing materials should involve in vivo clinical trials to assess any anti-cariogenic effect and validate the reliability of in vitro studies. 


\section{References}

Arneberg P, Giertsen E, Emberland H, Øgaard B. Intra-oral variations in total plaque fluoride related to plaque $\mathrm{pH}$. A study in orthodontic patients. Caries Research $1997 ; 31: 451-456$

Arneberg P, Øgaard B, Scheie AAa, Rølla G. Selection of Streptococcus mutans and lactobacilli in an intra-oral human caries model. Journal of Dental Research 1984;63:1197-1200.

Ashcraft DB, Staley RN, Jakobsen JR. Fluoride release and shear bond strengths of three light-cured glass-ionomer cements. American Journal of Orthodontics and Dentofacial Orthopedics 1997;111:260-265.

Assure $^{\mathrm{TM}}$ Product Literature. Reliance Orthodontic Products, Itasca, IL, 2001.

Banks PA, Burn A, O'Brien K. A clinical evaluation of the effectiveness of including fluoride into an orthodontic bonding adhesive. European Journal of Orthodontics $1997 ; 19: 391-395$

Basdra EK, Huber H, Komposch G. Fluoride released from orthodontic bonding agents alters the enamel surface and inhibits enamel demineralization in vitro. American Journal of Orthodontics and Dentofacial Orthopedics 1996;109:466-472. 
Boyd RL. Comparison of three self-applied topical fluoride preparations for control of decalcification. Angle Orthodontist 1993;63:25-30.

Chadwick SM, Gordon PH. An investigation to estimate the fluoride uptake adjacent to a fluoride-releasing bonding agent. British Journal of Orthodontics 1995;22:113-122.

Chan DCN, Swift EJ Jr., Bishara SE. In vitro evaluation of fluoride-releasing orthodontic resin. Journal of Dental Research 1990;69:1576-1579.

Chang HS, Walsh LJ, Freer TJ. Enamel demineralization during orthodontic treatment. Aetiology and prevention. Australian Dental Journal 1997;42:322-327.

Chung CK, Millett DT, Creanor SL, Gilmour WH, Foye RH. Fluoride release and cariostatic ability of a compomer and a resin-modified glass ionomer cement used for orthodontic bonding. Journal of Dentistry 1998;26:533-538.

Clarkson BH, Hansen SE, Wefel JS. Effect of topical fluoride treatments on fluoride distribution during in vitro caries-like lesion formation. Caries Research 1988;22:263268.

Cooley RL, Barkmeier WW, Hicks JL. Fluoride release from orthodontic adhesives. American Journal of Dentistry 1989;2:86-88. 
Cranfield M, Kuhn AT, Winter GB. Factors relating to the rate of fluoride-ion release from glass-ionomer cement. Journal of Dentistry 1982;10:333-341.

Creanor SL, Carruthers LMC, Saunders WP, Strang R, Foye RH. Fluoride uptake and release characteristics of glass ionomer cements. Caries Research 1994;28:322-328.

De Witte MJC, De Maeyer EAP, Verbeeck RMH, Martens LC. Fluoride release profiles of mature restorative glass-ionomer cements after fluoride application. Biomaterials $2000 ; 21: 475-482$.

Eliades G, Kakaboura A, Palaghias G. Acid-base reaction and fluoride release profiles in visible light-cured polyacid-modified composite restoratives (compomers). Dental Materials 1998;14:57-63.

Erickson RL, Glasspoole EA. Model investigations of caries inhibition by fluoridereleasing dental materials. Advances in Dental Research 1995;9:315-323.

Featherstone JDB, Glena R, Shariati M, Shields CP. Dependence of in vitro demineralization of apatite and remineralization of dental enamel on fluoride concentration. Journal of Dental Research 1990;69 (Special issue):620-625. 
Fejerskov O, Clarkson BH. Dynamics of caries lesion formation. In: Fejerskov O, Ekstrand J, Burt BA, eds. Fluoride in Dentistry. Copenhagen: Munksgaard 1996: 187213.

Fejerskov O, Thylstrup A, Larsen MJ. Rational use of fluorides in caries prevention. A concept based on possible cariostatic mechanisms. Acta Odontologica Scandinavia 1981;39:241-249.

Forsten L. Fluoride release from a glass ionomer cement. Scandinavian Journal of Dental Research 1977;85:503-504.

Forsten L. Short- and long-term fluoride release from glass ionomers and other fluoridecontaining filling materials in vitro. Scandinavian Journal of Dental Research 1990;98:179-185.

Forsten L. Fluoride release and uptake by glass-ionomers and related materials and its clinical effect. Biomaterials 1998;19:503-508.

Fox NA. Fluoride release from orthodontic bonding materials. An in vitro study. British Journal of Orthodontics 1990;17:293-298. 
Fricker JP. A 12-month clinical evaluation of a light-activated glass polyalkenoate (ionomer) cement for the direct bonding of orthodontic brackets. American Journal of Orthodontics and Dentofacial Orthopedics 1994;105:502-505.

Geiger AM, Gorelick L, Gwinnett AJ, Benson BJ. Reducing white spot lesions in orthodontic populations with fluoride rinsing. American Journal of Orthodontics and Dentofacial Orthopedics 1992;101:403-407.

Ghani SH, Creanor SL, Luffingham JK, Foye RH. An ex vivo investigation into the release of fluoride from fluoride-containing orthodontic bonding composites. British Journal of Orthodontics 1994;21:239-243.

Gorelick L, Geiger AM, Gwinnett AJ. Incidence of white spot formation after bonding and banding. American Journal of Orthodontics 1982;81:93-98.

Grobler SR, Rossouw RJ, Van Wyk Kotze TJ. A comparison of fluoride release from various dental materials. Journal of Dentistry 1998;26:259-265.

Hamilton IR, Bowden GHW. Fluoride effects on oral bacteria. In: Fejerskov O, Ekstrand J, Burt BA, eds. Fluoride in Dentistry. Copenhagen: Munksgaard 1996: 230251. 
Harper DS, Loesche WJ. Inhibition of acid production from oral bacteria by fluorapatitederived fluoride. Journal of Dental Research 1986;65:30-33.

Hassard TH. Understanding Biostatistics. St. Louis: Mosby Yearbook, 1991.

Hatibovic-Kofman S, Koch G. Fluoride release from glass ionomer cement in vivo and in vitro. Swedish Dental Journal 1991;15:253-258.

Jones DW, Jackson G, Sutow EJ, Hall GC. Fluoride release from glass ionomer materials@ 37 and 21 degrees C. Journal of Dental Research 1987;66:Abstract 49.

Kakaboura A, Eliades G, Palaghias G. An FITR study on the setting mechanism of resinmodified glass ionomer restoratives. Dental Materials 1996;12:173-178.

Kindelan JD. In vitro measurement of enamel demineralization in the assessment of fluoride-leaching orthodontic bonding agents. British Journal of Orthodontics $1996 ; 23: 343-349$.

Lai PY, Woods MG, Tyas MJ. Bond strengths of orthodontic brackets to restorative resin composite surfaces. Australian Journal of Orthodontics 1999;15:235-45.

Levine RS. Fluoride and caries prevention: 1. Scientific rationale. Dental Update $1991 ; 18: 105-106,108-110$. 
Lundström F, Krasse B. Streptococcus mutans and lactobacilli frequency in orthodontic patients; the effect of chlorhexidine treatments. European Journal of Orthodontics 1987a;9:109-116.

Lundström F, Krasse B. Caries incidence in orthodontic patients with high levels of Streptococcus mutans. European Journal of Orthodontics 1987b;9:117-121.

Margolis HC, Moreno EC. Physicochemical perspectives on the cariostatic mechanisms of systemic and topical fluorides. Journal of Dental Research 1990;69 (Special issue):606-613.

Material Safety Data Sheet. Assure. Reliance Orthodontic Products, Inc., Itasca, IL, 1998.

Material Safety Data Sheet. Assure Primer. Reliance Orthodontic Products, Inc., Itasca, IL, 1998.

Material Safety Data Sheet. Python. M.S.D.S. 151-100, 151-105.

Material Safety Data Sheet. Quick Cure. Reliance Orthodontic Products, Inc., Itasca, IL, 2000. 
McCabe JF. Resin-modified glass-ionomers. Biomaterials 1998;19:521-527.

McLean JW, Nicholson JW, Wilson AD. Proposed nomenclature for glass-ionomer dental cements and related materials. Quintessence International 1994;25:587-589.

McNeill CJ. Fluoride release from light-cured orthodontic bonding materials. Winnipeg, MB: University of Manitoba, 2000.

McNeill CJ, Wiltshire WA, Dawes C, Lavelle CLB. Fluoride release from new lightcured orthodontic bonding agents. American Journal of Orthodontics and Dentofacial Orthopedics 2001;120:392-397.

Millett DT, Nunn JH, Welbury RR, Gordon PH. Decalcification in relation to brackets bonded with glass ionomer cement or a resin adhesive. Angle Orthodontist 1999;69:6570.

Mitchell L. An investigation into the effect of a fluoride releasing adhesive on the prevalence of enamel surface changes associated with directly bonded orthodontic attachments. British Journal of Orthodontics 1992;19:207-214.

Momoi Y, McCabe JF. Fluoride release from light-activated glass ionomer restorative cements. Dental Materials 1993;9:151-154. 
Monteith VL, Millett DT, Creanor SL, Gilmour WH. Fluoride release from orthodontic bonding agents: a comparison of three in vitro models. Journal of Dentistry 1999;27:5361.

Moreno EC, Margolis HC. Composition of human plaque fluid. Journal of Dental Research 1988;67:1181-1189.

Mount GJ. Clinical performance of glass-ionomers. Biomaterials 1998;19:573-579.

Nicholson JW. Chemistry of glass-ionomer cements: a review. Biomaterials $1998 ; 19: 485-494$.

O'Reilly MM, Featherstone JDB. Demineralization and remineralization around orthodontic appliances: an in vivo study. American Journal of Orthodontics and Dentofacial Orthopedics 1987;92:33-40.

Øgaard B. Prevalence of white spot lesions in 19-year-olds: a study on untreated and orthodontically treated persons 5 years after treatment. American Journal of Orthodontics and Dentofacial Orthopedics 1989;96:423-427.

Øgaard B, Rezk-Lega F, Ruben J, Arends J. Cariostatic effect and fluoride release from a visible light-curing adhesive for bonding of orthodontic brackets. American Journal of Orthodontics and Dentofacial Orthopedics 1992;101:303-307. 
Øgaard B, Rølla G, Arends J. Orthodontic appliances and enamel demineralization. Part I: Lesion development. American Journal of Orthodontics and Dentofacial Orthopedics 1988;94:68-73.

Proffit WR. Contemporary Orthodontics $3^{\text {rd }}$ ed. St. Louis: Mosby, 2000:397.

Quick Cure ${ }^{\mathrm{TM}}$ Product Literature. Reliance Orthodontic Products, Itasca, IL, 2001.

Rawls HR. Fluoride-releasing acrylics. Journal of Biomaterials Applications 1987;1:382405.

Rawls HR. Preventive dental materials: sustained delivery of fluoride and local therapeutic agents. Advances in Dental Research 1991;5:50-55.

Rawls HR. Evaluation of fluoride-releasing dental materials by means of in vitro and in vivo demineralization models: reaction paper. Advances in Dental Research 1995;9:324331.

Rix D. Bond strengths and fluoride release of modified glass ionomer and resin adhesives. London, ON: Faculty of Graduate Studies, University of Western Ontario, 1999. 
Rix D, Foley TF, Banting D, Mamandras A. A comparison of fluoride release by resinmodified GIC and polyacid-modified composite resin. American Journal of Orthodontics and Dentofacial Orthopedics 2001;120:398-405.

Rosenbloom RG, Tinanoff N. Salivary Streptococcus mutans levels in patients before, during, and after orthodontic treatment. American Journal of Orthodontics and Dentofacial Orthopedics 1991;100:35-37.

Saito S, Tosaki S, Hirota K. Characteristics of glass-ionomer cements. In: Davidson CL, Mjör IA, eds. Advances in Glass-Ionomer Cements. Chicago: Quintessence Publishing Co, Inc 1999:15-50.

Sonis AL, Snell W. An evaluation of a fluoride-releasing, visible light-activated bonding system for orthodontic bracket placement. American Journal of Orthodontics and Dentofacial Orthopedics 1989;95:306-311.

Stratemann MW, Shannon IL. Control of decalcification in orthodontic patients by daily self-administered application of a water-free 0.4 per cent stannous fluoride gel. American Journal of Orthodontics 1974;66:273-279.

Takahashi K, Emilson CG, Birkhed D. Fluoride release in vitro from various glass ionomer cements and resin composites after exposure to NaF solutions. Dental Materials $1993 ; 9: 350-354$ 
Tam LE, McComb D, Pulver F. Physical properties of proprietary light-cured lining materials. Operative Dentistry 1991;16:210-217.

Tay WM, Braden M. Fluoride ion diffusion from polyalkenoate (glass-ionomer) cements. Biomaterials 1988;9:454-456.

Temin SC, Csuros Z. Long-term fluoride release from a composite restorative. Dental Materials 1988;4:184-186.

ten Cate JM, Featherstone JDB. Physicochemical aspects of fluoride-enamel interactions. In: Fejerskov O, Ekstrand J, Burt BA, ed. Fluoride in Dentistry. Copenhagen: Munksgaard 1996:252-272.

Thilander BL. Complications of orthodontic treatment. Current Opinion in Dentistry $1992 ; 2: 28-37$.

Trimpeneers LM, Verbeeck, RMH, Dermaut LR. Long-term fluoride release of some orthodontic bonding resins. A laboratory study. Dental Materials 1998;14:142-149.

Underwood ML, Rawls HR, Zimmerman BF. Clinical evaluation of a fluorideexchanging resin as an orthodontic adhesive. American Journal of Orthodontics and Dentofacial Orthopedics 1989;96:93-99. 
Valk JWP, Davidson CL. The relevance of controlled fluoride release with bonded orthodontic appliances. Journal of Dentistry 1987;15:257-260.

Van Loveren C. The antimicrobial action of fluoride and its role in caries inhibition. Journal of Dental Research 1990;69 (Special Issue):676-681.

Verbeeck RMH, De Maeyer EAP, Marks LAM, De Moor RJG, De Witte AMJC, Trimpeneers LM. Fluoride release process of (resin-modified) glass-ionomer cements versus (polyacid-modified) composite resins. Biomaterials 1998;19:509-519.

Verbeeck RMH, De Moor RJG, Van Even DFJ, Martens LC. The short-term fluoride release of a hand-mixed vs. capsulated system of a restorative glass-ionomer cement. Journal of Dental Research 1993;72:577-581.

Vermeersch G, Leloup G, Vreven J. Fluoride release from glass-ionomer cements, compomers and resin composites. Journal of Oral Rehabilitation 2001;28:26-32.

Vorhies AB, Donly KJ, Staley RN, Wefel JS. Enamel demineralization adjacent to orthodontic brackets bonded with hybrid glass ionomer cements: an in vitro study. American Journal of Orthodontics and Dentofacial Orthopedics 1998;114:668-674. 
White DJ, Nancollas GH. Physical and chemical considerations of the role of firmly and loosely bound fluoride in caries prevention. Journal of Dental Research 1990; 69 (Special Issue):587-594.

Williams JA, Billington RW, Pearson GJ. The influence of sample dimensions on fluoride ion release from a glass ionomer restorative cement. Biomaterials 1999;29:1327-1337.

Wilson AD, Groffman DM, Kuhn AT. The release of fluoride and other chemical species from a glass-ionomer cement. Biomaterials 1985;6:431-433.

Wiltshire WA. In vitro and in vivo fluoride release from orthodontic elastomeric ligature ties. American Journal of Orthodontics and Dentofacial Orthopedics 1999;115:288-292.

Wiltshire WA, Janse van Rensburg SD. Fluoride release from four visible light-cured orthodontic adhesive resins. American Journal of Orthodontics and Dentofacial Orthopedics 1995;108:278-283.

Yip HK, Smales RJ. Fluoride release and uptake by aged resin-modified glass-ionomers and a polyacid-modified resin composite. International Dental Journal 1999;49:217-225. 
Young A, von der Fehr FR, Sønju T, Nordbø H. Fluoride release and uptake in vitro from a composite resin and two orthodontic adhesives. Acta Odontologica Scandanavia $1996 ; 54: 223-228$. 


\section{Appendix 1: Long-Term Fluoride Release Samples}

\begin{tabular}{|c|c|c|c|}
\hline Adhesive & Sample \# & Day & $\mu \mathrm{gF}^{-} / \mathrm{cm}^{2} /$ day \\
\hline Transbond XT & 1 & 546 & 0 \\
\hline Transbond XT & 1 & 637 & 0 \\
\hline Transbond XT & 1 & 730 & 0 \\
\hline Transbond XT & 1 & 821 & 0 \\
\hline Transbond XT & 1 & 913 & 0 \\
\hline Transbond XT & 2 & 546 & 0 \\
\hline Transbond XT & 2 & 637 & 0 \\
\hline Transbond XT & 2 & 730 & 0 \\
\hline Transbond XT & 2 & 821 & 0 \\
\hline Transbond $\mathrm{XT}$ & 2 & 913 & 0 \\
\hline Transbond XT & 3 & 546 & 0 \\
\hline Transbond XT & 3 & 637 & 0 \\
\hline Transbond XT & 3 & 730 & 0 \\
\hline Transbond XT & 3 & 821 & 0 \\
\hline Transbond $\mathrm{XT}$ & 3 & 913 & 0 \\
\hline Transbond XT & 4 & 546 & 0 \\
\hline Transbond XT & 4 & 637 & 0 \\
\hline Transbond XT & 4 & 730 & 0 \\
\hline Transbond XT & 4 & 821 & 0 \\
\hline Transbond XT & 4 & 913 & 0 \\
\hline Transbond XT & 5 & 546 & 0 \\
\hline Transbond XT & 5 & 637 & 0 \\
\hline Transbond XT & 5 & 730 & 0 \\
\hline Transbond XT & 5 & 821 & 0 \\
\hline Transbond XT & 5 & 913 & 0 \\
\hline Python & 1 & 546 & 8.72 \\
\hline Python & 1 & 637 & 5.96 \\
\hline Python & 1 & 730 & 4.57 \\
\hline Python & 1 & 821 & 6.70 \\
\hline Python & 1 & 913 & 7.13 \\
\hline Python & 2 & 546 & 7.98 \\
\hline Python & 2 & 637 & 4.68 \\
\hline Python & 2 & 730 & 4.04 \\
\hline Python & 2 & 821 & 4.89 \\
\hline Python & 2 & 913 & 6.17 \\
\hline Python & 3 & 546 & 7.66 \\
\hline Python & 3 & 637 & 4.89 \\
\hline Python & 3 & 730 & 4.04 \\
\hline Python & 3 & 821 & 5.96 \\
\hline Python & 3 & 913 & 6.60 \\
\hline Python & 4 & 546 & 7.66 \\
\hline Python & 4 & 637 & 6.60 \\
\hline Python & 4 & 730 & 4.57 \\
\hline Python & 4 & 821 & 6.49 \\
\hline
\end{tabular}

\begin{tabular}{|c|c|c|c|}
\hline Adhesive & Sample \# & Day & $\mu \mathrm{gF} / \mathrm{cm}^{2} /$ day \\
\hline Python & 4 & 913 & 6.60 \\
\hline Python & 5 & 546 & 8.40 \\
\hline Python & 5 & 637 & 6.81 \\
\hline Python & 5 & 730 & 5.11 \\
\hline Python & 5 & 821 & 6.91 \\
\hline Python & 5 & 913 & 7.34 \\
\hline Assure & 1 & 546 & 8.40 \\
\hline Assure & 1 & 637 & 3.83 \\
\hline Assure & 1 & 730 & 0.87 \\
\hline Assure & 1 & 821 & 0.96 \\
\hline Assure & 1 & 913 & 4.68 \\
\hline Assure & 2 & 546 & 7.34 \\
\hline Assure & 2 & 637 & 7.34 \\
\hline Assure & 2 & $730 \mid$ & 1.60 \\
\hline Assure & 2 & 821 & 1.06 \\
\hline Assure & 2 & 913 & 4.89 \\
\hline Assure & 3 & 546 & 8.30 \\
\hline Assure & 3 & 637 & 2.77 \\
\hline Assure & 3 & 730 & 0.85 \\
\hline Assure & 3 & 821 & 0.90 \\
\hline Assure & 3 & 913 & 5.53 \\
\hline Assure & 4 & 546 & 9.04 \\
\hline Assure & 4 & 637 & 5.32 \\
\hline Assure & 4 & 730 & 1.01 \\
\hline Assure & 4 & 821 & 1.01 \\
\hline Assure & 4 & 913 & 4.68 \\
\hline Assure & 5 & 546 & 5.32 \\
\hline Assure & 5 & 637 & 3.83 \\
\hline Assure & 5 & $|730|$ & 0.85 \\
\hline Assure & 5 & 821 & 2.13 \\
\hline Assure & 5 & 913 & 4.36 \\
\hline Fuji Ortho LC & 1 & 546 & 10.53 \\
\hline Fuji Ortho LC & 1 & 637 & 10.32 \\
\hline Fuji Ortho LC & 1 & 730 & 10.21 \\
\hline Fuji Ortho LC & 1 & 821 & 10.05 \\
\hline Fuji Ortho LC & 1 & 913 & 10.43 \\
\hline Fuji Ortho LC & 2 & 546 & 11.70 \\
\hline Fuji Ortho LC & 2 & 637 & 10.43 \\
\hline Fuji Ortho LC & 2 & 730 & 10.11 \\
\hline Fuji Ortho LC & 2 & 821 & 10.11 \\
\hline Fuji Ortho LC & 2 & 913 & 10.37 \\
\hline Fuji Ortho LC & 3 & 546 & 11.70 \\
\hline Fuji Ortho LC & 3 & 637 & 10.53 \\
\hline
\end{tabular}




\begin{tabular}{|c|c|c|c|}
\hline Adhesive & Sample \# & Day & $\mu \mathrm{g} F / \mathrm{cm}^{2} /$ day \\
\hline Fuji Ortho LC & 3 & 730 & 10.32 \\
\hline Fuji Ortho LC & 3 & 821 & 10.21 \\
\hline Fuji Ortho LC & 3 & 913 & 10.27 \\
\hline Fuji Ortho LC & 4 & 546 & 10.64 \\
\hline Fuji Ortho LC & 4 & 637 & 10.53 \\
\hline Fuji Ortho LC & 4 & 730 & 10.32 \\
\hline Fuji Ortho LC & 4 & 821 & 10.32 \\
\hline Fuji Ortho LC & 4 & 913 & 10.27 \\
\hline Fuji Ortho LC & 5 & 546 & 10.64 \\
\hline Fuji Ortho LC & 5 & 637 & 10.43 \\
\hline Fuji Ortho LC & 5 & 730 & 9.95 \\
\hline Fuji Ortho LC & 5 & 821 & 10.05 \\
\hline Fuji Ortho LC & 5 & 913 & 10.32 \\
\hline
\end{tabular}




\section{Appendix 2: Fluoride Re-release Samples}

\begin{tabular}{|c|c|c|c|}
\hline Adhesive & Sample \# & Day & $\mu \mathrm{gF} / \mathrm{cm}^{2} /$ day \\
\hline Transbond XT & 1 & 546 & 6.28 \\
\hline Transbond XT & 1 & 548 & 0.21 \\
\hline Transbond XT & 1 & 552 & 0 \\
\hline Transbond XT & 1 & 575 & 0.11 \\
\hline Transbond XT & 1 & 637 & 0.13 \\
\hline Transbond XT & 1 & 730 & 0 \\
\hline Transbond XT & 1 & 821 & 0 \\
\hline Transbond XT & 1 & 913 & 0 \\
\hline Transbond XT & 2 & 546 & 8.72 \\
\hline Transbond XT & 2 & 548 & 0 \\
\hline Transbond XT & 2 & 552 & 0 \\
\hline Transbond XT & 2 & 575 & 0 \\
\hline Transbond XT & 2 & 637 & 0 \\
\hline Transbond XT & 2 & 730 & 0 \\
\hline Transbond XT & 2 & 821 & 0 \\
\hline Transbond XT & 2 & 913 & 0 \\
\hline Transbond XT & 3 & 546 & 8.30 \\
\hline Transbond XT & 3 & 548 & 0 \\
\hline Transbond XT & 3 & 552 & 0 \\
\hline Transbond XT & 3 & 575 & 0 \\
\hline Transbond XT & 3 & 637 & 0 \\
\hline Transbond XT & 3 & 730 & 0 \\
\hline Transbond XT & 3 & 821 & 0 \\
\hline Transbond XT & 3 & 913 & 0 \\
\hline Transbond XT & 4 & 546 & 2.13 \\
\hline Transbond XT & 4 & 548 & 0 \\
\hline Transbond XT & 4 & 552 & 0 \\
\hline Transbond XT & 4 & 575 & 0 \\
\hline Transbond XT & 4 & 637 & 0 \\
\hline Transbond XT & 4 & 730 & 0 \\
\hline Transbond XT & 4 & 821 & 0 \\
\hline Transbond XT & 4 & 913 & 0 \\
\hline Transbond XT & 5 & 546 & 4.26 \\
\hline Transbond XT & 5 & 548 & 0 \\
\hline Transbond XT & 5 & 552 & 0 \\
\hline Transbond XT & 5 & 575 & 0 \\
\hline Transbond XT & 5 & 637 & 0 \\
\hline Transbond XT & 5 & 730 & 0 \\
\hline Transbond XT & 5 & 821 & 0 \\
\hline Transbond XT & 5 & 913 & 0 \\
\hline Python & 1 & 546 & 40.43 \\
\hline Python & 1 & 548 & 6.28 \\
\hline Python & 1 & 552 & 2.87 \\
\hline
\end{tabular}

\begin{tabular}{|c|c|c|c|}
\hline Adhesive & Sample $\#$ & Day & $\mu \mathrm{gF} / \mathrm{cm}^{2} /$ day \\
\hline Python & 1 & 575 & 4.89 \\
\hline Python & 1 & 637 & 5.53 \\
\hline Python & 1 & 730 & 5.53 \\
\hline Python & 1 & 821 & 5.32 \\
\hline Python & 1 & 913 & 6.38 \\
\hline Python & 2 & 546 & 19.15 \\
\hline Python & 2 & 548 & 4.68 \\
\hline Python & 2 & 552 & 0.96 \\
\hline Python & 2 & 575 & 2.55 \\
\hline Python & 2 & 637 & 5.32 \\
\hline Python & 2 & 730 & 5.53 \\
\hline Python & 2 & 821 & 6.92 \\
\hline Python & 2 & 913 & 7.34 \\
\hline Python & 3 & 546 & 51.06 \\
\hline Python & 3 & 548 & 5.32 \\
\hline Python & 3 & 552 & 1.60 \\
\hline Python & 3 & 575 & 3.83 \\
\hline Python & 3 & 637 & 6.60 \\
\hline Python & 3 & 730 & 5.85 \\
\hline Python & 3 & 821 & 7.66 \\
\hline Python & 3 & 913 & 7.66 \\
\hline Python & 4 & 546 & 34.04 \\
\hline Python & 4 & 548 & 6.50 \\
\hline Python & 4 & 552 & 1.60 \\
\hline Python & 4 & 575 & 3.30 \\
\hline Python & 4 & 637 & 5.74 \\
\hline Python & 4 & 730 & 5.32 \\
\hline Python & 4 & 821 & 7.02 \\
\hline Python & 4 & 913 & 7.13 \\
\hline Python & 5 & 546 & 38.30 \\
\hline Python & 5 & 548 & 6.49 \\
\hline Python & 5 & 552 & 2.34 \\
\hline Python & 5 & 575 & 3.83 \\
\hline Python & 5 & 637 & 5.74 \\
\hline Python & 5 & 730 & 4.79 \\
\hline Python & 5 & 821 & 6.49 \\
\hline Python & 5 & 913 & 7.66 \\
\hline Assure & 1 & 546 & 70.21 \\
\hline Assure & 1 & 548 & 3.62 \\
\hline Assure & 1 & 552 & 0.85 \\
\hline Assure & 1 & 575 & 0.83 \\
\hline Assure & 1 & 637 & 4.68 \\
\hline Assure & 1 & 730 & 1.91 \\
\hline
\end{tabular}




\begin{tabular}{|c|c|c|c|}
\hline Adhesive & Sample \# & Day & $\mu \mathrm{gF} / \mathrm{cm}^{2} /$ day \\
\hline Assure & 1 & 821 & 1.49 \\
\hline Assure & 1 & 913 & 4.36 \\
\hline Assure & 2 & 546 & 76.60 \\
\hline Assure & 2 & 548 & 3.83 \\
\hline Assure & 2 & 552 & 0.64 \\
\hline Assure & 2 & 575 & 1.49 \\
\hline Assure & 2 & 637 & 4.04 \\
\hline Assure & 2 & 730 & 1.60 \\
\hline Assure & 2 & 821 & 0.90 \\
\hline Assure & 2 & 913 & 5.74 \\
\hline Assure & 3 & 546 & 51.06 \\
\hline Assure & 3 & 548 & 0.81 \\
\hline Assure & 3 & 552 & 0.43 \\
\hline Assure & 3 & 575 & 0.69 \\
\hline Assure & 3 & 637 & 3.83 \\
\hline Assure & 3 & 730 & 0.64 \\
\hline Assure & 3 & 821 & 0.85 \\
\hline Assure & 3 & 913 & 3.40 \\
\hline Assure & 4 & 546 & 55.32 \\
\hline Assure & 4 & 548 & 0.91 \\
\hline Assure & 4 & 552 & 0.53 \\
\hline Assure & 4 & 575 & 0.62 \\
\hline Assure & 4 & 637 & 2.77 \\
\hline Assure & 4 & 730 & 0.85 \\
\hline Assure & 4 & 821 & 1.811 \\
\hline Assure & 4 & 913 & 5.11 \\
\hline Assure & 5 & 546 & 63.83 \\
\hline Assure & 5 & 548 & 5.32 \\
\hline Assure & 5 & 552 & 0.85 \\
\hline Assure & 5 & 575 & 0.69 \\
\hline Assure & 5 & 637 & 1.03 \\
\hline Assure & 5 & 730 & 1.38 \\
\hline Assure & 5 & 821 & 0.96 \\
\hline Assure & 5 & 913 & 3.40 \\
\hline Fuji Ortho LC & 1 & 546 & 89.36 \\
\hline Fuji Ortho LC & 1 & 548 & 10.21 \\
\hline Fuji Ortho LC & 1 & 552 & 9.47 \\
\hline
\end{tabular}

\begin{tabular}{|c|c|c|c|}
\hline Adhesive & Sample \# & Day & $\mu \mathrm{gF} / \mathrm{cm}^{2} /$ day \\
\hline Fuji Ortho LC & 1 & 575 & 10.11 \\
\hline Fuji Ortho LC & 1 & 637 & 10.21 \\
\hline Fuji Ortho LC & 1 & 730 & 10.21 \\
\hline Fuji Ortho LC & 1 & 821 & 10.11 \\
\hline Fuji Ortho LC & 1 & 913 & 10.37 \\
\hline Fuji Ortho LC & 2 & 546 & 88.30 \\
\hline Fuji Ortho LC & 2 & 548 & 10.21 \\
\hline Fuji Ortho LC & 2 & 552 & 9.15 \\
\hline Fuji Ortho LC & 2 & 575 & 9.79 \\
\hline Fuji Ortho LC & 2 & 637 & 9.89 \\
\hline Fuji Ortho LC & 2 & 730 & 10.00 \\
\hline Fuji Ortho LC & 2 & 821 & 10.10 \\
\hline Fuji Ortho LC & 2 & 913 & 10.27 \\
\hline Fuji Ortho LC & 3 & 546 & 94.68 \\
\hline Fuji Ortho LC & 3 & 548 & 10.64 \\
\hline Fuji Ortho LC & 3 & 552 & 9.68 \\
\hline Fuji Ortho LC & 3 & 575 & 10.11 \\
\hline Fuji Ortho LC & 3 & 637 & 10.16 \\
\hline Fuji Ortho LC & 3 & 730 & 10.11 \\
\hline Fuji Ortho LC & 3 & 821 & 10.27 \\
\hline Fuji Ortho LC & 3 & 913 & 10.32 \\
\hline Fuji Ortho LC & 4 & 546 & 93.62 \\
\hline Fuji Ortho LC & 4 & 548 & 10.53 \\
\hline Fuji Ortho LC & 4 & 552 & 9.68 \\
\hline Fuji Ortho LC & 4 & 575 & 10.21 \\
\hline Fuji Ortho LC & 4 & 637 & 10.27 \\
\hline Fuji Ortho LC & 4 & 730 & 10.00 \\
\hline Fuji Ortho LC & 4 & 821 & 10.32 \\
\hline Fuji Ortho LC & 4 & 913 & 10.37 \\
\hline Fuji Ortho LC & 5 & 546 & 95.74 \\
\hline Fuji Ortho LC & 5 & 548 & 21.28 \\
\hline Fuji Ortho LC & 5 & 552 & 9.57 \\
\hline Fuji Ortho LC & 5 & 575 & 10.11 \\
\hline Fuji Ortho LC & 5 & 637 & 10.16 \\
\hline Fuji Ortho LC & 5 & 730 & 10.00 \\
\hline Fuji Ortho LC & 5 & 821 & 10.21 \\
\hline Fuji Ortho LC & 5 & 913 & 10.32 \\
\hline
\end{tabular}




\section{Appendix 3: Tooth-Bracket Samples}

\begin{tabular}{|l|c|c|c|}
\hline Adhesive & Sample \# & Day & $\mu \mathrm{gF} / \mathrm{cm}^{2} /$ day \\
\hline Transbond XT & 1 & 1 & 0 \\
\hline Transbond XT & 1 & 3 & 0 \\
\hline Transbond XT & 1 & 7 & 0 \\
\hline Transbond XT & 1 & 30 & 0 \\
\hline Transbond XT & 1 & 90 & 0 \\
\hline Transbond XT & 1 & 180 & 0 \\
\hline Transbond XT & 2 & 1 & 0 \\
\hline Transbond XT & 2 & 3 & 0 \\
\hline Transbond XT & 2 & 7 & 0 \\
\hline Transbond XT & 2 & 30 & 0 \\
\hline Transbond XT & 2 & 90 & 0 \\
\hline Transbond XT & 2 & 180 & 0 \\
\hline Transbond XT & 3 & 1 & 0 \\
\hline Transbond XT & 3 & 3 & 0 \\
\hline Transbond XT & 3 & 7 & 0 \\
\hline Transbond XT & 3 & 30 & 0 \\
\hline Transbond XT & 3 & 90 & 0 \\
\hline Transbond XT & 3 & 180 & 0 \\
\hline Transbond XT & 4 & 1 & 0 \\
\hline Transbond XT & 4 & 3 & 0 \\
\hline Transbond XT & 4 & 7 & 0 \\
\hline Transbond XT & 4 & 30 & 0 \\
\hline Transbond XT & 4 & 90 & 0 \\
\hline Transbond XT & 4 & 180 & 0 \\
\hline Transbond XT & 5 & 1 & 0 \\
\hline Transbond XT & 5 & 3 & 0 \\
\hline Transbond XT & 5 & 7 & 0 \\
\hline Transbond XT & 5 & 30 & 0 \\
\hline Transbond XT & 5 & 90 & 0 \\
\hline Transbond XT & 5 & 180 & 0 \\
\hline Transbond XT & 6 & 1 & 0 \\
\hline Transbond XT & 6 & 3 & 0 \\
\hline Transbond XT & 6 & 7 & 0 \\
\hline Transbond XT & 6 & 30 & 0 \\
\hline Transbond XT & 6 & 90 & 0 \\
\hline Transbond XT & 6 & 180 & 0 \\
\hline Transbond XT & 7 & 1 & 0 \\
\hline Transbond XT & 7 & 3 & 0 \\
\hline Transbond XT & 7 & 7 & 0 \\
\hline Transbond XT & 7 & 30 & 0 \\
\hline Transbond XT & 7 & 90 & 0 \\
\hline Transbond XT & 7 & 180 & 0 \\
\hline Transbond XT & 8 & 1 & 0 \\
\hline
\end{tabular}

\begin{tabular}{|l|c|c|c|}
\hline /day Adhesive & Sample \# & Day & $\mu \mathrm{gF} / \mathrm{cm}^{2} /$ day \\
\hline Transbond XT & 8 & 3 & 0 \\
\hline Transbond XT & 8 & 7 & 0 \\
\hline Transbond XT & 8 & 30 & 0 \\
\hline Transbond XT & 8 & 90 & 0 \\
\hline Transbond XT & 8 & 180 & 0 \\
\hline Transbond XT & 9 & 1 & 0 \\
\hline Transbond XT & 9 & 3 & 0 \\
\hline Transbond XT & 9 & 7 & 0 \\
\hline Transbond XT & 9 & 30 & 0 \\
\hline Transbond XT & 9 & 90 & 0 \\
\hline Transbond XT & 9 & 180 & 0 \\
\hline Transbond XT & 10 & 1 & 0 \\
\hline Transbond XT & 10 & 3 & 0 \\
\hline Transbond XT & 10 & 7 & 0 \\
\hline Transbond XT & 10 & 30 & 0 \\
\hline Transbond XT & 10 & 90 & 0 \\
\hline Transbond XT & 10 & 180 & 0 \\
\hline Quick Cure & 1 & 1 & 0 \\
\hline Quick Cure & 1 & 3 & 0 \\
\hline Quick Cure & 1 & 7 & 0 \\
\hline Quick Cure & 1 & 30 & 0 \\
\hline Quick Cure & 1 & 90 & 0 \\
\hline Quick Cure & 1 & 180 & 0 \\
\hline Quick Cure & 2 & 1 & 0 \\
\hline Quick Cure & 2 & 3 & 0 \\
\hline Quick Cure & 2 & 7 & 0 \\
\hline Quick Cure & 2 & 30 & 0 \\
\hline Quick Cure & 2 & 90 & 0 \\
\hline Quick Cure & 2 & 180 & 0 \\
\hline Quick Cure & 3 & 1 & 0 \\
\hline Quick Cure & 3 & 3 & 0 \\
\hline Quick Cure & 3 & 7 & 0 \\
\hline Quick Cure & 3 & 30 & 0 \\
\hline Quick Cure & 3 & 90 & 0 \\
\hline Quick Cure & 3 & 180 & 0 \\
\hline Quick Cure & 4 & 1 & 0 \\
\hline Quick Cure & 4 & 3 & 0 \\
\hline Quick Cure & 4 & 7 & 0 \\
\hline Quick Cure & 4 & 30 & 0 \\
\hline Quick Cure & 4 & 90 & 0 \\
\hline Quick Cure & 4 & 180 & 0 \\
\hline Quick Cure & 5 & 1 & 0 \\
\hline Quick Cure & 5 & 3 & 0 \\
\hline
\end{tabular}




\begin{tabular}{|c|c|c|c|}
\hline Adhesive & Sample \# & Day & $\mu \mathrm{gF} / \mathrm{cm}^{2} /$ day \\
\hline Quick Cure & 5 & 7 & 0 \\
\hline Quick Cure & 5 & 30 & 0 \\
\hline Quick Cure & 5 & 90 & 0 \\
\hline Quick Cure & 5 & 180 & 0 \\
\hline Quick Cure & 6 & 1 & 0 \\
\hline Quick Cure & 6 & 3 & 0 \\
\hline Quick Cure & 6 & 7 & 0 \\
\hline Quick Cure & 6 & 30 & 0 \\
\hline Quick Cure & 6 & 90 & 0 \\
\hline Quick Cure & 6 & 180 & 0 \\
\hline Quick Cure & 7 & 1 & 53.00 \\
\hline Quick Cure & 7 & 3 & 0 \\
\hline Quick Cure & 7 & 7 & 0 \\
\hline Quick Cure & 7 & 30 & 0 \\
\hline Quick Cure & 7 & 90 & 0 \\
\hline Quick Cure & 7 & 180 & 0 \\
\hline Quick Cure & 8 & 1 & 0 \\
\hline Quick Cure & 8 & 3 & 0 \\
\hline Quick Cure & 8 & 7 & 0 \\
\hline Quick Cure & 8 & 30 & 0 \\
\hline Quick Cure & 8 & 90 & 0 \\
\hline Quick Cure & 8 & 180 & 0 \\
\hline Quick Cure & 9 & 1 & 0 \\
\hline Quick Cure & 9 & 3 & 0 \\
\hline Quick Cure & 9 & 7 & 0 \\
\hline Quick Cure & 9 & 30 & 0 \\
\hline Quick Cure & 9 & 90 & 0 \\
\hline Quick Cure & 9 & 180 & 0 \\
\hline Quick Cure & 10 & 1 & 51.50 \\
\hline Quick Cure & 10 & 3 & 0 \\
\hline Quick Cure & 10 & 7 & 0 \\
\hline Quick Cure & 10 & 30 & 0 \\
\hline Quick Cure & 10 & 90 & 0 \\
\hline Quick Cure & 10 & 180 & 0 \\
\hline Assure & 1 & 1 & 152.81 \\
\hline Assure & 1 & 3 & 25.88 \\
\hline Assure & 1 & 7 & 2.26 \\
\hline Assure & 1 & 30 & 15.37 \\
\hline Assure & 1 & 90 & 0 \\
\hline Assure & 1 & 180 & 0 \\
\hline Assure & 2 & 1 & 246.10 \\
\hline Assure & 2 & 3 & 84.85 \\
\hline Assure & 2 & 7 & 72.18 \\
\hline Assure & 2 & 30 & 9.18 \\
\hline Assure & 2 & 90 & 0 \\
\hline Assure & 2 & 180 & 0 \\
\hline
\end{tabular}

\begin{tabular}{|c|c|c|c|}
\hline Adhesive & Sample \# & Day & $\mu \mathrm{gF} / \mathrm{cm}^{2} / \mathrm{day}$ \\
\hline Assure & 3 & 1 & 137.19 \\
\hline Assure & 3 & 3 & 19.71 \\
\hline Assure & 3 & 7 & 1.11 \\
\hline Assure & 3 & 30 & 0 \\
\hline Assure & 3 & 90 & 0 \\
\hline Assure & 3 & 180 & 0 \\
\hline Assure & 4 & 1 & 599.41 \\
\hline Assure & 4 & 3 & 42.21 \\
\hline Assure & 4 & 7 & 0 \\
\hline Assure & 4 & 30 & 0 \\
\hline Assure & 4 & 90 & 0 \\
\hline Assure & 4 & 180 & 0 \\
\hline Assure & 5 & 1 & 394.26 \\
\hline Assure & 5 & 3 & 43.06 \\
\hline Assure & 5 & 7 & 11.95 \\
\hline Assure & 5 & 30 & 0 \\
\hline Assure & 5 & 90 & 0 \\
\hline Assure & 5 & 180 & 0 \\
\hline Assure & 6 & 1 & 185.73 \\
\hline Assure & 6 & 3 & 60.79 \\
\hline Assure & 6 & 7 & 19.20 \\
\hline Assure & 6 & 30 & 0 \\
\hline Assure & 6 & 90 & 0 \\
\hline Assure & 6 & 180 & 0 \\
\hline Assure & 7 & 1 & 134.23 \\
\hline Assure & 7 & 3 & 18.40 \\
\hline Assure & 7 & 7 & 5.15 \\
\hline Assure & 7 & 30 & 2.22 \\
\hline Assure & 7 & 90 & 0 \\
\hline Assure & 7 & 180 & 0 \\
\hline Assure & 8 & 1 & 124.53 \\
\hline Assure & 8 & 3 & 22.54 \\
\hline Assure & 8 & 7 & 2.49 \\
\hline Assure & 8 & 30 & 0 \\
\hline Assure & 8 & 90 & 0 \\
\hline Assure & 8 & 180 & 0 \\
\hline Assure & 9 & 1 & 108.91 \\
\hline Assure & 9 & 3 & 15.75 \\
\hline Assure & 9 & 7 & 0 \\
\hline Assure & 9 & 30 & 0 \\
\hline Assure & 9 & 90 & 0 \\
\hline Assure & 9 & 180 & 0 \\
\hline Assure & 10 & 1 & 280.71 \\
\hline Assure & 10 & 3 & 82.70 \\
\hline Assure & 10 & 7 & 30.60 \\
\hline Assure & 10 & 30 & 3.55 \\
\hline
\end{tabular}




\begin{tabular}{|c|c|c|c|}
\hline Adhesive & Sample \# & Day & $\mu \mathrm{gF} / \mathrm{cm}^{2} /$ day \\
\hline Assure & 10 & 90 & 0 \\
\hline Assure & 10 & 180 & 0 \\
\hline
\end{tabular}

